\title{
DYNAMIC STABILITY OF PLATES BY \\ FINITE ELEMENTS
}

\author{
By \\ JOHNNY MACK HUTT \\ Bachelor of Sclence \\ University of Alabama \\ University, Alabama \\ 1963 \\ Master of Science \\ University of Alabama \\ University, Alabama \\ 1965
}

\author{
Submitted to the faculty of the Graduate College \\ of the Oklahoma State University \\ in partial fulfillment of the requirements \\ for the degree of \\ DOCTOR OF PHILOSOPHY \\ May, 1968
}




\section{DYNAMIC STABILITY OF PLATES BY}

\section{FINITE ELEMENTS}

Thesis Approved:

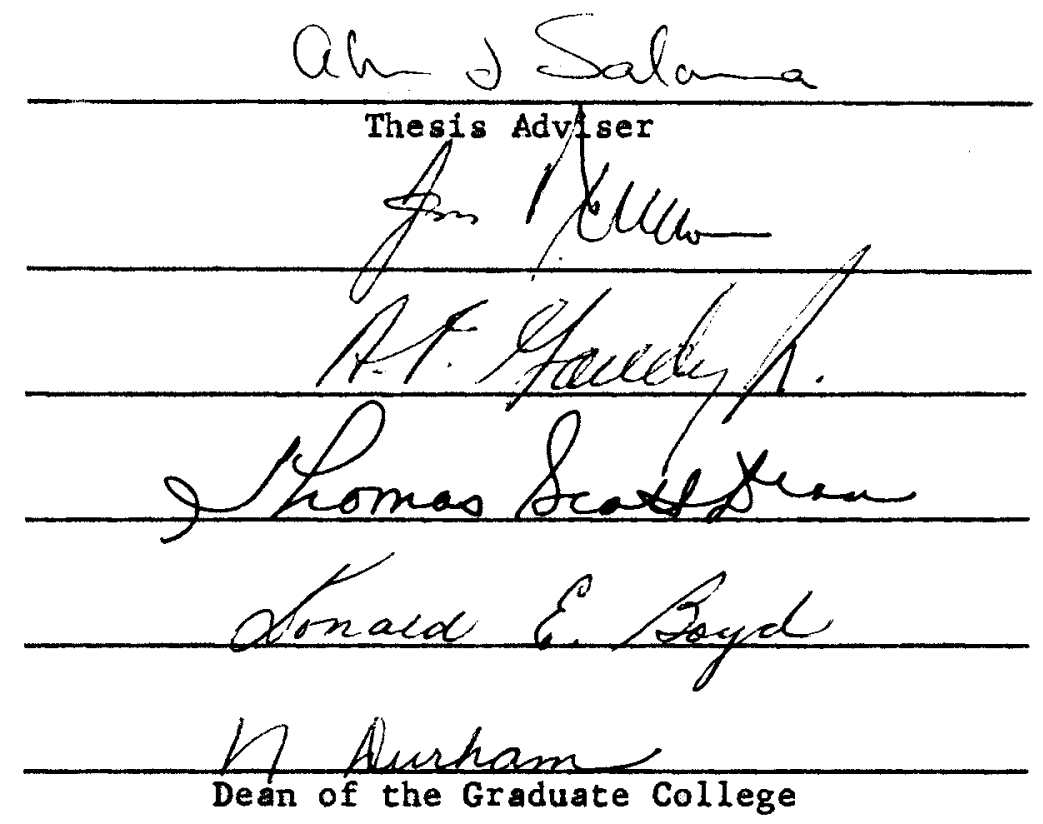

638398 
ACKNOWLEDGMENTS

The author wishes to express his gratitude and sincere appreciation to the following individuals and organizations:

To Professor Ahmed E. Salama for his advice and friendship in the preparation of this thesis;

To Professor Jan J. Tuma for serving as chairman of the advisory committee and for his inspirational teaching and guidance;

To the members of the advisory committee, Professors Ahmed E. Salama, Donald E. Boyd, Anthony F. Gaudy, and Thomas S. Dean for their guidance and encouragement;

To the Civil Engineering Department at Oklahoma State University and the National Science Foundation for providing the opportunity for financial assistance;

To the staffs of the University Computer Center and the University Libxary for their invaluable assistance;

To Mr. Eldon Hardy for preparing the final sketches;

To his wife, Mary Elaine, and daughter, Lisa, for their patient understanding, encouragement, and assistance;

To Mrs. Donna Defrain, who typed the manuscript.

May, 1968

Stillwater, Oklahoma 
I. TIRRODUCLION .................... 1

1.1 Statement of the Problem. . . . . . . . . 1

1.2 Review of Previous Work............ 2

1.3 scope .................. 3

II. COVERNTNG FINITE EIEMTEN EQUATIONS. . . . . . . . 6

2. K Knetic Energy. . . . . . . . . . . 8

2.2 Stran Energy................. 10

2.3 Work Done by In-Plane Loads . .......... 11

2.4 Damping and Elastic Foundation......... 13

2.5 Governing Equations .............. 14

2.6 Development of Elemental Matrices....... 16

III. BOUNDARYES OF STABILTTY FOR LINEAR EQUATIONS WITH

PERIODIC COEEETCIENTS . . . . . . ........ 26

3.1 Behavior of solutions . . . . . . . . 26

3.2 Roocs of Chatacteristic Equation. ....... 31

3.3 Reglons of Stability and Instability....... 32

3.4 Boundary Erequencies for Instability....... 34

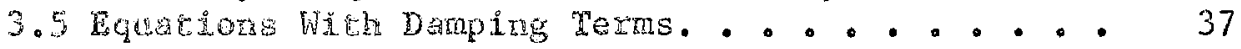

3.6 Prysical considerations . . . . . . . . . 38

IN. SOLUTLN FOR FHE REGTONS OW DYNAMIC INSTABILITY. . . . 40

4.1 Formulation of the Structural Matrices. . . . 42

4.2 Bonndary Conditions . . . . . . . . . . . 43

4.3 solktion. . . . . . . . . . . . . 45

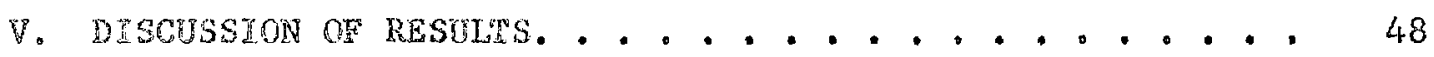

5.1 Interpretation of Results.......... 48

5.2 Elates Wehort Dampirg. ........... 49

5.3 plakes or Elastic Foundations . . . . . . 68

5.4 Plates Wh Viscous Danping . . . . . . . . 79

5.5 Piste on Elestic Poundation With Viscous

remping ................. 79 
TABLE OF CONTENTS (Continued)

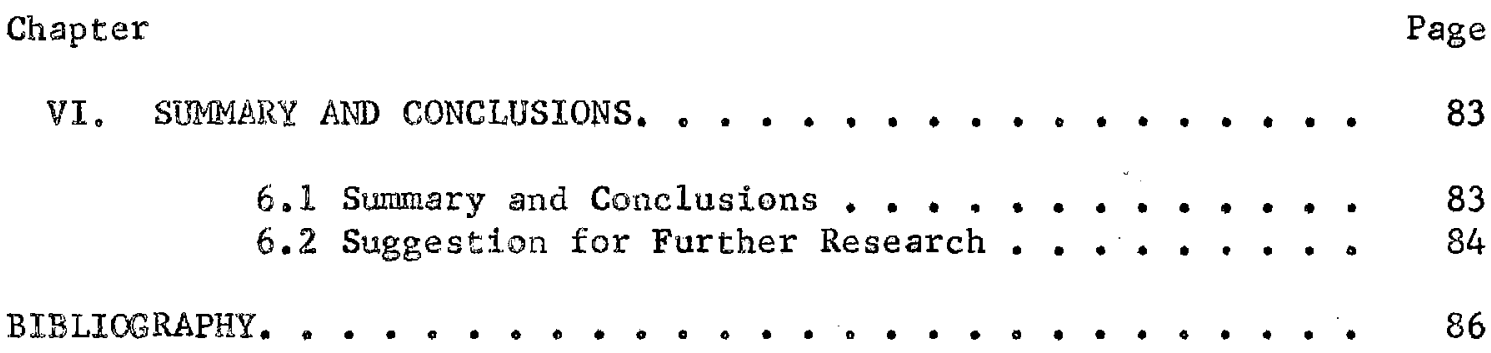


LIST OF TABLES

rable

Page

I. Mode Shapes, Natural Frequencies, and Buckling Loads for Several Plates ..................

II. Information for Obtaining the Fundamental Region of Instability for Several Plates . . . . . . . . 
LIST OF FIGURES

Figure

Page

1. Finite Element With Generalized Coordinates. . . . . . 16

2. Generalized Coordinates, Function of Constants . . . . . 18

3. [E] and [G] Matrices ............... 19

4. Elemental Mass Matrix. . . . . . . . . . . 21

5. Elemental Stiffness Matrix . . . . . . . . . . 22

6. Elemental Stability Matrix for $\mathrm{N}_{\mathrm{x}}$............. 23

7. Elemental Stability Matrix for $\mathrm{N}_{\mathrm{y}}$. . . . . . . . . 24

3. Eiemental stability Matrix for $\mathrm{N}_{\mathrm{xy}}$. . . . . . . . . 25

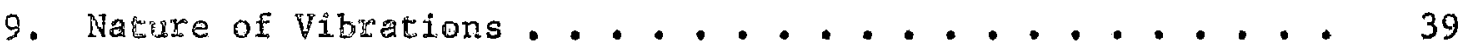

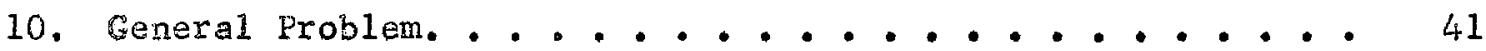

11. Regions of Dynamic Instability . . . . . . . . . 51

12. Instability Regions for Mathieu Equation . . . . . . . 52

13. Regions of Dynamic Instability for a Simply Supported Plate $\left(\mathbb{N}_{\mathrm{xy}}=\mathrm{N}, \mathrm{N}_{\mathrm{x}}=0, \mathrm{~N}_{\mathrm{y}}=0\right) . \cdots \cdot 59$

14. Mode Shapes for a Simply Supported Plate $\left(\mathrm{N}_{\mathrm{xy}}=\mathrm{N}\right)$. . . . 60

15. Regions of Dynamic Instability for a Simply Supported Plate $\left(\mathrm{N}_{\mathrm{x}}=.1 \mathrm{~N}_{\mathrm{g}} \mathrm{N}_{\mathrm{y}}=.1 \mathrm{~N}, \mathrm{~N}_{\mathrm{xy}}=\mathrm{N}\right) . . . . . . . .$.

16. Mode Shapes for a Simply Supported Plate $\left(\mathrm{N}_{\mathrm{x}}=.1 \mathrm{~N}, \mathrm{~N}_{\mathrm{y}}=\right.$

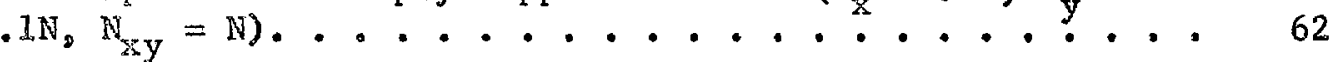

17. Regions of Dynamic Instability for a Cantilevered Plate

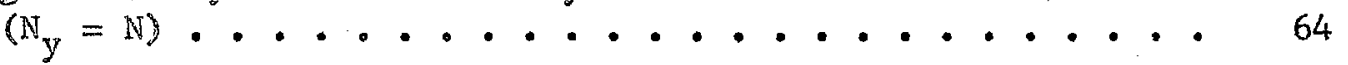

18. Mode Shapes for a Cantilevered Plate $\left(\mathrm{N}_{\mathrm{y}}=\mathrm{N}\right)$. . . . . 65

19. Regions of Dynamic Instability for a Fixed Ended Plate

$\left(\mathbb{N}_{\mathrm{y}}=\mathbb{N}\right) \cdot \cdot \cdot \cdot \cdot \cdot \cdot \cdot \cdot \cdot \cdot \cdot \cdot \cdot \cdot \cdot \cdot \cdot \cdot \cdot \cdot \cdot$ 
Figure

Page

20. Mode Shapes for a Fixed Ended Plate $\left(\mathrm{N}_{\mathrm{y}}=\mathrm{N}\right)$. . . . . 67

21. Regions of Dymamic Instability for a Simply Supported Plate on an Elastic Foundation $(\delta=.0002, \alpha=0) . .$. . 69

22. Regions of Dynamic Instability for a Simply Supported Plate on an Elastic Foundation $(\delta=.0002, \alpha=0.6)$...

23. Mode Shapes Eor a Simply Supported Plate on an Elastic Foundation $\left(\delta=.0002, N_{x}=N_{y}=N\right) . \cdots 11$

24. Regions of Dynamic Instability for a Simply Supported Plate on an Elastic Foundation $(\delta=.0006, \alpha=0) . .$.

25. Regions of Dynamic Instability for a Simply Supported Place on an Elastic Foundation $(\delta=.0006, \alpha=0.6) .$. .

26. Mode Shapes for a Simply Supported Plate on an Elastic Foundation $\left(\delta=.0006, \mathrm{~N}_{\mathrm{x}}=\mathrm{N}_{\mathrm{y}}=\mathrm{N}\right)$. ....... 74

27. Regions of Dynamic Instability for a Clamped Plate on an Elastic Foundation $(\delta=.0002) . . . . . .$.

28. Mode Shapes for a Clamped Plate on an Elastic Foundation

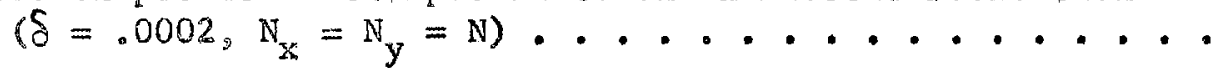

29. Regions of Dynamic Instability for a Clamped Plate on an Elastic Foundation $(\delta=.0006)$..........

30. Mode Shapes for a Clamped Plate on an Elastic Foundation

$$
\left(\delta=.0006 . N_{x}=N_{y}=N\right) \cdot \cdots \cdot \cdot \cdot \cdot \cdot \cdot \cdot \cdot \cdot \cdot \cdot
$$

31. Regions of Dynamic Instability for a Simply Supported Plate With Viscous Damping................

32. Regions of Dynamic Instability for a Clamped Plate With Viscous Damping. . . . . . . . . . . . . . . .

33. Region of Dynamic Instability for a Simply Supported Plate on an Elastic Foundation With Viscous Damping. . . . . 
NOMENCLATURE

a. ...... plate dimension in the $x$-direction, also a constant

$A_{i}, a_{i j}, \bar{a} \ldots . .$. constants

$\{A\},[A],\left\{a_{k}\right\}, \ldots$ constant matrices

b. ....... plate dimension in the $y$-direction, also a constant

$b_{i}, b_{.} \cdot \ldots \cdot$.... constants

$\left\{b_{k}\right\} \ldots . \cdots$ constant vector

$[B]$. . . . . constant matrix which relates $\{A\}$ to the node displacements

$[\bar{B}] \ldots \ldots$..... periodic matrix

c......... damping coefficient

c........ constant

$\{c\} . \ldots \ldots$ matrix of second partial derivatives of $w$

$\mathrm{CK}_{i j} \cdot \cdots \cdot \cdot \cdot \cdot$ nodal carry-over stiffness matrix

d. ........ constant

D........ plate rigidity

[D]. . . . . matrix used to express the strain energy of a plate in matrix form

e........ base of natural logarithms

$\bar{e}_{s} \overline{\bar{e}} \cdot \ldots . . . \cdot$ constants

[E]. - . . . . matrix which relates the second partial derivaw tives of $w$ to the nodal displacements

f........ variable function

f. ....... constant 
$E_{n}(x, y) . \cdots \cdot$.... polynomial functions

$\{f(t)\}$....... variable vector

F.......... force

$\{\mathrm{F}\} . . . . .$. matrix of the first partial derivatives of $\mathrm{W}$

g......... constant

$g_{i}(x, y) . . . .$. shape functions

[G]. ...... matrix which relates the first partial derivatives of $w$ to the nodal displacements

h. ....... constant

[H]........ constant matrix

i......... subscript

[I]........ identity matrix

j. ........ subscript

[j]........ constant matxix

k. ....... subscript

[k]. . . . . . elemental stiffness matrix

$\mathrm{K}_{\mathrm{g}} \cdot \cdots \cdot \cdot \cdot \cdot$ nodal stiffness matrirs

[k]......... structeral atifiness matrix

Ł......... constant

$[L]$. . . . . . constant matrix

m. . . . . . - congtanta

[m]. ....... elemental mass matrix

$M_{i x}{ } M_{i y} \cdot$..... moments

$[\mathrm{M}] . . . . . . .$. structural mass matrix

n........ constant

$[\mathrm{N}]$. . . . . . constant matrix also used as load matrix

$N_{x^{2}} \mathbb{N}_{y^{9}} \mathbb{N}_{x y^{*}} \cdot \ldots \cdot$ in-plane loads per unit length

$N_{S}$. . . . . . inoplane static load 
$N_{t} \cdot \ldots \cdot \ldots \cdot \ldots$ in plane time dependent load

$\mathrm{N}_{\mathrm{i}}^{\text {*e }}$....... static buckling loads

p......... eigenvalues

q. . . . . . modulus of an elastic fcundation per unit area

$Q_{i} \cdot \ldots \cdot \cdot \cdot$ generalized forces

r........ subscript

$R(t)$....... general time function

$\left[R_{i k}\right],[\bar{R}(t)]$. . . periodic matrices

s. . . . . . subscript

$s_{i} \cdot . \cdot . \cdot . \cdot$ generalized displacement

$\dot{s}_{i} \cdot$. . . . generalized velocities

$[S],\left[S_{x}\right],\left[S_{y}\right],\left[S_{x y}\right]$ elemental stability matrix for, all loads, loads in $x$-direction, loads in $y$-direction, and shear loads, respectively

$[\overline{\mathbf{S}}],\left[\overline{\mathbf{s}}_{\mathrm{x}}\right],\left[\overline{\mathbf{s}}_{\mathrm{y}}\right],\left[\overline{\mathbf{s}}_{\mathrm{xy}}\right]$ structural stability nawices for, all loads, loads in $x$-direction, loads in $y$-direction, and shear loads respectively

$\left[\bar{s}_{s}\right]$....... static structural stability matrix

$\left[\bar{s}_{t}\right]$....... time dependent structural stability matrix

t........ time

T. . . . . . kinetic energy and also period of transverse vibration

U. ....... strain energy

$\{u(t)\}$....... variable vector

V. . . . . . potential energy

$\left\{v_{1} R(t)\right\}$.... generalized displacements

$w(x, y, t)$. . . . transverse displacement function of a plate element

$w_{i} \cdot . \cdot \cdot \cdot$.. transverse nodal displacement

$w_{i x}, w_{i y} \cdot \cdot \cdot \cdot \cdot$ nodal slopes 
W. ....... . work

x. ........ spatial variable

$\left\{x_{s}(\leftarrow)\right\} . . . .$. variable vector

y. . . . . . spatial variable

$\left\{z_{s}(t)\right\}$...... periodic vector

a. . . . . . percentage of the static buckling load which is applied statically

ß........ percentage of the static buckling which is applied as the amplitude of the pulsating loads

v........ Poisson's ratio

ค........ mass per unit area

๑. . . . . . . frequency of the in-plane pulsating loads

w. . . . . . natural frequency of transverse vibration

[ ]....... square or rectangular matrix

\{\} ........ column matrix

[]$^{-1}$...... matrix inverse

[]$^{T}$...... matrix transpose 
CHAPTER I

INTRODUCTION

\subsection{Statement of the Problem}

The term "dynamic stability" has been used frequently in the 1iterature to refer to several phenomena. Among these are, buckling under impulsive loading, the snap through of shallow arches and shells, the stability of axtomatic control systems, and the stability of structures submitted to the action of pulsating parametric loads. The last phenomenon mentioned is sometimes referred to as parametric resonance and is the subject of investigation of this thesis.

Quite generally, whenever a static load of a particular configura tion can cause a loss of the static stability of a given structural system, a pulsating load of the same configuration can cause a loss of its dynamic stability when certain conditions are satisfied. Several examples of this phenomenon can be found in the literature (1). In particular, if a flat plate is subjected to pulsating in-plane loads, and if the amplitudes of the pulses are smaller than the static buckling load, the plate will perform inoplane or longitudinal vibrations, and for certain frequencies of the pulses, in-plane resonance will occur. However, an entirely different type of resonance will occur in the plate when a definite relationship between the frequency of the pulses and the natural frequency of transverse vibration of the plate exists. Thus, besides the in-plare vibration, transverse vibrations will be 
Indreed in the plate, and the plate is said to be dynamically unstable. The distinction between the ordinary resonance and the parametric resonance (dynamic stability) now becomes apparent. In the ordinary resonance the vibrations accompanying the load are in the direction of the load, i.e. In the direction of the associated deformations, while in the parametic resonance the induced vibrations are in the direction of the buckling deformations and arise only for a definite ratio of the forcing frequency and the natural frequency of transverse vibration. Thus, like the brckling problem, the amplitude of the pulsating load and 1ts frequency appear in the governing differential equation parametrically rather than as a forcing function, as is the case for ordinary resonance.

The spertrum of values of the parameters causing unstable motion is referred to as the regions of dynamic instability. It is interesting to note that the governing differential equation is always of the Matheiu-Hill type, and that dynamic instability may occur for any magnitude of the pulsating load, less or greater than the static buckling load. For practical considerations, however, only loads with magnitudes less than the static buckling load are of interest. This pulsating type loading may be encountered in plate structures housing vibratory machinery as well as in aircraft structures traveling at transonic and low supersonic speeds. The analysis of such structures for dynamic instability is useful in preventing failure due to parametric resonance as well as in avolding fatigue resulting from the induced vibrations.

\subsection{Review of Previous Work}

The dynamic stability problem was first recognized by Lord 
Rayleigh (2) who investiguted the stability of a string under variable tension. Later, Beliaev (3) published an article in which he discussed the dynamic stability of a straight rod pinned at both ends, and determined the boundaries of the region of instability. Since Beliaev's work, many investigators have refined and applied the theory to bars, rings, plates, and shells. A review of the literature on the subject up to 1951 is available in an article by E. A. Beilin and G. Dzhanelidze (4). The most comprehensive account on the subject was presented by Bolotin (1) in his book Dynamie Stability of Elastic Systems.

The dynarnc stability of plates under compressive in plane loads was investigated by Bodner (5), Khalilov (6), Rinaudi (7), Ambart sumian and Khachatran (8), Bolotin and others. The effect of damping on the instability regions was discussed by Mettler (9), and Naumov (10). Froblems involving nonlinear damping and other nonlinear effects are due to Bolotin (1), Metter and Weidenhamer (11). A comon feature of most of the woxks mentioned is that the governing differential equathons are reduced either exacty or approximately to a single second order differentia equation with periodic coefficients of the Mathieu Hid 1 type. However, Chelomei (12) has shown that in the general case the problam is governed by a system of differential equations with periodic coefficierts.

\subsection{Scope}

In a11 of the atove cited works, the authors have employed either incegral equations or Galetrin's Method to establish the governing equation or equations. The success of eithex method depends to a great excent on the rature of the problen to be investigated. For instance, to use a Galerkin approach a prior knowledge of some suitable functions 
that satify the bowadary condtions is necessary in ordex to approximate either the buckling or vibration modes. Because such functions are not always available, many problems of relatively complex loading or geometrical nature have remained unsolved. An alternative approximate method that is capable of handling a wide range of complex problems with regard to geometry, loading, and matexial property is, therefore, extremely desirable. For such a method, the finite element approach originally developed by Clough and others (13), seems to be most suitable for these purposes, and its application to dynamic stablity analysis of plates is demonstrated in this thesis.

The purpose of this thesis is to develop, using the finite element method, a procedure to determine the regions of dynamic instability for plates subjected to vardous in-plane pulsating loads and boundary conditiona. Incladed in the analysis are plates without damping, plates with viscous damping, plates on elastic foundations, and plates on elastic foundations with viscous damping. The plates to be examined are assumed to be tectangalar, homogeneous, and isotropic. The material is also assumed to obey Hooke's Law, and the well known assumptions of the small deflecirion theory of plates are employed. Although these limitgtions are imposed upon the examples which are solved, it is pointed out in the conclusions that the method that is developed is not limited to all of these restrictions. Only principal regions of instability are investigated. Experimental data for pinned rods presented by Boløidn (I) showed that no experimental correlation could be found for higher regions, and that the data for the principal regions agreed exceptionaliy well with the theory. It is further assumed that the effects of inoplane inertha can be neglected. It has been shown by 
Bolotin (D) and others that thas asuption is vald provided the frew quency of the pulsating load is not close to the resonance frequency of in w plane vibration of the plate.

The rollowing are the steps 10 the determination of the regions of dynamic instability of plates:

(a) Divide plate into a grid of finite elements;

(b) Assume a suitable displacement function for the finite elements;

(c) Determine ethe elemental bending stiffness matrices;

(d) Deternine the elemental inertia or mass matrices;

(e) Determine the elemental stability matrices;

(f) Determine any other elemental matrices needed to analyze a particular problem, such as stiffness modifier matrices due to an elastic foundation, and a matrix which accounts fox damping;

(g) Assemble elemental matries to form matrices for the entre structure;

(h) Apply the boundary conditions;

(i) Solve for the natural frequencies of transverse vibration;

(j) Solve for tre stric byekling loud corresponding to the load configureation of interest;

(k) Solve for the regions of dynamic instability.

In the following Chapters, Chapter II gives the development of the governing set of math differental equations, and the procedure for the development of the elemental matrices; Chapter III discusses the mathematies involved in finding the boundaries of instability for the governing equations; Chapter IV formulates the solution for the regions of instubility: Chapter V presents typical examples, and chapter VI gives the conclusions and suggestions for further research. 
GHAPTER II

\section{GOVERNING FIRITE ELEMENT EQUATIONS}

In this chapter the governing finite element aquations are developed for a plate which undergoes parametrically excited vibrations. other than the assumption that the given structure can be represented by a series of finite elements, the development is completely general. The developed matrices in the latter part of this chapter are determined for specific cases of mass and load distributions. The Lagrangian equation is used together with the finite element method in the development of these equations.

The Lagrangian equation may be written as follows (14);

$$
\frac{d}{d t}\left(\frac{\partial T}{\partial s_{i}}\right) \cdot \frac{\partial(T-U)}{\partial s_{i}}-\frac{\partial V}{\partial \varepsilon_{i}}+\frac{\partial W}{\partial v_{i}}=Q_{i}
$$

in which

$$
\begin{aligned}
& I=\text { Kinetic energy } \\
& U=\text { strain energy die to bending } \\
& V=\text { Potential energy developed by in-plane loads moving } \\
& \text { through bending displacements } \\
& W \text { = One-half the time rate at which energy is dissipated } \\
& \text { by viscous damping } \\
& \mathrm{Q}_{\mathrm{i}}=\text { Generalined forces } \\
& s_{i}=\text { Generaliged coordinates } \\
& \dot{s}_{i}=\text { Generalized veloeities. }
\end{aligned}
$$


Let amal element of finite dimensions be isolated from a plate and the lateral displatements of the element be represented as

$$
w(x, y, t)=w(x, y) R(t)
$$

in which $w(x, y)$ is a Entution of $x$ and $y$ only, and $R(t)$ is a time function. Here the middle surface of the plate is taken as lying in the $x-y$ plane and $w$ is measured downward from this plane. Further it is assumed that the function $w(x, y)$ can be represented as a linear combination of $(n)$ functions $f_{n}(x, y)$. Thus

$$
w(x, y, t)=\left[f_{1}(x, y), f_{2}(x, y), \ldots f_{n}(x, y)\right]\left[\begin{array}{l}
A_{1} \\
A_{2} \\
\vdots \\
\cdot \\
A_{n}
\end{array}\right] R(t) .
$$

To determine the constants $\left\{\mathfrak{A}_{\text {a }}\right\}$ the $\mathrm{n}$ nodal displacements of the finite plate alement, $\left\{y_{i}(t)\right\}$, ate chosen as generalized displacements. That is to say

$$
\left\{s_{i}\right\}=\left\{v_{i} R(t)\right\}
$$

These node dighacements can be expressed as follows,

$$
\left\{V_{i} R(t)\right\}=[B]\{A\} R(t)
$$

The matrix [R] i.s obtained by evgluating the matrix $\left[f_{n}(x, y)\right]$ and its dexivatives at the node points. Solving for the constants, $\{A\}$, from Eq. (5) gields 


$$
\{A\}=[B]^{-1}\left\{v_{1}\right\}
$$

and by substitution into Eq. (3) the displacement function can be expressed as

$$
w(x, y, t)=\left[f_{1}(x, y), f_{2}(x, y), \ldots f_{n}(x, y)\right][B]^{-1}\left\{v_{i} P_{l}(t)\right\}
$$

Because the matrices $[B]$ and $\left\{v_{i} R(t)\right\}$ are not functions of $x$ and $y$, the derivatives of $w(x, y, t)$ may be formed as follows;

$$
\begin{aligned}
\frac{\partial w}{\partial x} & =\frac{\partial f_{n}(x, y)}{\partial x}[B]^{-1}\left\{v_{i} R(t)\right\} \\
\dot{y} & \frac{\partial w}{\partial y}=\frac{\partial f_{n}(x, y)}{\partial y}[B]^{-1}\left\{v_{i} R(t)\right\} \\
\vdots & \frac{\partial w}{\partial t}=\left[f_{n}(x, y)\right][B]^{-1}\left\{v_{i} \frac{d R(t)}{d t}\right\} .
\end{aligned}
$$

With the above information expressing the displacements of the plate element in terms of nodal or generalized displacements, the terms in the Lagragian equâsin can be evaluated in a finite element form.

\subsection{Kinetic Energy}

The kinetic energy for an infinitesimal area of the plate element is

$$
d T=\frac{1}{2} \rho\left[\frac{\partial w\left(x_{2} y_{2} t\right)}{\partial t}\right]^{2} d x d y,
$$

in which $\rho$ is the mass of the plate for a unit surface area. If this expression is irtegrated ovex the entire surface of the plate element, the cotal kinewic energy for the element becomes, 


$$
T=\frac{1}{2} \iint_{\rho}\left[\frac{\partial w(x, y, t)}{\partial t}\right]^{2} \mathrm{dxdy}
$$

Substituting from Eq. (8) into Eq. (10),

$$
T=\frac{1}{2} \iint_{\rho}\left[\left[f_{n}(x, y)\right][B]^{-1}\left\{v_{i} \frac{d R(t)}{d t}\right\}\right]^{2} d x d y
$$

The squaring of the term in the brackets can be accomplished by multiplying the expression by its transpose.

$$
T=\frac{1}{2} \iint_{\rho}\left[\left\{v_{i} \frac{d R(t)}{d t}\right\}^{T}\left[[B]^{-1}\right]^{T}\left[f_{n}(x, y)\right]^{T}\left[f_{n}(x, y)\right][B]^{-1}\left\{v_{i} \frac{d R(t)}{d t}\right\}\right] d x d y .
$$

This expresses the total kinetic energy of the plate element in terms of the generalized nodal displacements.

Now the nevessary operations are performed on the kinetic energy term for substitution into the Lagrangian equation. The first term of Eq. (1) then becomes,

$$
\begin{aligned}
\frac{d}{d t}\left(\frac{\partial T}{\partial s_{i}}\right)= & \frac{d}{d t}\left(\frac{\partial T}{\partial\left(v_{i} \frac{d R(t)}{d t}\right)}\right)=\left[[B]^{-1}\right]^{T}\left[\iint\left[f_{n}(x, y)\right]^{T}\right. \\
& {\left.\left[f_{n}(x, y)\right] p d x d y\right][B]^{-1}\left\{v_{i} \frac{d^{2} R(t)}{d t^{2}}\right\}(i=1,2,--n) . }
\end{aligned}
$$

The $\left[[B]^{-1}\right]^{T},[B]^{-1}$ and $\left\{v_{i} \frac{d^{2} R(t)}{d t^{2}}\right\}$ matrices can be factored out as shown since they are independent of the variables $x$ and $y$. Using a more concise notation

$$
\frac{d}{d t}\left|\frac{\partial T}{\partial s_{i}}\right|_{(i=1,2,3-n)}=[m]\left\{v_{i} \frac{d^{2} R(t)}{d t^{2}}\right\}
$$


in which

$$
[m]=\left[[B]^{-1}\right]^{\mathrm{T}}\left[\iint\left[f_{n}(x, y)\right]^{T}\left[f_{n}(x, y)\right] \rho d x d y\right][B]^{-1}
$$

The matrix [m] is designated as the elemental mass matrix and hereafter is referred to as such.

The remaining term involving the kinetic energy is

$$
\frac{\partial \mathbf{T}}{\partial s_{i}} \equiv 0
$$

since the kinetic energy function is independent of the variables $s_{i}$.

\subsection{Strain Energy}

The strain energy for the entire area of the plate element is

$$
U=\iint \frac{D}{2}\left[\frac{\partial^{2} w}{\partial x^{2}} \frac{\partial^{2} w}{\partial y^{2}}-2(1-v)\left[\frac{\partial^{2} w}{\partial x^{2}} \frac{\partial^{2} w}{\partial y^{2}}-\left(\frac{\partial^{2} w}{\partial x \partial y}\right)^{2}\right]\right] d x d y
$$

This can be reptesented in matrix form as

$$
U=\iint \frac{D}{2}\{C\}^{T}[D]\{C\} d x d y
$$

In which

$$
\{C\}=\left[\begin{array}{c}
\frac{\partial^{2} w}{\partial x^{2}} \\
\frac{\partial^{2} w}{\partial y^{2}} \\
\frac{\partial^{2} w}{\partial x \partial y}
\end{array}\right], \text { and }[D]=\left[\begin{array}{ccc}
1 & v & 0 \\
v & 1 & 0 \\
0 & 0 & 2(1-v)
\end{array}\right] \text {. }
$$

Matrix $\{c\}$ can be expressed in terms of the generalized displacements as

$$
\{C\}=[E][B]^{-1}\left\{v_{i} R(t)\right\}
$$


in which

$$
[E]=\left[\begin{array}{cccc}
\frac{\partial^{2} f_{1}(x, y)}{\partial x^{2}} & \frac{\partial^{2} f_{2}(x, y)}{\partial x^{2}} & \cdots \infty & \frac{\partial^{2} f_{n}(x, y)}{\partial x^{2}} \\
\frac{\partial^{2} f_{1}(x, y)}{\partial y^{2}} & \frac{\partial^{2} f_{2}(x, y)}{\partial y^{2}} & \cdots & \frac{\partial^{2} f_{n}(x, y)}{\partial y^{2}} \\
\frac{\partial^{2} f_{1}(x, y)}{\partial x \partial y} & \frac{\partial^{2} f_{2}(x, y)}{\partial x \partial y} & \cdots & \frac{\partial^{2} f_{n}(x, y)}{\partial x \partial y}
\end{array}\right]
$$

Substituting into the scrain energy expression the strain energy becomes,

$$
U=\iint \frac{D}{2}\left\{v_{i} R(t)\right\}^{T}\left[[B]^{-1}\right]^{T}[E]^{T}[D][E][B]^{-1}\left\{v_{i} R(t)\right\} d x d y .
$$

Now the operations indicated by Eq. (1) are performed

$$
\frac{\partial U}{\partial s_{i}}=\frac{\partial U}{\partial\left(v_{i} R(t)\right)}=\left[[B]^{-1}\right]^{T}\left[\iint D[E]^{T}[D][E] d x d y\right][B]^{-1}\left\{v_{i} R(t)\right\}
$$

or

$$
\frac{\partial \mathbb{U}}{\partial s_{i}}=[k]\left\{v_{i} R(t)\right\}
$$

in which

$$
[k]=\left[[B]^{-1}\right]^{T}\left[\iint[E]^{T}[D][E] d x d y\right][B]^{-1}
$$

By definition the [k] matrix is the stiffness matrix for the element.

\subsection{Work Done By Ine Plane Loads}

The work done by the paramectic or in-plane loads when they move through the beriding displacenents is

$$
\nabla=\frac{3}{2} \iint\left[N_{x}\left(\frac{\partial w}{\partial x}\right)^{2}+N_{y}\left(\frac{\partial w}{\partial y}\right)^{2}+2 N_{x y}\left(\frac{\partial w}{\partial x} \frac{\partial w}{\partial y}\right)\right] d x d y .
$$


This expression may be represented in matrix form as follows;

$$
\nabla=\frac{1}{2} \iint\{F\}^{T}[N]\{F\} d x d y
$$

in which

$$
\{F\}=\left[\begin{array}{l}
\frac{\partial w}{\partial x} \\
\frac{\partial w}{\partial y}
\end{array}\right]=[G][B]^{-1}\left\{v_{i} R(t)\right\}
$$

and

$$
[N]=\left[\begin{array}{ll}
N_{x} & N_{x y} \\
N_{x y} & N_{y y}
\end{array}\right]
$$

The matrix [O] is as follows;

$$
[G]=\left[\begin{array}{cccc}
\frac{\partial f_{1}(x, y)}{\partial x} & \frac{\partial f_{2}(x, y)}{\partial x} & \cdots & \frac{\partial f_{n}(x, y)}{\partial x} \\
\frac{\partial f_{1}(x, y)}{\partial y} & \frac{\partial f_{2}(x, y)}{\partial y} & \cdots & \frac{\partial f_{n}(x, y)}{\partial y}
\end{array}\right] .
$$

Substruting these expressions into Eq. (25) the potential energy term becomes,

$$
V=\frac{1}{2} \iint\left\{v_{1} R(t)\right\}^{T}\left[[B]^{-1}\right]^{T}[G]^{T}[N][G][B]^{-1}\left\{v_{i} R(t)\right\} d x d y,
$$

whith when differentiaced with respect to $s_{i}$, yields

$$
\frac{\partial V}{\partial s_{1}}=\frac{\partial V}{\partial\left(v_{I} R(C)\right)}=\left[[B]^{-1}\right]^{T}\left[\iint[G]^{T}[N][G] d x d y\right][B]^{-1}\left\{v_{i} R(t)\right\}
$$

or

$$
\frac{\partial V}{\partial s_{i}}=[S]\left\{v_{i} R(t)\right\}
$$


in which

$$
[S]=\left[[B]^{-1}\right]^{T}\left[\iint[G]^{T}[N][G] d x d y\right][B]^{-1}
$$

Matrix [s] is hereafter refexred to as the elemental stability matrix.

\subsection{Damping and Elastic Foundation}

To include the effect of viscous damping, the expression for the rate at which energy is dissipated due to the damping forces must be calculated. This is done by multiplying the damping force by the velocity. Onewalf the rate at which damping energy is expended is

$$
d y=\frac{1}{2}(2 c)\left(\frac{\partial w}{\partial t}\right)^{2} d x d y
$$

where $2 c$ is the damping coefficient, and here it is assumed to be constant over the plate element. Integrating over the area of the plate element

$$
W=\iint(c)\left[\frac{\partial w(x, y, t)}{\partial t}\right]^{2} d x d y
$$

Comparing Eq. (30) with the expression for kinetic energy, Eq. (10), it can be seen that when the mass ( $\rho$ ) and damping coefficient (c) are both constant over the element's area the integrals to be evaluated are identical except for these constant terms. The damping term in the Lagrangian equation is not, however, differentiated with respect to time. By comparison with the development for the kinetic energy the damping term is

$$
\frac{\partial W}{\partial \dot{s}_{i}}=\frac{2 c}{p}[\mathrm{~m}]\left\{v_{1} \frac{d R(t)}{d t}\right\}
$$

In writing chis expression the mass has been assumed to be constant over the entire plate element. 
The effect of an elastic foundation can be taken into account by finding the work done by the elastic foundation forces and differentiating the work with respect to the generalized coordinates. Thus,

$$
\left.W_{E F}=\frac{1}{2} \iint_{q[w}[x, y, t)\right]^{2} d x d y
$$

where $q$ is the spring constant for the elastic foundation per unit area of plate surface. Here again, as for damping, by comparing this expression with the kinetic energy development it is obvious that

$$
\frac{\partial W_{E F}}{\partial s_{i}}=\frac{q}{\rho}[m]\left\{v_{i} R(t)\right\} .
$$

In the above expression it is assumed that both the foundation modulus and the mass are constant over a given plate element.

\subsection{Governing Equations}

By using Eqs. (14), (16), (22), (28), (31), and (33) in conjunction with Eq. (1), the governing equations for a plate can now be generated for the various cases of loading and motion. Several cases are 1 isted below. The matrices in these equations denoted by the capital letters axe matrices for cotaplete plate corresponding to the elemental matrices with the same small letters. For example the matrix [K] in Eg. (34) is the structural stiffness matrix. The details involved in constructing these structuxal matrices are discussed in Chapter IV. 1. Static deflections of a plate due to transverse loading

$$
[\mathrm{K}]\{\mathrm{v}\}=\{\mathrm{Q}\}
$$

2. Free vibration, no damping 


$$
[M]\left\{\frac{v^{2} R(t)}{d t^{2}}\right\}+[K]\{v R(t)\}=0
$$

and for harmonic motion of the form

$$
v_{i} R(t)=A_{i} \sin \omega t
$$

the frequency determinant becomes

$$
\left|[K]-\omega^{2}[M]\right|=0
$$

3. Static buckling

$$
[[\mathrm{k}]-[\overline{\mathrm{s}}]]\{\mathrm{v}\}=0
$$

or

$$
|[\mathrm{K}]-[\overline{\mathrm{s}}]|=0
$$

From this determinant static buckling loads can be determined.

4. Deflections of a plate on an elastic foundation

$$
[K]\{v\}+\frac{Q}{\rho}[M]\{v\}=\{Q\}
$$

5. Dynamic Stability

$$
[M]\left\{\frac{d^{2} R(t)}{d t^{2}}\right\}+[[K]-[\bar{s}]]\{v R(t)\}=0
$$

6. Dynamic Stability including damping

$$
[M]\left\{\frac{d^{2} R(t)}{d t^{2}}\right\}+\frac{2 C}{\rho}[M]\left\{v \frac{d R(t)}{d t}\right\}+[[K]-[\bar{S}]]\{v R(t)\}=0
$$

The equations for other combinations of factors affecting the plate response can be formed in a sirailar manner. 


\subsection{Development of Elemental Matrices}

In the expressions for the mass, stiffness, and stability matrices, once the displacement function $w(x, y)$ is known the matrices $\left[f_{n}(x, y)\right]$, [E] and [G] can be determined, and the integrals can be evaluated for particular cases.

Assume the displacement function for the rectangular plate element shown in Figure (1) takes the form,

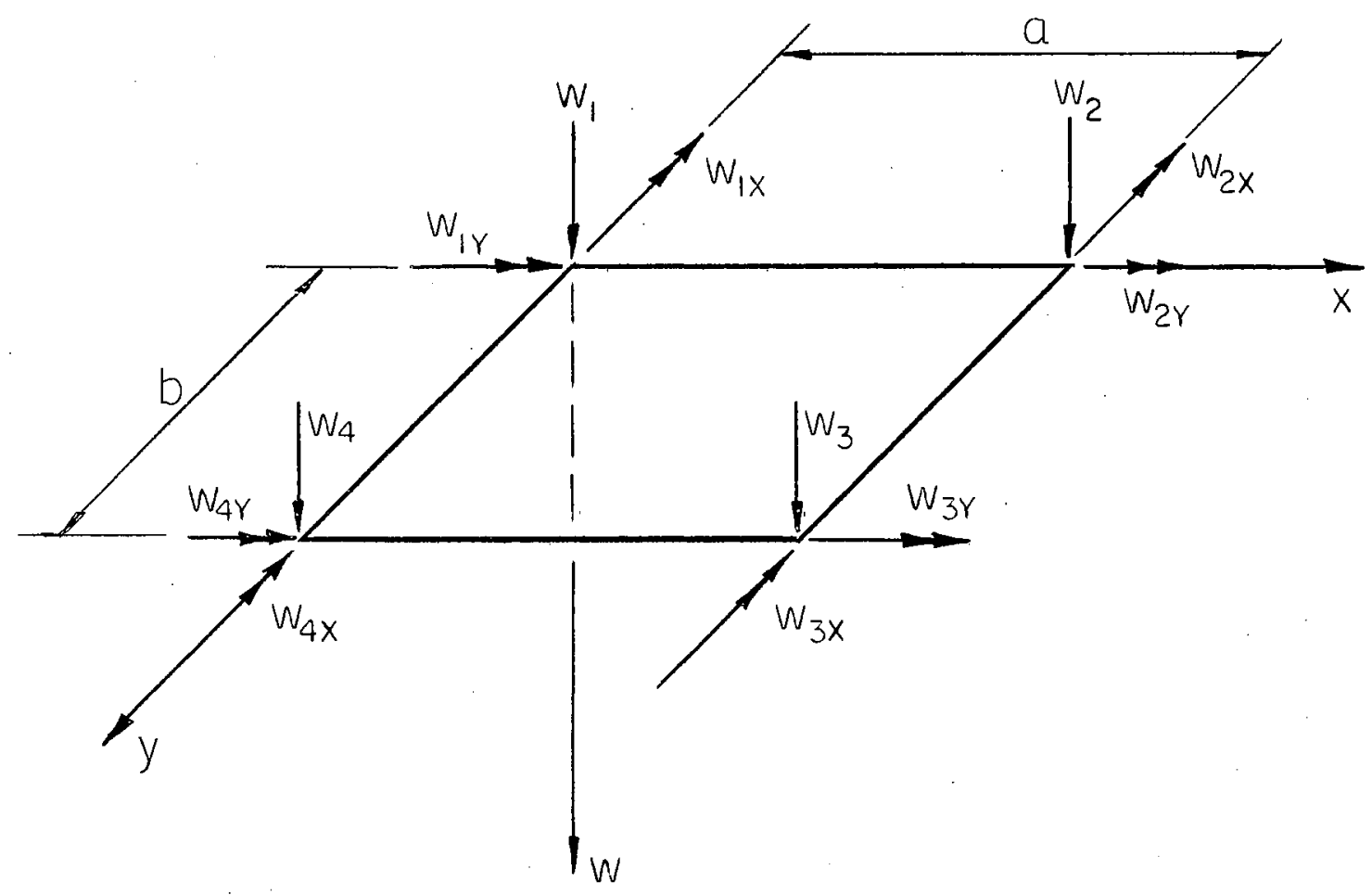

Figure 1. Finite Element With Generalized Coordinates 


$$
\begin{gathered}
w(x, y)=A_{1}+A_{2} \frac{x}{a}+A_{3} \frac{y}{b}+A_{4} \frac{x^{2}}{a^{2}}+A_{5} \frac{x y}{a b}+A_{6} \frac{y^{2}}{b^{2}}+A_{7} \frac{x^{3}}{a^{3}}+A_{8} \frac{x^{2} y}{a^{2} b}+ \\
A_{9} \frac{x y^{2}}{a b^{2}}+A_{10} \frac{y^{3}}{b^{3}}+A_{11} \frac{x^{3} y}{a^{3} b}+A_{12} \frac{x y^{3}}{a b^{3}}
\end{gathered}
$$

or in matrix form

$w(x, y)=\left[1, \frac{x}{2}, \frac{y}{b} \frac{x^{2}}{a^{2}}, \frac{x y}{a b}, \frac{y^{2}}{b^{2}}, \frac{x^{3}}{a^{3}}, \frac{x^{2} y}{a^{2} b}, \frac{x y^{2}}{a b^{2}}, \frac{y^{3}}{b^{3}}, \frac{x^{3} y}{a^{3} b}, \frac{x y^{3}}{a b^{3}}\right]\{A\}$.

Although other displacement functions could be used, the one chosen here has certain advantages. Eq. $(40)$ is the highest order polynomial which identically satisfies the homogeneous plate equation

$$
\nabla^{4} w(x, y)=0
$$

If the generalized coordinates are chosen as the ones shown in Figure (1), then Eq. (5) can be expressed as shown in Figure (2). When the various elements are assembled together to represent a plate, the deflections and slopes are completely compatible only at the node points. Compatibility is also maintained along the connecting boundaries in the direction of the boundaries, whereas in general slopes are slightly discontinuous across the boundaries.

Matrices [E] and [G] in Eqs. (20) and (26) may now be constructed using the chosen displacement function. These matrices are shown in Figure (3). The elemental mass, stiffness, and stability matrices, [m], $[\mathrm{k}]$ and $[\mathrm{S}]$, are developed by substituting into Eqs. (15), (23), and 


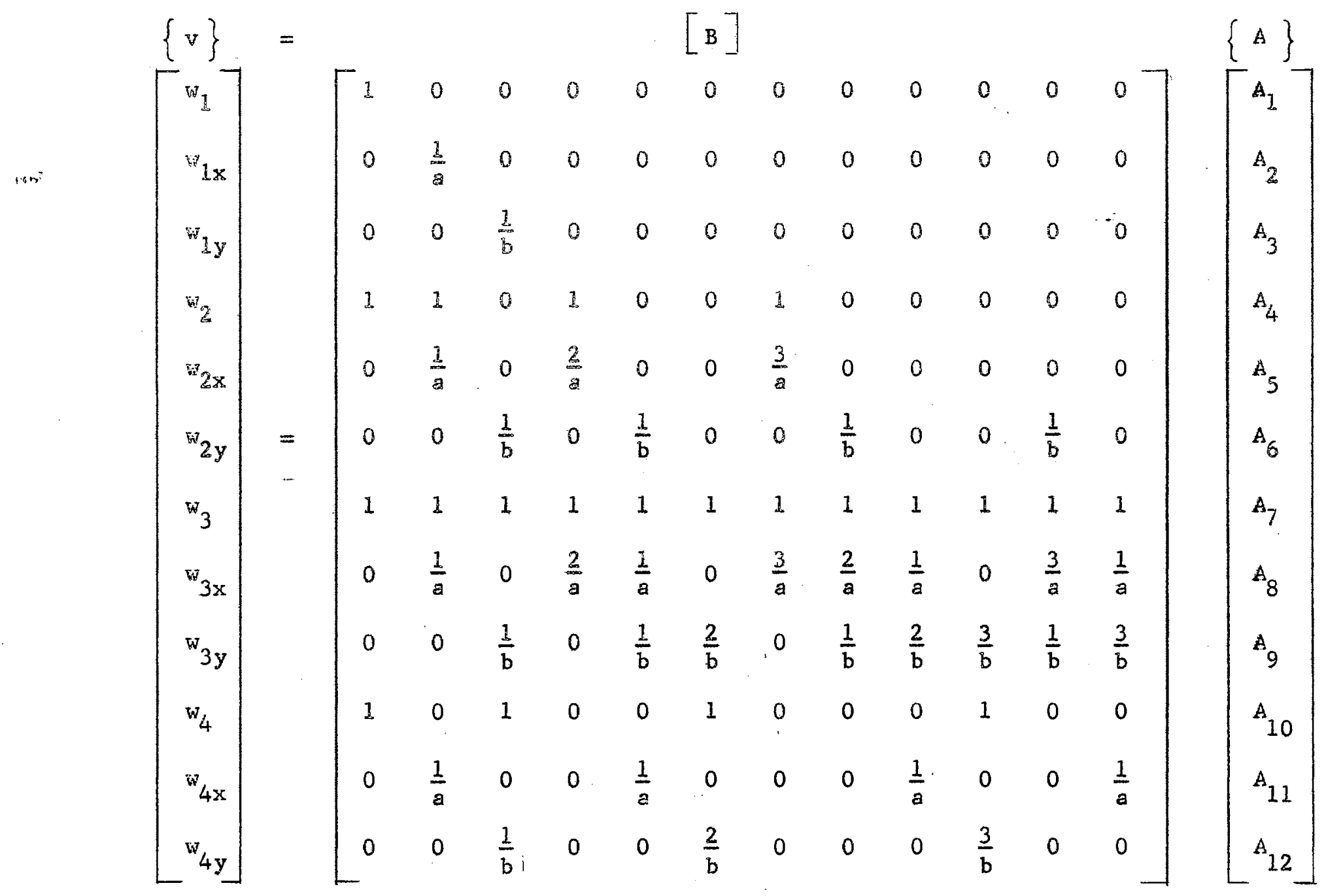

Figure 2. Generalized Coordinates, Function of Constants 


$$
\begin{aligned}
& {[E]=\left[\begin{array}{cccccccccccc}
0 & 0 & 0 & \frac{2}{2} & 0 & 0 & \frac{6 x}{3} & \frac{2 y}{2} & 0 & 0 & \frac{6 x y}{3} & 0 \\
0 & 0 & 0 & 0 & 0 & \frac{2}{a^{2} b} & 0 & 0 & \frac{2 x}{a^{2}} & \frac{6 y}{3} & 0 & \frac{6 x y}{3} \\
0 & 0 & 0 & 0 & \frac{1}{a b} & 0 & 0 & \frac{2 x}{a^{2}} & \frac{2 y}{a b^{2}} & 0 & \frac{3 x^{2}}{3} & \frac{3 y^{2}}{a b} \\
a b^{3}
\end{array}\right]}
\end{aligned}
$$

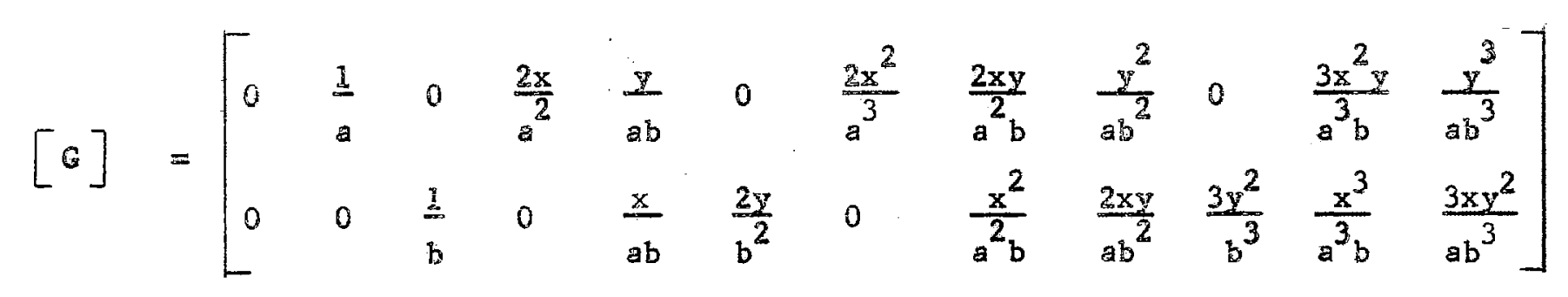

$$
\begin{aligned}
& \text { Figure 3. [E] and [G] Matrices }
\end{aligned}
$$


(28) respectively. Matrices [m] and [k] are shown in Figures (4) and (5). In the mass matrix shown the mass per unit area is taken as constant. The stability matrix is sepaxated into three parts reflecting individtally the Influence of $N_{x}, N_{y}$ and $N_{x y}$. These matrices are shown in Figures (6) through (8) for load distributions which are con stant actoss an edge of the plate. All of the elemental matrices in Figures (4) through (8) have beer non-dimensionalized, and the generalized displacements and forces as a result are,

$$
\{v\}=\left[\begin{array}{c}
w_{1} \\
a w_{1 x} \\
b w_{1 y} \\
w_{2} \\
w_{2 x} \\
w_{2 y} \\
w_{3} \\
w_{3 x} \\
w_{1 x} / a \\
M_{1 y} / b \\
F_{2} \\
w_{3 y} \\
M_{2 x} / a \\
M_{2 y} / b \\
w_{3 y}
\end{array}\right],\{Q\}=\left[\begin{array}{c}
F_{1} \\
F_{3 x} / a \\
M_{3 y} / b \\
F_{4} \\
M_{4 x} / a \\
M_{4 y} / b
\end{array}\right] \text {. }
$$




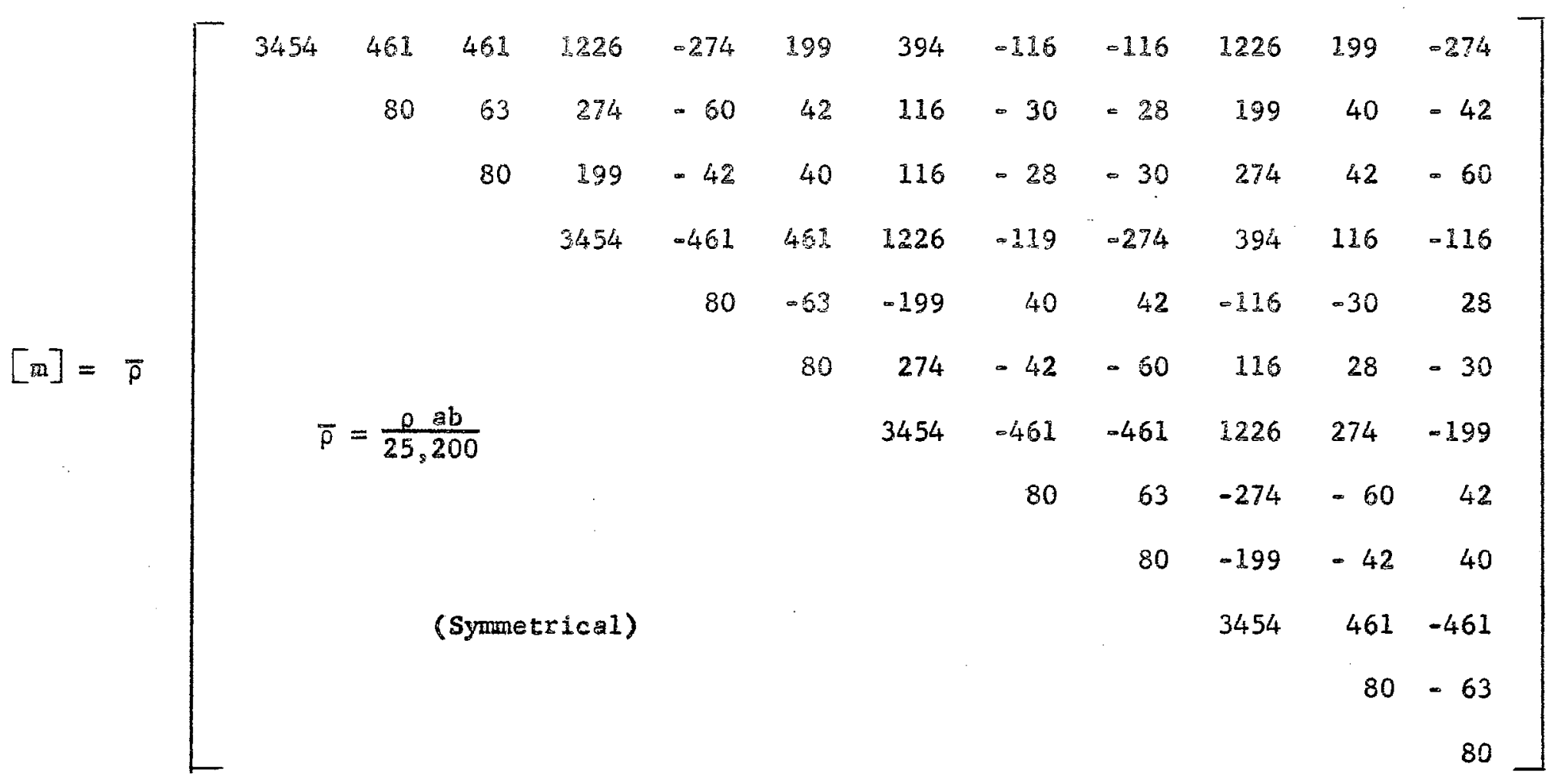

Figure 4. Elemental Mass Matrix 


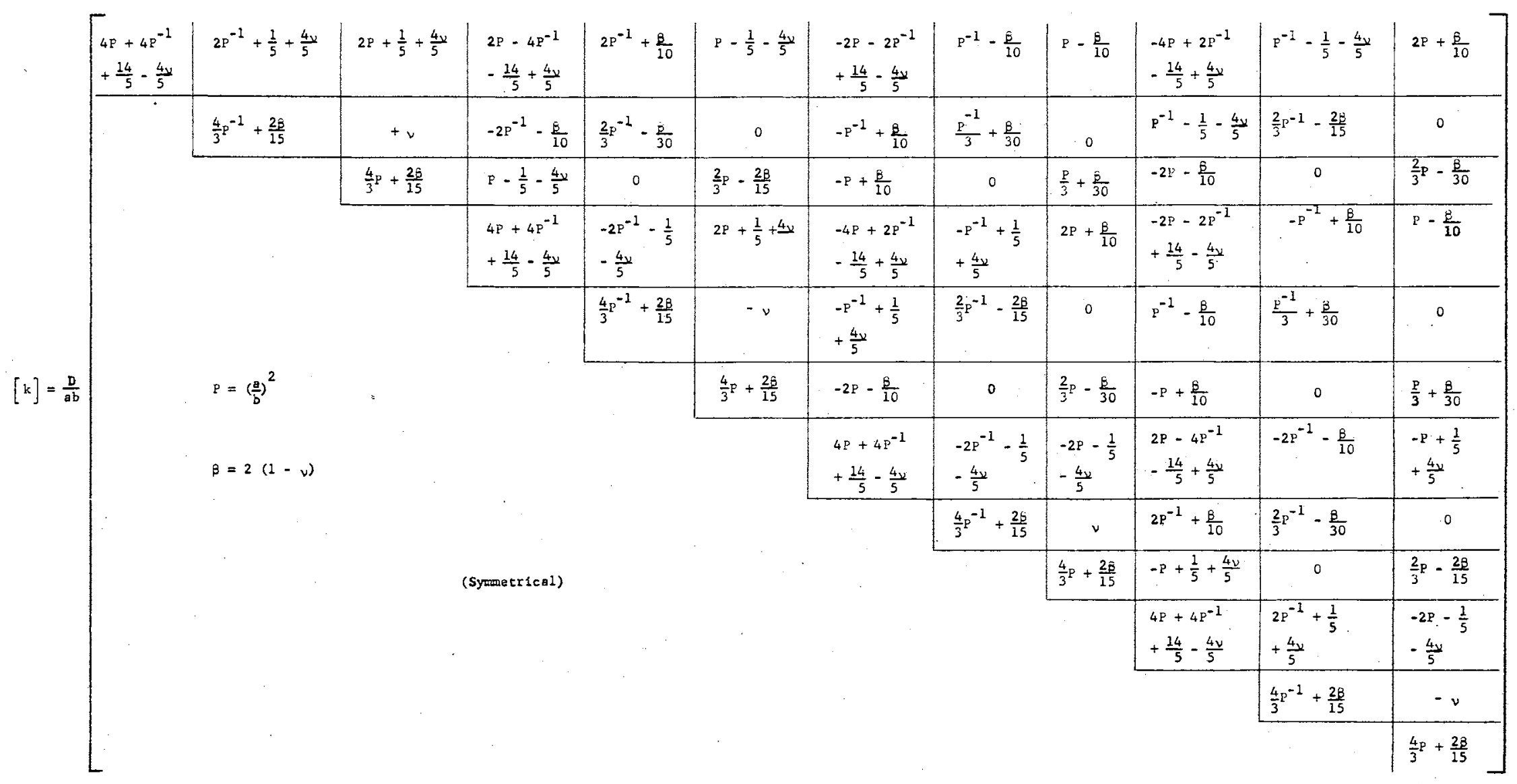

Figure 5. Elemental Stiffness Matrix 


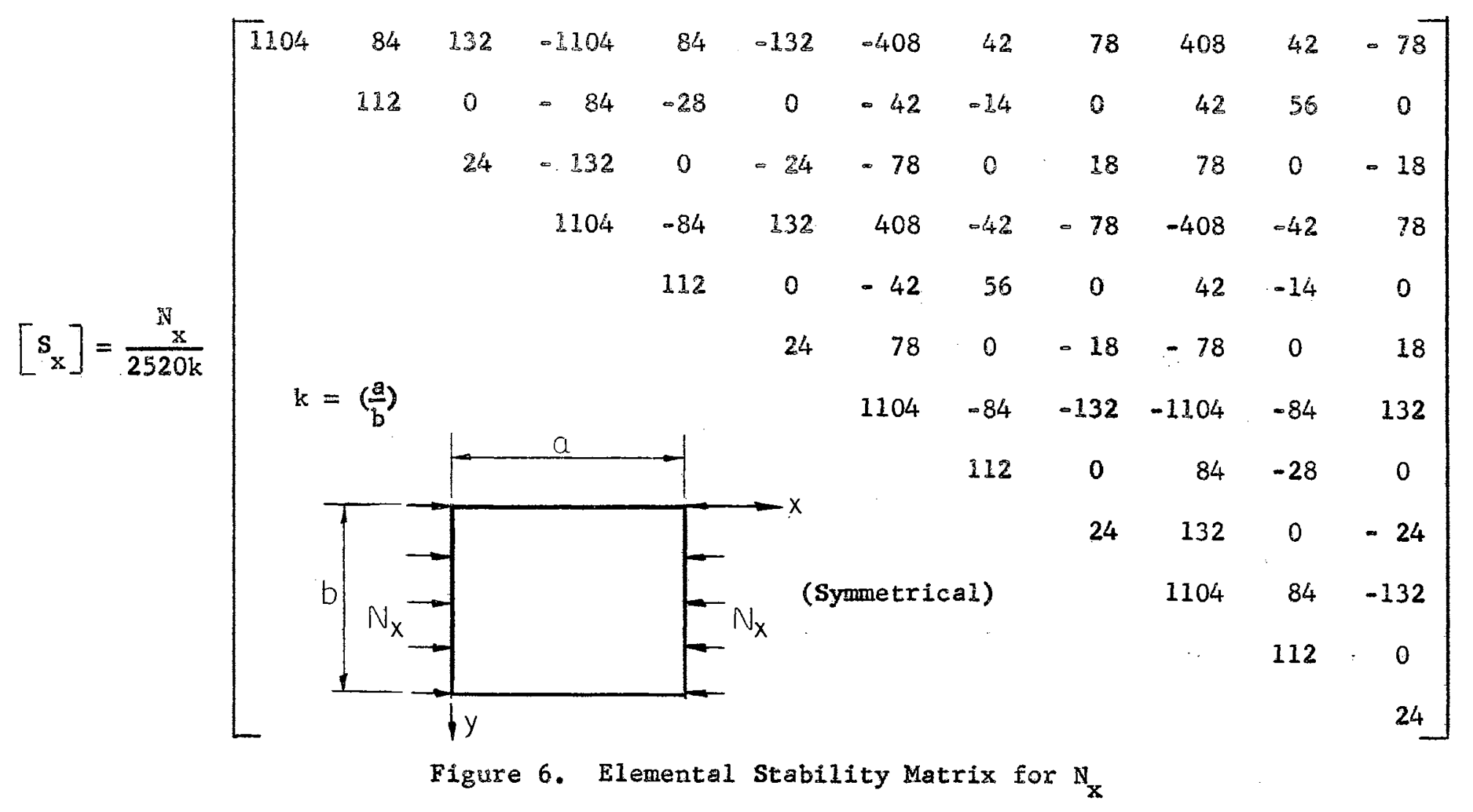




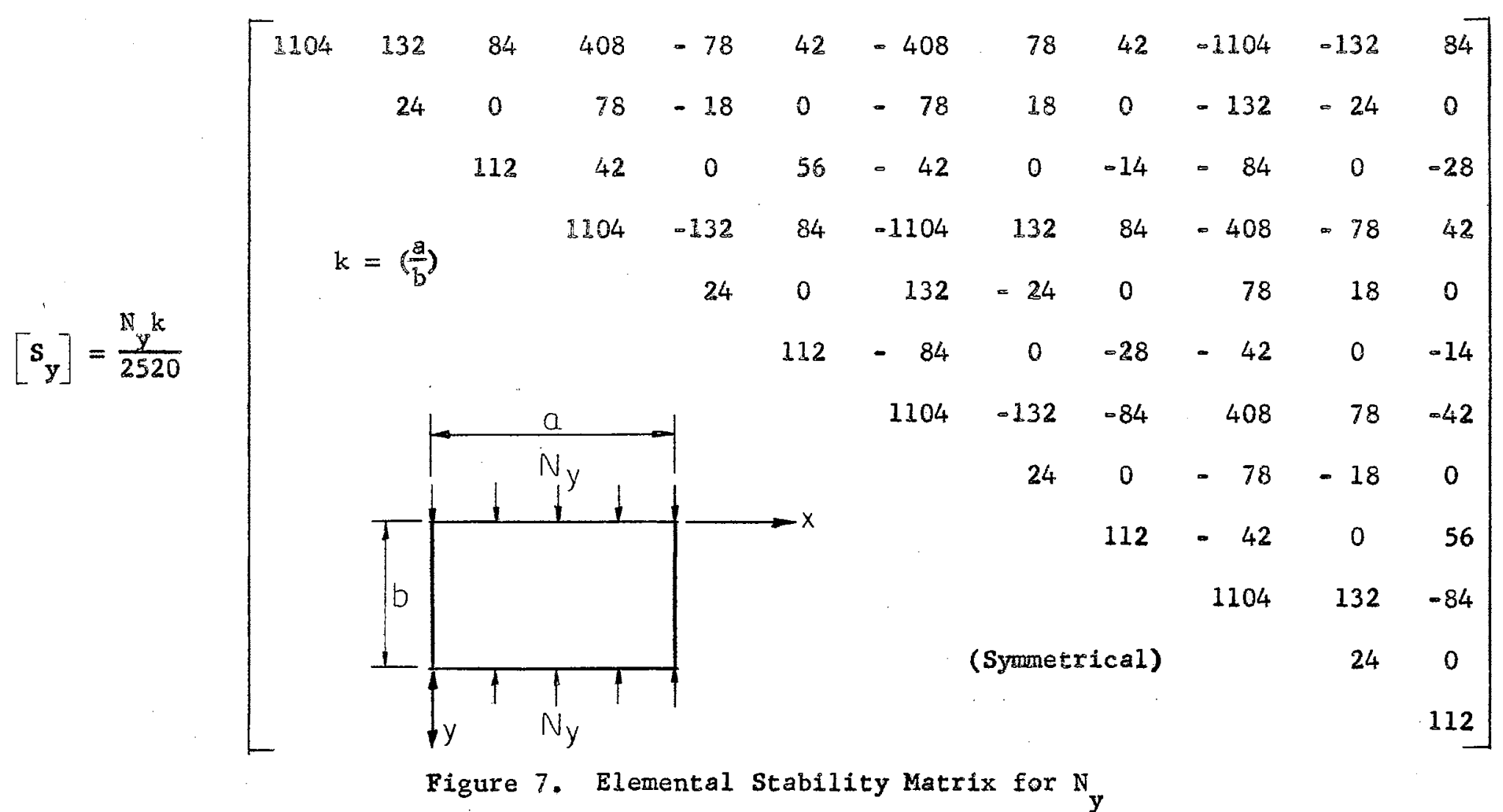




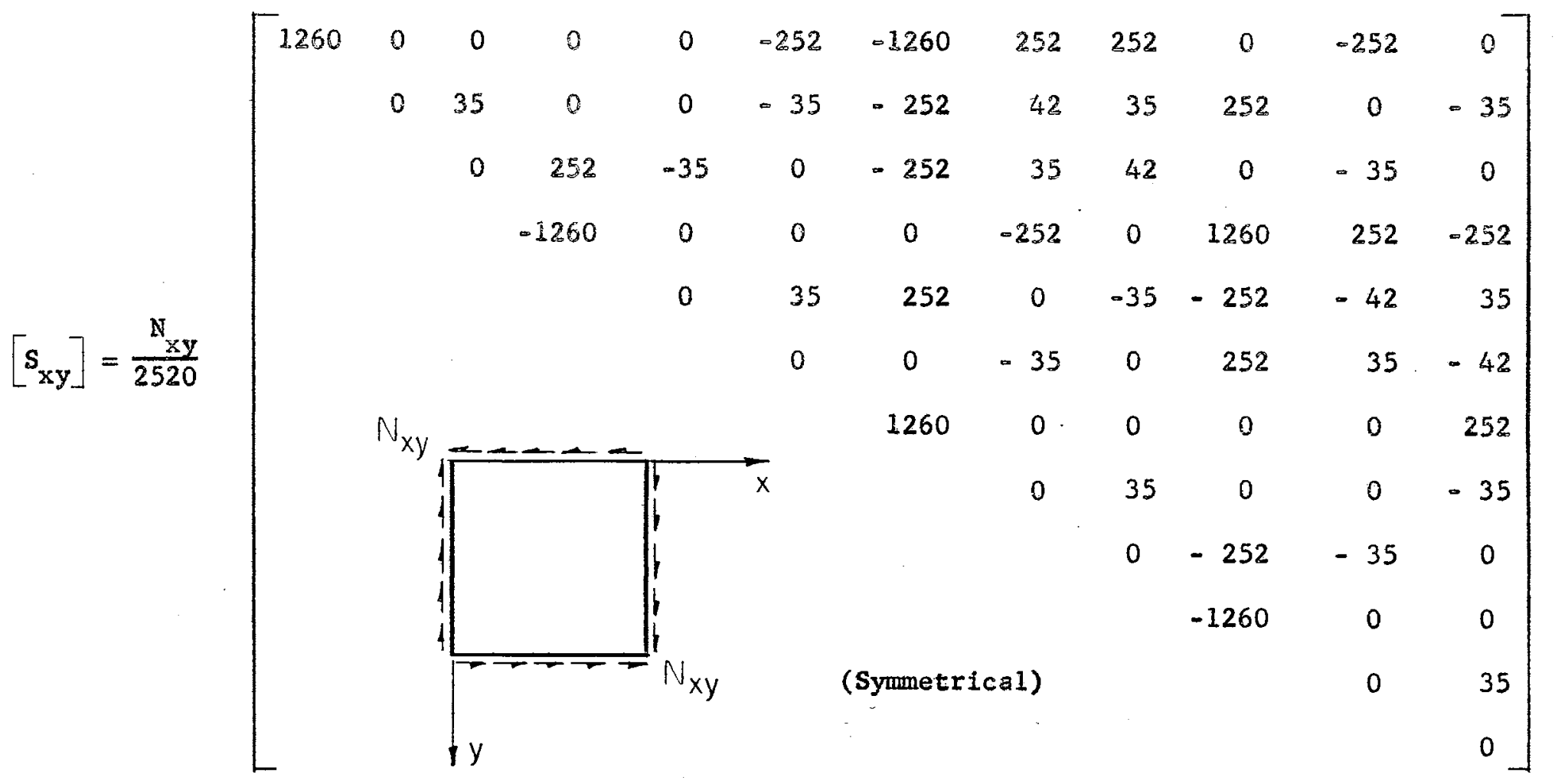

Figure 8. Elemental Stability Matrix for $\mathrm{N}_{x y}$ 


\section{CHAPTER III}

\section{BOUNDARIES OF STABILITI FOR LINEAR EQUATIONS WITH PERIODIC COEFFICIENTS}

Both Eq. (38) and the more general one, Eq. (39), of the previous chapter represent a system of second order differential equations with periodic coefficients. Equations of this type are known sathieuHill equations, and the criteria for stability of their solutions have been well established by several investigators such as Cesari (15), and Chetayev (16). The solutions may be grouped into two classes; one class is stable and bounded and the other is unstable and unbounded. The stability or Instability of the solutions corresponds to the stability or instability of the structural system at hand. The spectrum of values of the parameters yielding stable solutions form the so called regions of stability, while those yielding unstable solutions form the regions of instability. It is clear that the analysis of structures for dynamic instability reduces to the finding of the boundaxies separating the regions of stability from the regions of instability. It is the purpose of this chapter to review the basic principles of the theory of these equations and to formulate the neces. sary conditions for the determination of the above mentioned boundaries in a form amenable to the finite element method.

\subsection{Behavior of Solutions}

First consider a system of equations which has the same form as 
the syster given by Eq. (38).

$$
[H]\left\{\frac{d^{2} f}{d t^{2}}\right\}+[[J]-\alpha[L]-\beta R(t)[N]]\{f\}=0
$$

in which $[\mathrm{H}],[\mathrm{J}],[\mathrm{L}]$ and $[\mathrm{N}]$ are matrices containing constant terms and $R(t)$ is a continuows perindic function with a period $T$,

$$
R(t+T)=R(t)
$$

For convenience and to give greater symmetry to the solution of these equations, this sytern of (n) second order equations is replaced by an equivalent system of $(2 \pi)$ first order equations by making appropriate variable changes.

Rewriting Eq. (41) as

$$
\frac{d^{2} \tilde{I}_{i}}{d t^{2}}+\sum_{k=1}^{n} R_{i k} E_{k}=0
$$

in which

$$
R_{\mathfrak{i k}}=[H]^{-1}[[\mathrm{~J}]-\alpha[\mathrm{L}]-\beta R(t)[\mathrm{N}]] \text {, }
$$

and incroducing the new variables

$$
\begin{aligned}
& x_{j}=f_{j} \quad(j=1,2, \ldots n) \\
& x_{j}=\frac{d f_{j-n}}{d t}(j=n+1, n+2, \ldots-2 n)
\end{aligned}
$$

the resulting system of (2n) equations becomes

$$
\begin{aligned}
& \frac{d x}{d t}-x_{i+n}=0 \quad(i=1,2, \ldots \infty n) \\
& \frac{d x}{d t}+\sum_{k=1}^{n} R_{i k} x_{k}=0 \quad(i=n+1, n+2, \ldots-2 n) .
\end{aligned}
$$


In matrix notation

$$
\frac{d\{x\}}{d t}+[\bar{R}(t)]\{x\}=0
$$

The structure of $[\bar{R}(t)]$ will be as follows:

$$
[\bar{R}(t)]=\left[\begin{array}{c:c}
0 & {[-I]} \\
--- & -- \\
{\left[R_{i k}\right]} & 0
\end{array}\right] \text {. }
$$

It is clear from Eq. (42), that matrix $[\bar{R}(t)]$ is periodic with a period I.

The solution of equations of the form given in Eq. (45) is not always possible, but fortunately the complete solution is not needed to determine the spectrum of the stability or instability of the equations $(15,16)$. The investigation of these equations is facilitated by the fact that with the substitution

$$
t+T=t
$$

the form of the equations remain unchanged. Applying this substitution an unlimited number of times to the solutions $\left\{x_{s}\right\}$, which are assumed to be known for the time interval $(0, T)$, the behavior of the solution can be determined for an unlimited variation of the variable $t$ (16). Assume that the (2n) linearly independent solutions of Eq. (45) axe known within the interval $t=(0, T)$,

$$
\left\{x_{1}\right\},\left\{x_{2}\right\}, \cdots-\left\{x_{2 n}\right\} .
$$

Ox witing in matrix form 


$$
[X(t)]=\left[\begin{array}{cccc}
x_{11}(t) & x_{12}(t) & \cdots & x_{1,2 n}(t) \\
x_{21}(t) & x_{22}(t) & \cdots & x_{2,2 n}(t) \\
\vdots & \vdots & & \vdots \\
x_{2 n, 1}(t) & x_{2 n, 2}(t) & \cdots & x_{2 n, 2 n}(t)
\end{array}\right]
$$

where the first subscript represents the number of the function and the second subscript represents the number of solution. From the properties of linear equations with pexiodic coefficients with the invariant substitution $t+\mathbb{T}=t$, the functions

$$
\left\{x_{1}(t+T)\right\},\left\{x_{2}(t+r)\right\}, \cdots-\left\{x_{2 n}(t+T)\right\}
$$

also represent set of solutions, and they can be expressed as a linear combination of the independent solutions $(15,16)$.

$$
[X(t+T)]=[\bar{A}][X(t)]
$$

From the selected independent solutions a similar set of solutions is constructed by a linear transformation with constant coefficients.

$$
\left\{x_{s}\right\}=\left\{b_{1} x_{1, s}(t)+\cdots+b_{2 n} x_{2 n, s}(t)\right\}
$$

The constants, $b_{i}$ aze chosen such that this set of solutions has the fundamental property,

$$
\left\{x_{s}(t+T)\right\}=p\left\{x_{s}(t)\right\}
$$

To determine the constants $b_{i}$ substitute from Eqs. (49) and (50) into Eq. (51). 


$$
\begin{array}{r}
b_{1}\left[a_{11} x_{1, s}(t)+\cdots+a_{n 1} x_{2 n, s}(t)\right]+\cdots+ \\
b_{n}\left[a_{2 n, 1} x_{1 s}(t)+\cdots a_{2 n, 2 n} x_{2 n, s}(t)\right]= \\
p\left[b_{1} x_{1 s}(t)+\cdots+b_{n} x_{2 n, s}(t)\right] \\
(s=1,2, \cdots 2 n)
\end{array}
$$

These relationships should be satisfied regardless of the value of the variable $t$, therefore, identical coefficients can be equated.

$$
[\bar{A}]\{b\}=p\{b\}
$$

This system of linear algebraic equations has a non-trivial solution if the determinant of the coefficients vanish.

$$
|[\bar{A}]-P[I]|=0 \text {. }
$$

The values $p_{1}, p_{2},-p_{n}$ which satisfy the relationship given in Eq. (53) are then connected with the fundamental particular solutions. For this particular set of solutions Eq. (49) becomes

$$
[X(t+T)]=\left[D I A G P_{k}\right][X(t)]
$$

or in vector notation

$$
\left\{x_{k}(t+T)\right\}=p_{k}\left\{x_{k}(t)\right\}
$$

Eq. (54) can be written with the diagonal matrix of $\mathrm{p}^{\prime} \mathrm{s}$ only if the roots of the characteristic Eq. (53) are distinct, which permits $[\overline{\mathrm{A}}]$ to be reduced to the diagonal form. In the case where there are multiple roots of the characteristic equation, $[\bar{A}]$ can be reduced to the Jordan normal form, and the form of the solutions depends upon the 
structure of the elementary divisors $\left(p-p_{i}\right)$ of the characteristic equation. In either case there is at least one solution of the form

$$
\left\{x_{k}(t+T)\right\}=p_{k}\left\{x_{k}(t)\right\}
$$

The fundamental form of a continuous, single valued function which satisfies this relationship is

$$
\left\{x_{k}(t)\right\}=\left\{z_{k}(t) e^{(t / T) l n p_{k}}\right\}
$$

where $\left\{Z_{k}(t)\right\}$ is periodic vector with a period $(T)$.

\subsection{Roots of Characteristic Equation}

It can be shown that the characteristic equation formed from Eq. (53) is a reciprocal equation. That is to say the equation

$$
p^{2 n}+a_{1} p^{2 n-1}+\cdots \cdots+a_{2 n-1} p+a_{2 n}=0
$$

has roots $\mathrm{p}_{\mathrm{k}}$ and also $1 / \mathrm{p}_{\mathrm{k}}$. The proof of this is given here for the case when $R(t)$ is an even function (1). This case is the one of most importance to the work presented in this thesis. For an even valued function

$$
R(t)=R(-t)
$$

Since the form of the differential equation system is unchanged when $(-t)$ is substituted for $(t)$, and since

$$
\{x(t)\}=\left\{z(t) e^{\frac{t}{T^{l n p}}}\right\}
$$

is a solution of the system of equations, then

$$
\{x(-t)\}=\left\{z(-t) e^{-\frac{t}{T} \ln p}\right\}=\left\{z(-t) e^{\frac{t}{T} \ln 1 / p}\right\}
$$


is also one of the solutions of the system. Therefore, $1 / p$ is also one of the characteristic roots.

\subsection{Regions of Stability and Instability}

The system under consideration has solutions, other than the trivial solution, of the form given in Eq. (55). The characteristic exponent in this relationship is

$$
\mathrm{h}=\frac{1}{\mathrm{~T}} \operatorname{lnp}_{\mathrm{k}}
$$

It is clear that if all the characteristic exponents have negative real parts the solutions will damp out with time increasing. But if among the characteristic exponents there is one with positive real part the solutions will be unbounded or unstable. Considering that

$$
\ln p_{k}=\ln \left|p_{k}\right|+i \arg p_{k}
$$

it can be seen that if any root of the characteristic equation has an absolute value greater than unity instability occurs.

Now consider the fact that if $\mathrm{p}_{k}$ is a root of the characteristic equation then $1 / \mathrm{p}_{\mathrm{k}}$ is also a root of the equation. The solutions corresponding to these two roots are

$$
\begin{aligned}
& \left\{x_{k}(t)\right\}=\left\{z_{k}(t) e^{\left(\frac{t}{T}\right) 1 n p_{k}}\right\} \\
& \left\{x_{n+k}(t)\right\}=\left\{z_{n+k}(t) e^{\frac{t}{T} \ln 1 / p_{k}}\right\}=\left\{z(t){ }_{n+k} e^{-\frac{t}{T} l n p_{k}}\right\} .
\end{aligned}
$$

If $\mathrm{p}_{k}$ is any real number different from \pm 1 , then one of the solutions above will increase unboundedly with time. Therefore, when any one of the roots of the characteristic equation is real and different from \pm 1 instability will occur. If the coefficients of the system are varied 
such that the roots $\mathrm{p}_{\mathrm{k}}=1$ or $\mathrm{p}_{\mathrm{k}}=-1$ are obtained then the solution will be periodic since the function $\{z(t)\}$ is periodic. In the case where $p_{k}=1$

$$
\left\{x_{k}(t)\right\}=\left\{z_{k}(t) e^{\frac{t}{T}[\ln |1|+i(0)]}\right\}=\left\{z_{k}(t)\right\} .
$$

The solution has a period of $T$ since $\left\{z_{k}(t)\right\}$ has a period of $T$. For the case when $p_{k}=-1$

$$
\begin{gathered}
\ln p_{k}=\ln |1|+i \pi \\
\left\{x_{k}(t)\right\}=\left\{z_{k}(t) e^{\frac{t}{T} i \pi}\right\} .
\end{gathered}
$$

This solution is periodic and has a period equal to $2 \mathrm{~T}$. With a further variation of the coefficients of the system the pairs of roots of the chaxacteristic equation will become complex conjugates,

$$
\begin{aligned}
p_{k} & =m+i h \\
p_{n+k} & =m-i h
\end{aligned}
$$

Since it has been shown that $p_{k}$ and $1 / p_{k}$ are roots, then in this case $p_{k} p_{n+k}=1$. The absolute value of each complex root is therefora equal to unity, and the region of stability or bounded solutions is the region of complex roots.

It follows from the preceding treatment that the boundaries between stability and instability are periodic solutions with periods of $T$ or $2 \mathrm{~T}$. Two solutions of the same period confine the region of instability and two solutions with different parlods confine the region of stability. This follows from the fact that the root $\mathrm{p}_{\mathrm{k}}=0$ cannot 1 ie in the interval between $p_{k}=1$ and $p_{k}=-1$ because of the nonisingularity of the transfornation given in Eq. (49). Therefore, 
the problem of determining the regions of instability of Eq. (41) is merely a problem of finding periodic solutions of periods $T$ or $2 T$ of these equations ( 1 ).

\subsection{Boundary Frequencies for Instability}

As was shown in the preceding sections, the finding of regions of instability or boundaries for instability reduces to the finding of periodic solutions of period $T$ or $2 \mathrm{~T}$ for Eq. (41). Here the periodic function $R(t)$ will be taken as

$$
R(t)=\cos (\theta t)
$$

and Eq. (41) becones

$$
[H]\left\{\frac{d^{2} f}{d t^{2}}\right\}+[[J]-\alpha[L]-\beta[N] \cos (\theta t)]\{f\}=0 .
$$

The solution of Eq. (57) is sought in the form of the convergent trignometric series,

$$
\{f(t)\}=\sum_{k=1,3,5}\left\{a_{k}\right\} \sin \frac{k \theta t}{2}+\left\{b_{k}\right\} \cos \frac{k \theta t}{2},
$$

where $\left\{a_{k}\right\}$ and $\left\{b_{k}\right\}$ are time independent vectors. Substituting $E q$. (58) into Eq. (57) the following matrix equations are obtained;

$$
\begin{gathered}
{\left[[J]-\alpha[L]+\frac{1}{2} \beta[N]-\frac{\theta^{2}}{4}[H]\left\{a_{1}\right\}-\frac{3}{2} \beta[N]\left\{a_{3}\right\}=0\right.} \\
\left.\left[[J]-\alpha[L]-\frac{k^{2} \theta^{2}}{4}[H]\right]\left\{a_{k}\right\}-\frac{1}{2} \beta[N]\left[a_{k-2}\right\}+\left\{a_{k+2}\right\}\right]=0 \\
(k=3,5,7 \cdots \cdots)
\end{gathered}
$$


and

$$
\begin{gathered}
{\left[[J]-\alpha[L]-\frac{1}{2} \beta[N]-\frac{\theta^{2}}{4}[H]\right]\left\{b_{1}\right\}-\frac{3}{2} \beta[B]\left\{b_{3}\right\}=0} \\
{\left[[J]-\alpha[L]-\frac{k^{2} \theta^{2}}{4}[H]\right]\left\{b_{k}\right\}-\frac{1}{2} \beta[N]\left[\left\{b_{k-2}\right\}+\left\{b_{k+2}\right\}\right]=0} \\
(k=3,5,7 \ldots)
\end{gathered}
$$

The condition for the existence of solutions with a period $4 \pi / \theta$ is that the determinant of the coefficients of $\left\{a_{k}\right\}$ and $\left\{b_{k}\right\}$ must vanish. In this case the equations for $\left\{a_{k}\right\}$ and $\left\{b_{k}\right\}$ are separable and the two conditions are combined with the $( \pm)$ sign.

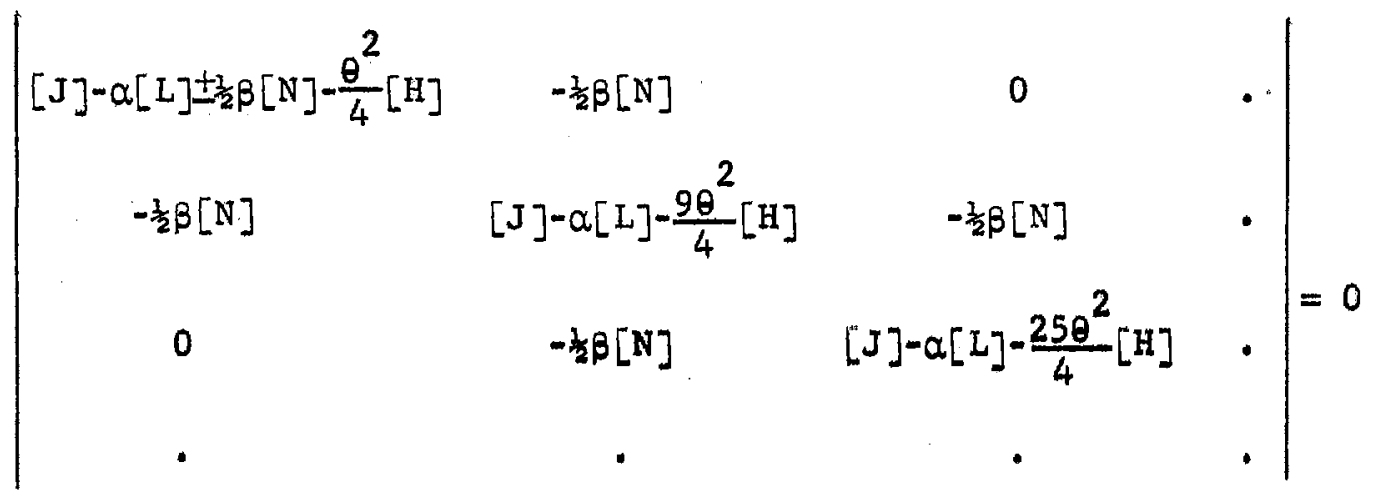

By substitution of the series

$$
\{f(t)\}=b_{0}\left\{b_{0}\right\} \sum_{k=2,4,6}\left\{a_{k}\right\} \sin \frac{k \theta t}{2}+\left\{b_{k}\right\} \cos \frac{k \theta t}{2},
$$

the following conditions are found for the existence of solutions with a perlod $2 \pi r \theta$; 


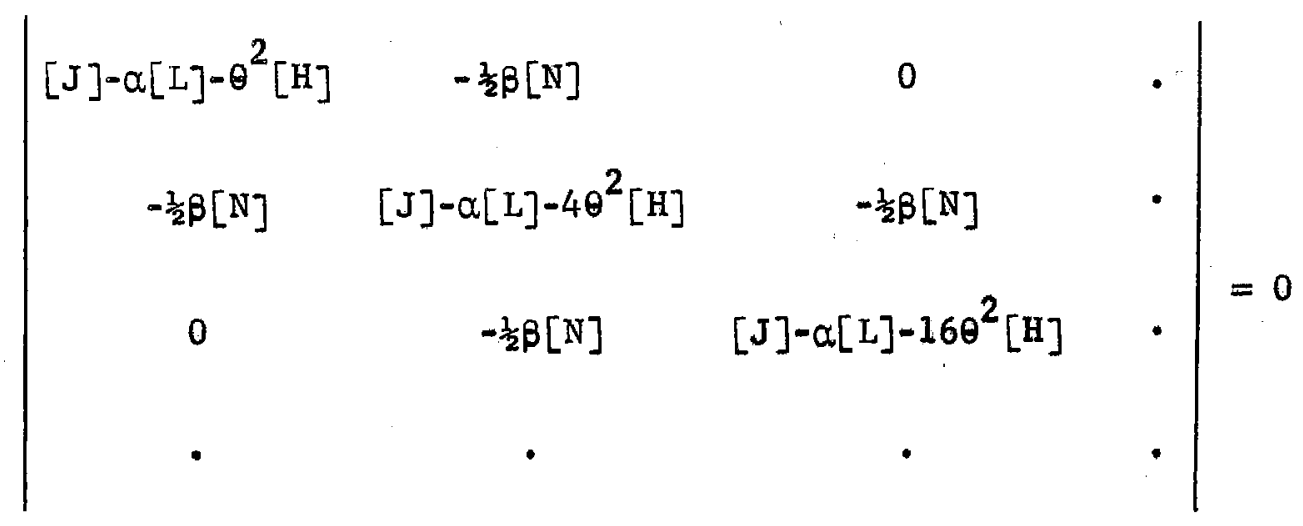

and

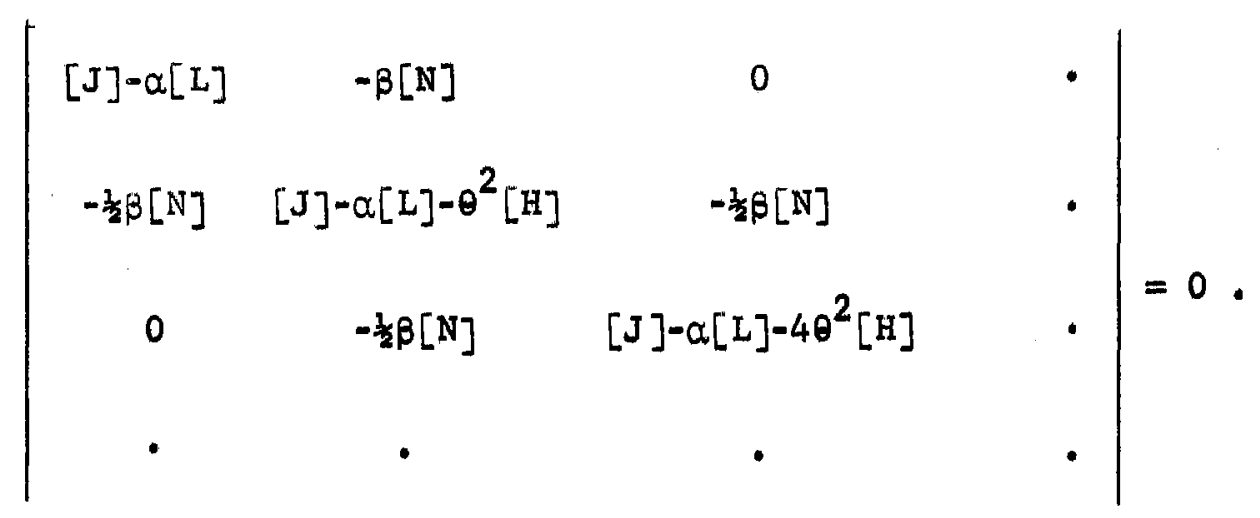

Al1 three of the relationsh1ps given in Eqs. (59), (61), and (62) are infinite determinants. For the case where the period is $4 \pi / \theta$, the first term of the determinant taken alone yields values of $\theta$ which give the zeroes of the infintte determinant with reasonable accuracy (1). Therefore

$$
\left|[J]-\alpha[L] \pm \frac{\hbar}{2} \beta[N]-\frac{\theta^{2}}{4}[H]\right|=0 \text {. }
$$

Using only this first term is equivalent to assuming that the function $\{f(t)\}$ can be adequately represented as follows;

$$
\{f(t)\}=\left\{a_{1}\right\} \sin \frac{\theta t}{2}+\left\{b_{1}\right\} \cos \frac{\theta t}{2}
$$

Similar approximations can be made for the case where the perlod is $2 \uparrow r \theta$. 


\subsection{Equation With Damping Terms}

In this section equations which contain terms involving the first derivative are considered. Consider the following matrix equation;

$$
[H]\left\{\frac{d^{2} f}{d t^{2}}\right\}+2 g[H]\left\{\frac{d f}{d t}\right\}+[\bar{B}]\{f\}=0
$$

where the matrix $[\bar{B}]$ is periodic with a period $T$, [H] is a constant matrix and 8 is a constant. Assume that Eq. (64) has a solution of the same form as the andogous single equation with a damping term. That is

$$
\{f(t)\}=e^{-g t}\{u(t)\}
$$

Differentiating

$$
\begin{aligned}
& \left\{f^{\prime}(t)\right\}=e^{-g t}\left[\left\{u^{\prime}(t)\right\}-g\{u(t)\}\right] \\
& \left\{f^{\prime \prime}(t)\right\}=e^{-g t}\left[\left\{u^{\prime \prime}(t)\right\}-2 g\left\{u^{\prime}(t)\right\}+g^{2}\{u(t)\}\right]
\end{aligned}
$$

When these expressions are substituted into the differential Eq. (64), the terms involving the first derivative vanish and the resulting equation is as follows,

$$
[\mathrm{H}] \mathrm{e}^{-g t}\left\{\mathrm{u}^{\prime \prime}(t)\right\}+\left[[\bar{B}]-[H] g^{2}\right]\{u(t)\} e^{-g t}=0
$$

Since $e^{-g t}$ is a scalar factor it can be factored out of the equation

$$
e^{-8 t}\left[[H]\left\{u^{\prime \prime}(t)\right\}+\left[[\bar{B}]-8^{2}[H]\right]\{u(t)\}\right]=0
$$

The term $e^{-g t}$ does not vanish, therefore, the term in the bracket in the above expression must vanish. The oame arguments can bo used for finding the regions of stability of Eq. (65) as was done for Eq. (41), since the term in brackets, 


$$
[H]\left\{u^{\prime \prime}(t)\right\}+\left[[\bar{B}]-g^{2}[H]\right]\{u(t)\}=0
$$

has exactly the same form as Eq. (41).

If the matrix $[\bar{B}]$ is taken as

$$
[\bar{B}]=[J]-\alpha[L]-\beta \cos (\theta t)[N]
$$

then the condition for existence of solutions with a period $4 \pi \%$ is as follows;

$$
\left|\begin{array}{cc}
{[\mathrm{J}]-\alpha[\mathrm{L}]+\frac{2}{2} \beta[\mathrm{N}]-\frac{\theta^{2}}{4}[\mathrm{H}]} & -\theta \mathrm{g}[\mathrm{H}] \\
\theta \mathrm{g}[\mathrm{H}] & {[\mathrm{J}]-\alpha[\mathrm{L}]-\frac{2}{2} \beta[\mathrm{N}]-\frac{\theta^{2}}{4}[\mathrm{H}]}
\end{array}\right|=0
$$

The determinant shown is the central elements from the infinite determinant which is obtained.

\subsection{Physical Considerations}

The form of the equations discussed in this Chapter are identical to Eqs. (38) and (39) in Chapter II. The fact that the boundaries between stable and unstable solutions are periodic solutions of the differential equation is not surprising when the physicol system is visualized. Basically there are three types of vibrations that the plate can perform: (1) vibrations which are damped out with time, vibrations which are periodic, and (3) vibrations whose amplitudes become unbounded as time increases. Perlodic solutions, by their nature, form the boundary between bounded and unbounded solutions. The three types of vibration are shown in Figure (9). 

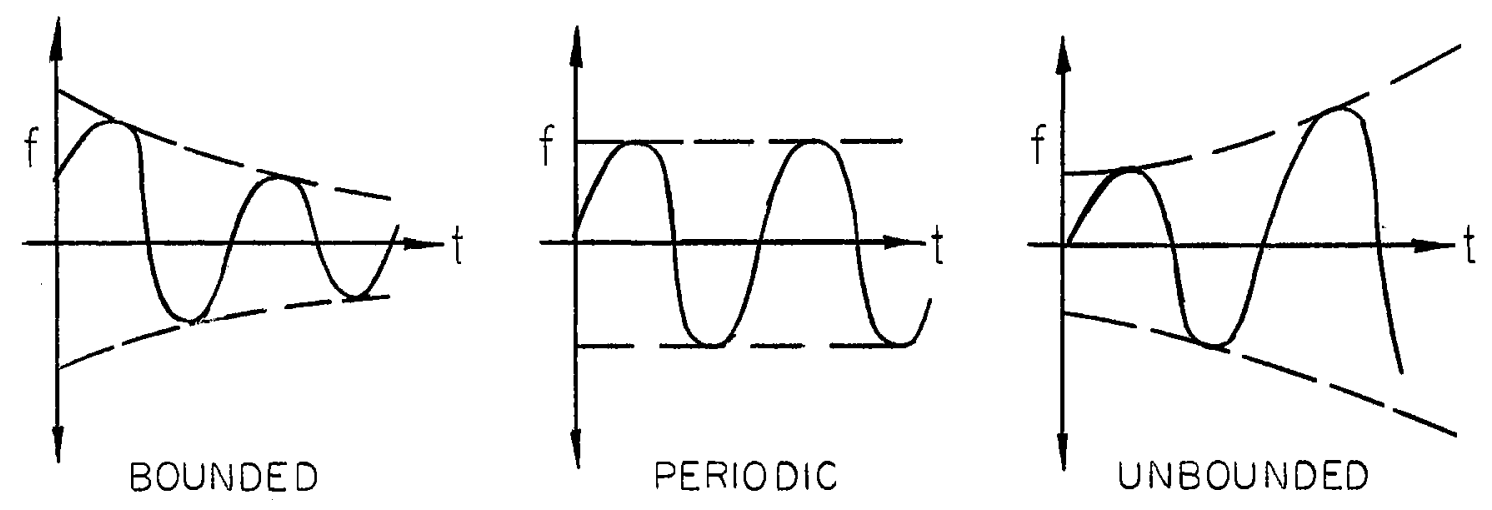

Figure 9. Nature of Vibrations

In the absence of rigorous mathematical proof, it is the opinion of the writer that an approximation of instability boundaries for other systems where factors such as non-linear damping are considered, can be represented by periodic solutions of the governing equations. The preceding statement is based entirely upon the intuitive physical argument that the nature of periodic solutions manifest themselves as the boundary between stability and instability. 
CHAPTER IV

SOLUTION FOR THE REGIONS OF

DYNAMIC INSTABILITY

The general problem which is solved in this thesis is illustrated in Figure (10). The boundaries of dynamic instability are found for this problem for different ratios of the loads $\mathrm{N}_{x}, \mathrm{~N}_{\mathrm{y}}$, and $\mathrm{N}_{\mathrm{xy}}$, different aspect ratios, and it is solved both with and without including the effects of an elastic foundation and viscous damping. The problem is also solved with various boundary conditions. The ease with which the different boundary conditions are handled is the primary advantage of the finite element method. The finite element grid size used to solve a particular problem is variable depending upon the amount of computer time and storage space available. The number of generalized coordinates or degrees of freedom for a given problem will depend upon the grid size selected. Since each node point can have three generalized displacements (one translation and two rotations), the total number of degrees of freedom for the plate will be $3(m+1)(n+1)$ minus the number of constraints imposed by the boundary conditions, where $m$ is the number of plate divisions in the $x$-direction and $n$ is the number of divisions in the $y$-direction. Another factor which influences the selection of a grid size is that the number of degrees of freedom allowed must be sufficient to represent adequately the mode shapes of the plate. 


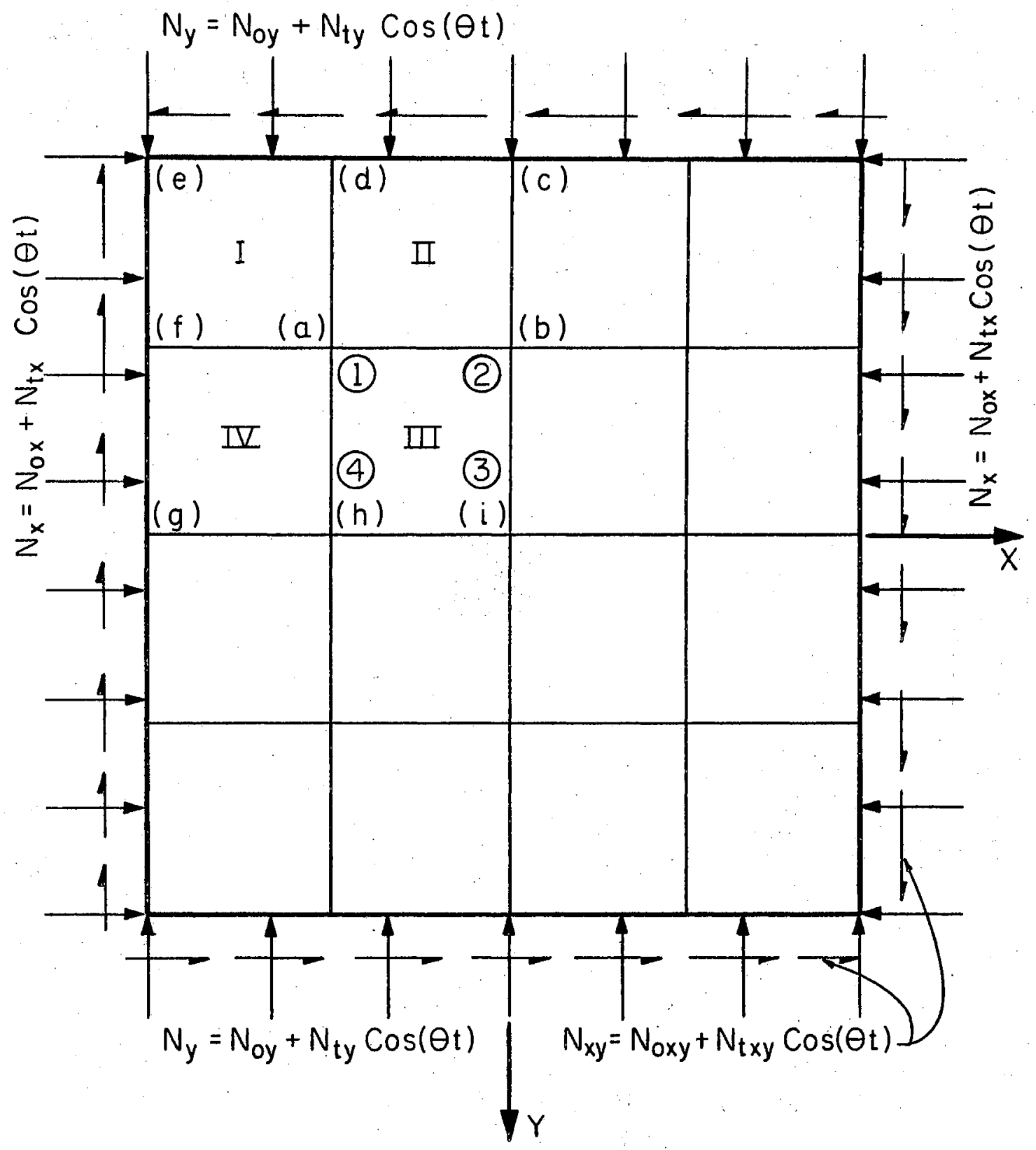

Figure 10. General Problem 


\subsection{Formulation of the Structural Matrices}

The first step in applying the finite element method to finding the regions of dynamic instability is to divide the plate into finite plate elements and form the total structural matrices corresponding to the elemental matrices developed in Chapter II. To accomplish this, the effects of all plate elements joining together at a node point are added together. For example, consider elements I, II, III, and IV which have the common node point (a) as shown in Figure (10). Let the node points for each individual element be numbered as the ones shown on element III. Then the elemental matrices shown in Figures (4) through (8) (the example used here is the stiffness matrix) may be partitioned into $(3 \times 3)$ matrices as follows;

$$
[k]=\left[\begin{array}{c|c|c|c}
k_{11 i} & k_{21 i} & k_{31 i} & k_{41 i} \\
\hline k_{12 i} & k_{22 i} & k_{32 i} & k_{42 i} \\
\hline k_{13 i} & k_{23 i} & k_{33 i} & k_{43 i} \\
\hline k_{14 i} & k_{24 i} & k_{34 i} & k_{44 i}
\end{array}\right]
$$

Noting that each term in the Lagrangian equation (Eq. (1)) has the units of generalized force, then the structural matrices may be formed by adding the forces at each node point. The subscripts used for the sub-matrices in Eq. (67) have the following meaning; the sub-matrix $\mathrm{k}_{1 \mathrm{mn}}$ is the force at node point $\mathrm{m}$ caused by the deformations at node point 1 for the plate element $n$. The structural stiffness matrix will have the following form 


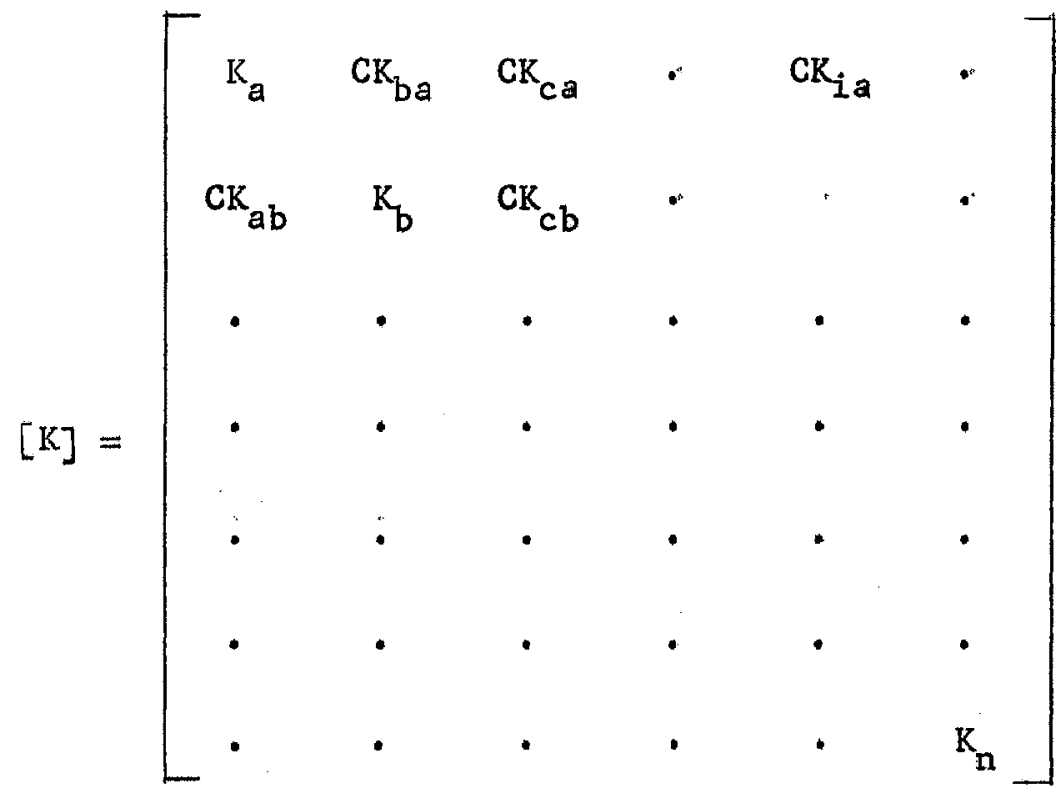

(68)

In each line of the above matrix there is a carry-over term, $\mathrm{CK}_{\mathrm{j} i}$, for every node point adjacent to node point $i$. The stiffness, $k_{i}$, and the carry ${ }^{\prime}$ over stiffness, $\mathrm{CK}_{j i}$, matrices for an arbitrary point (a) are

$$
\begin{aligned}
\mathrm{k}_{a} & =\mathrm{k}_{11 I I I}+\mathrm{k}_{22 I V}+\mathrm{k}_{33 I}+\mathrm{k}_{44 I I} \\
\mathrm{CK}_{\mathrm{ba}} & =\mathrm{k}_{21 I I I}+\mathrm{k}_{34 I I} \\
\mathrm{CK}_{\mathrm{ca}} & =\mathrm{k}_{24 I I}
\end{aligned}
$$

The structural mass and stability matrices are formed in exactly the same mannet as the stiffness matrix.

\subsection{Boundary Conditions}

After the formation of the structural matrices the necessary boundary conditions or constraint conditions must be applied. Since thexe are three possible degrees of freedom at any node point there are 
three possible constraints which may be applied either singly or in any combination. The possible displacement type constraints for node $i$ are,

$$
\begin{aligned}
& w_{i}=0 \\
& w_{i x}=0 \\
& w_{i y}=0
\end{aligned}
$$

The common types of boundary conditions for plates are as follows;

1. Rigid column support

$$
\begin{aligned}
& w=0 \\
& w_{x}=0 \\
& w_{y}=0
\end{aligned}
$$

2. Pinned column support

$$
\begin{aligned}
& w_{x}=0 \\
& M_{x}=0 \\
& M_{y}=0
\end{aligned}
$$

3. Simple edge

at all node points along the edge

$$
\begin{aligned}
& w_{w_{t}}=0 \\
& w_{n}=0
\end{aligned}
$$

4. Clamped edge

at all node points along the edge

$$
\begin{aligned}
& w=0 \\
& w_{t}=0 \quad \text { (slope along the edge) } \\
& w_{n}=0 \quad \text { (slope normal to the edge) }
\end{aligned}
$$

The constraint conditions are applied to the structural matrices by 
deleting the corresponding rows and columns. If $\mathfrak{n}$ is the number of node points and $r$ is the number of constraints, the final size of the structural matrices will be $(3 n-r)$.

\subsection{Solution}

The governing equations for the plate, Eqs. (38) and (39), can now be formed. Let the in-plane loads be expressed as

$$
\begin{aligned}
& N_{x}=N_{0 x}+N_{t x} \cos (\theta t)=\bar{a}_{s}+\bar{b}_{t} \cos (\theta t) \\
& N_{y}=N_{0 y}+N_{t y} \cos (\theta t)=\overline{c N}_{s}+\overline{d N}_{t} \cos (\theta t) \\
& N_{x y}=N_{0 x y}+N_{t x y} \cos (\theta t)=\overline{e N}_{s}+\overline{f N}_{t} \cos (\theta t)
\end{aligned}
$$

The loads are represented in this manner so that each term contains the common factors $\mathrm{N}_{\mathrm{s}}$ and $\mathrm{N}_{\mathrm{t}}$. Substituting into $\mathrm{Eq} \cdot(38)$ and factoring out the common terms in each matrix the following expression is obtained;

$$
\frac{\rho a b}{25,200}[M]\left\{\frac{d^{2} \bar{v}}{d t^{2}}\right\}+\left[\frac{D}{a b}[K]-\frac{\alpha N_{1}^{*}}{2520}\left[\bar{S}_{s}\right]-\frac{\beta N_{1}^{*}}{2520}\left[\bar{S}_{t}\right] \cos (\theta t)\right]\{\bar{v}\}=0 .
$$

In which

$$
\begin{aligned}
\mathrm{N}_{s} & =\alpha \mathrm{N}_{i}{ }^{*} \\
\mathrm{~N}_{t} & =\beta \mathrm{N}_{i}{ }^{*} \\
{\left[\overline{\mathrm{s}}_{\mathrm{s}}\right] } & =\overline{\mathrm{a}}\left[\overline{\mathrm{s}}_{\mathrm{x}}\right]+\overline{\mathrm{c}}\left[\overline{\mathrm{s}}_{\mathrm{y}}\right]+\overline{\mathrm{e}}\left[\overline{\mathrm{s}}_{\mathrm{xy}}\right] \\
{\left[\overline{\mathrm{s}}_{\mathrm{t}}\right] } & =\overline{\mathrm{b}}\left[\overline{\mathrm{s}}_{\mathrm{x}}\right]+\overline{\mathrm{d}}\left[\overline{\mathrm{s}}_{\mathrm{y}}\right]+\overline{\mathrm{f}}\left[\overline{\mathrm{s}}_{\mathrm{xyy}}\right]
\end{aligned}
$$

$\mathrm{N}_{\mathrm{i}}$ *'s are the static buckling loads which are determined as the eigenvalues of the determinant

$$
\left|\frac{D}{a b}[K]-\frac{N}{2520}\left[\bar{s}_{s}\right]\right|=0
$$

This determinant is obtained from Eq. (36). The term $a \mathbb{N}_{i} *\left[\bar{s}_{s}\right]$ in Eq. 
(69) Ieflects the infinence of the static components of the loads while the term $\beta N_{i}{ }_{i}\left[\bar{S}_{t}\right]$ reflects the influence of the pulsating components of the 1oads. By comparison of terms in Eqs. (38) and (41) the equation which gives the boundaries of dynamic instability (Eq. (63)) is found to be

$$
\left|\frac{\mathrm{D}}{a b}[\mathrm{~K}]-\frac{\alpha N_{i}^{*}}{2520}\left[\bar{s}_{s}\right] \pm \frac{\beta N_{1}^{*}}{2(2520)}\left[\bar{s}_{t}\right]-\frac{\rho a b\left(\bar{e}_{\omega_{1}}\right)^{2}}{4(25,200)}[M]\right|=0
$$

in which

$$
\theta_{i}=\overline{\bar{e}} w_{i}
$$

The $\omega_{i}{ }^{\prime} s$ are the natural frequencies of the system determined from Eq. (35),

$$
\left|\frac{D}{a b}[K]-\frac{\rho a b \omega^{2}}{25,200}[M]\right|=0
$$

In the same manner, the characteristic determinant for determining the regions of instability, when the effects of viscous damping (Eq. (66)) is considered, becomes

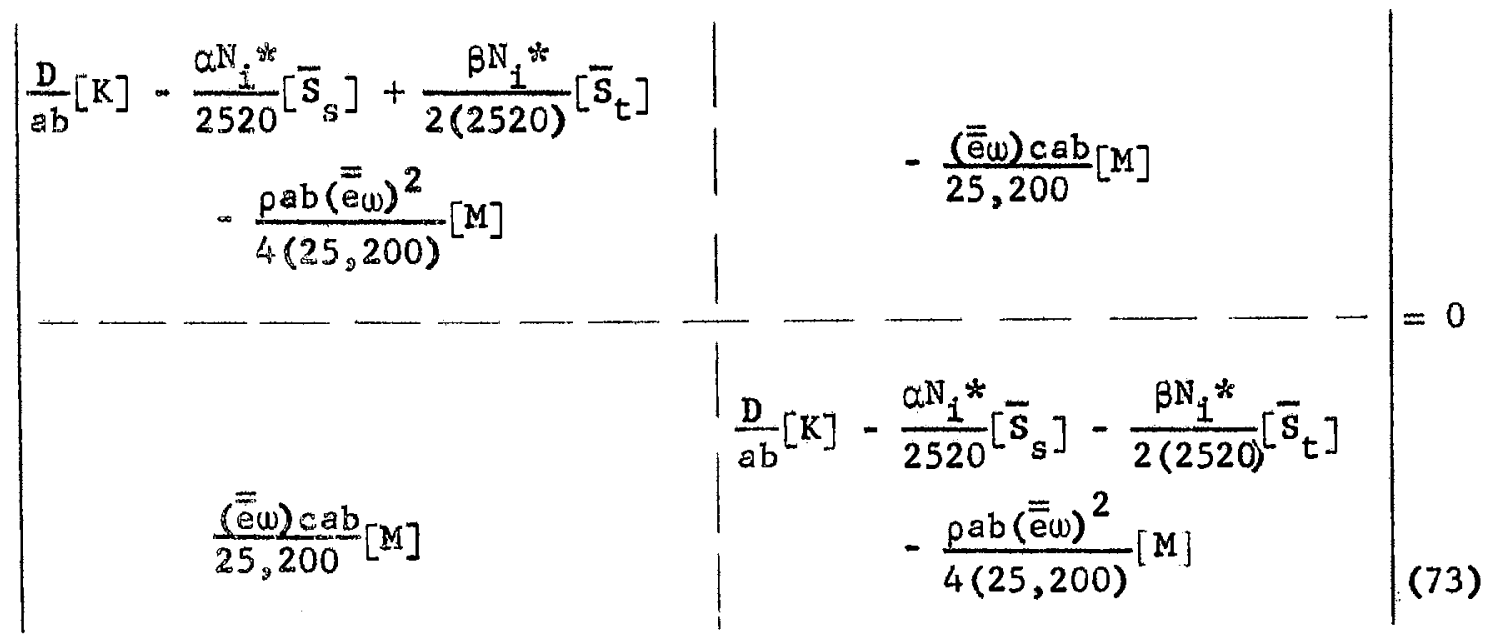

If the effect of an elastic foundation is considered the only change in Eqs. (70) through (73) is that the term 


\section{$\frac{\mathrm{D}}{\mathrm{ab}}[\mathrm{K}]$}

is replaced by

$$
\frac{D}{a b}\left[[K]+\frac{g a^{2} b^{2}}{25,200(D)}[M]\right] .
$$




\section{CHAPTER V}

\section{DISCUSSION OF RESULTS}

\subsection{Interpretation of Results}

A program for the IBM 7040 electronic digital computer was written to solve Eqs. (70) through (73) for the natural frequencies, static buckling loads, and regions of dynamic instability for several plates. The results are shown in a series of figures and tables, and are expressed non-dimensionally in terms of the parameters $\alpha, \beta$ and $\theta / \omega$. As can be seen in Chapter IV the parameter $\alpha$ is the percentage of the static buckling load which is applied statically, $\beta$ is the percentage of the static buckling load which is the amplitude of the pulsating load, and $\theta / \omega$ is the ratio of the frequency of the pulsating load to the natural frequency of transverse vibration of the plate. In all of the examples both the static and the pulsating components of the loads $\mathrm{N}_{\mathrm{x}}, \mathrm{N}_{\mathrm{y}}$, and $\mathrm{N}_{\mathrm{xy}}$ were applied proportionally. The static and the pulsating components of the loads were applied independently, but each type of loading was varied in the same proportions as the ones used to determine static buckling loads for a particular example. That is, if in determining the static buckling loads, $\mathrm{N}_{i}{ }^{*}$, the loading is applied as $N_{x}=N, N_{y}=.5 N$, and $N_{x y}=.5 N$, then the static and pulsating coriponents of the load used in determining the reglons of instability are varied with these same proportions. This type of loading allows the results to be presented in a uniform non-dimensional form. The 
method which has been presented is not, however, restricted to this type of loading. The subscript $i$ which appears with the parameters $a$, $\beta$ and $\theta / \omega$, on some of the figures depicting the results, indicates that the results are for the $i^{\text {th }}$ natural frequency and $i^{\text {th }}$ buckling load, each of which is ranked numerically. For example, when considering the region of dynamic instability corresponding to the $i^{\text {th }}$ natural frequency $\left(\theta_{1} / \omega_{i}\right)$ the load axis is non-dimensionalized with respect to the $i^{\text {th }}$ buckling load, with $\alpha$ and $\beta$ being percentages of the $i^{\text {th }}$ buckling load. Also shown on these figures are the constants necessary to calculate the natural frequencies and buckling loads for several of the lower modes once the physical properties of the plates are specified. With this information in addition to the curves, design loads and frequencies can be specified. In addition to the figures which show the regions of instability the mode shapes for free vibration and static buckling for some of the examples are shown. As is pointed out later, these mode shapes are helpful in interpreting the results which are obtained.

\subsection{Plates Wt thout Damping}

The first series of examples which was solved is as follows:

Boundary Conditions 位 Aspect Ratio

\begin{tabular}{|c|c|}
\hline \multicolumn{2}{|c|}{5.5} \\
\hline s.s & $\mathrm{s} . \mathrm{S}$ \\
\hline & \\
\hline
\end{tabular}

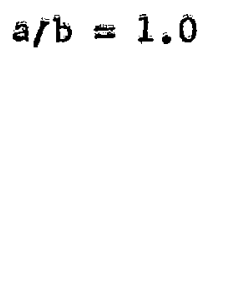

Loading

(*) $N_{x}=N, \ddot{N}_{y}=N, N_{x y}=0$ $\mathrm{N}_{\mathrm{x}}=\mathrm{N}, \mathrm{N}_{\mathrm{y}}=.5 \mathrm{~N}, \mathrm{~N}_{\mathrm{xy}}=.5 \mathrm{~N}$ $N_{x}=N, N_{y}=0, N_{\bar{x} y}=.5 N$ $\mathrm{N}_{\mathrm{x}}=0, \mathrm{~N}_{\mathrm{y}}=0, \mathrm{~N}_{\mathrm{xy}}=\mathrm{N}$ $N_{x}=.1 N, N_{y}=.1 N, N_{x y}=N$ 


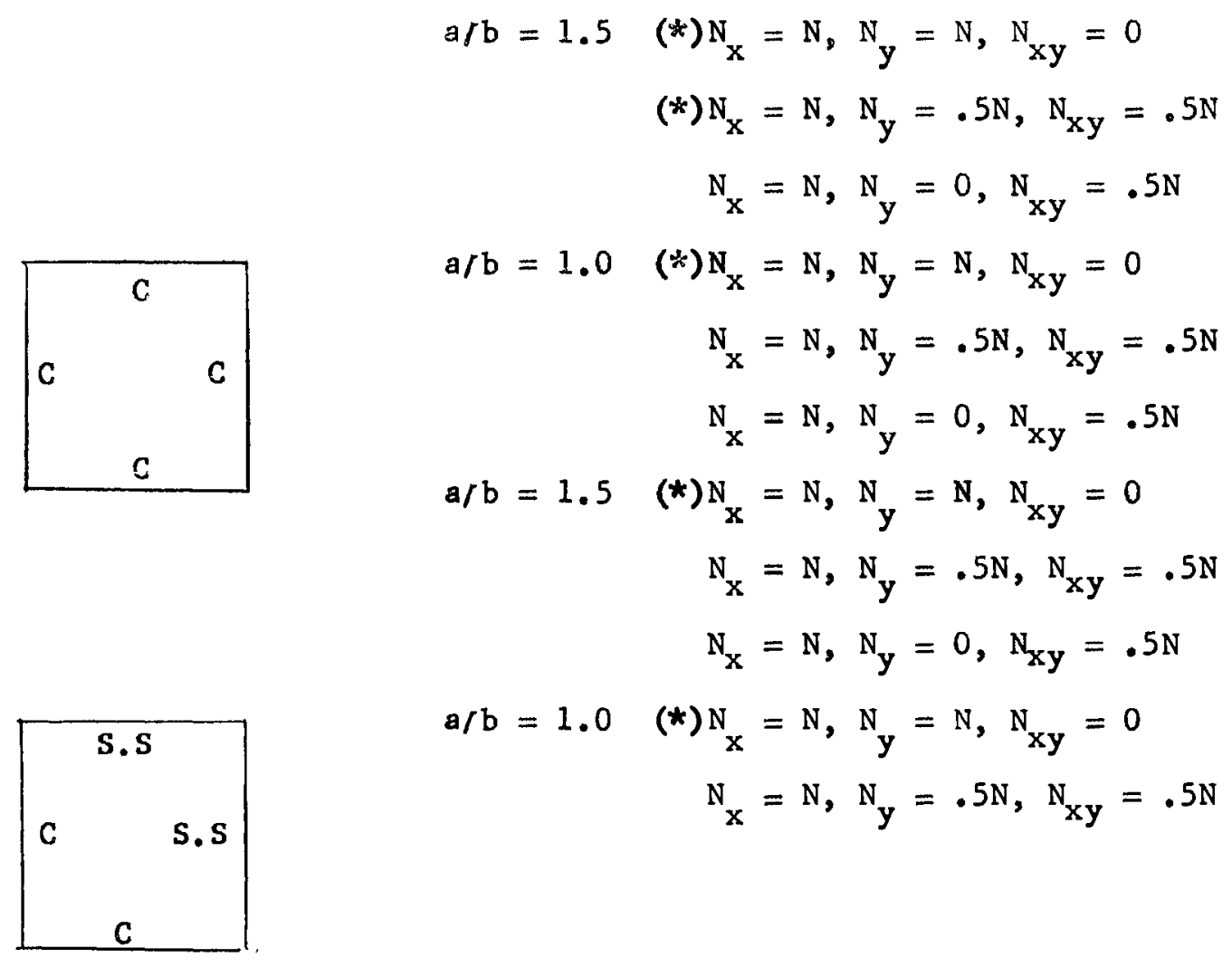

\# S.S - Simply Supported Edge C - Clamped Edge

The variation of results for these examples ranged between two extremes, one shown in Figure (11) and the other shown in Figure (13). The regions in Figure (13) were obtained for the simply supported plate under the action of pure shear. The reglons shown in Figure (11) correspond to the darkened portion of Figure (12) which shows the regions of stability and instability for the Mathieu equation,

$$
\frac{d^{2} f}{d t^{2}}+\left(l-h^{2} \cos 2 t\right) f=0
$$

McLachlan (17) states that for the more general case of 


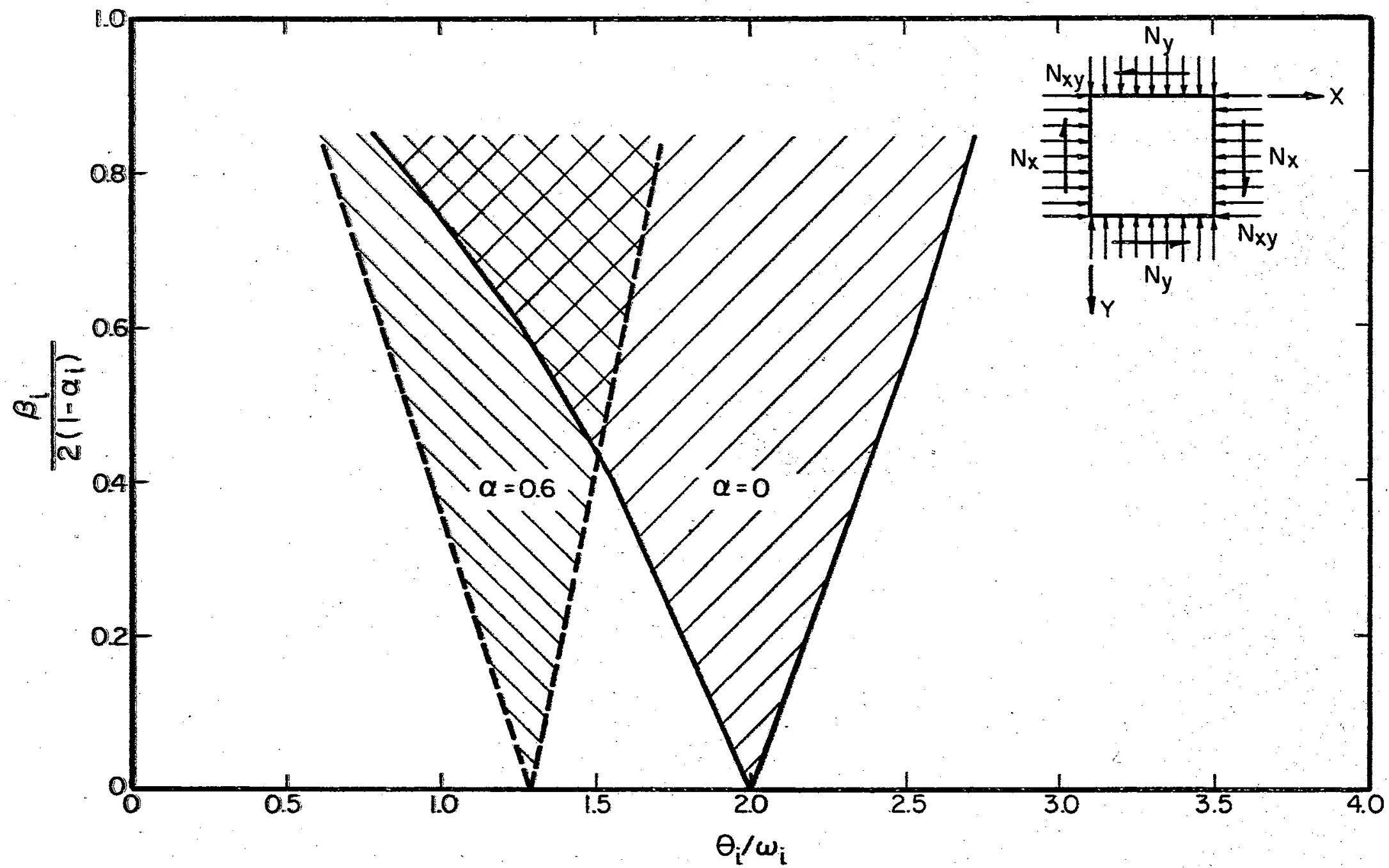

Figure 11. Regions of Dynamic Instability 


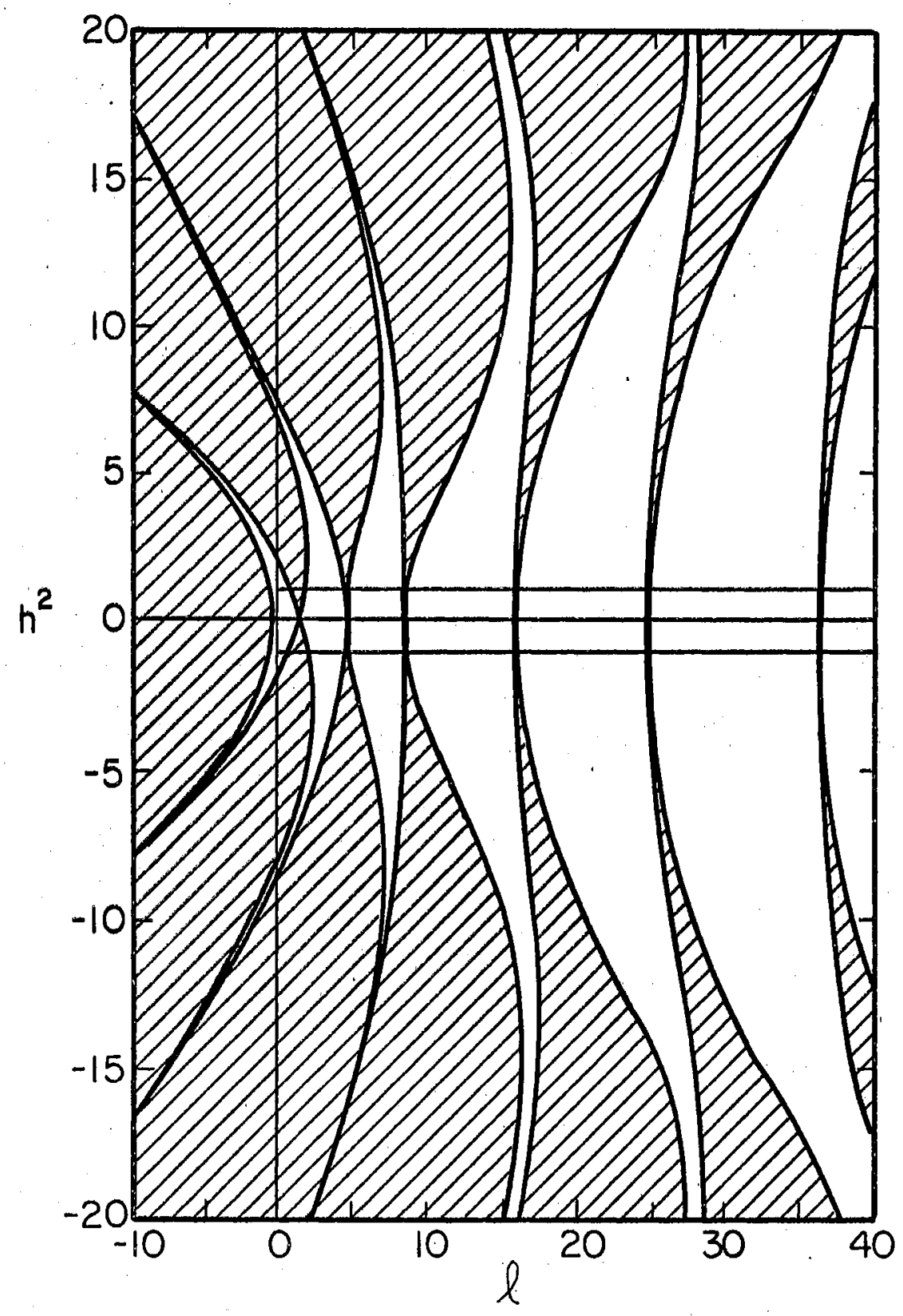

Figure 12, Instability Regions for Mathieu Equation 


$$
\frac{d^{2} f}{d t^{2}}+\left(l-h^{2} \cos \theta t\right) f=0
$$

regions equivalent to those in Figure (12) axe obtained. It should be pointed out that the region for $\alpha=0.6$ will coincide with the region for $\alpha=0.0$ in Figure (11) if in each case the horizontal axis is non-dimensionalized with respect to the natural frequency of the plate with the static component of the loads applied. This follows from Eq. (63) which gives the first approximation to the regions of instability. It can be seen from this equation that as $\alpha$ approaches zero, $\theta$ approaches twice the natural frequency of the plate with the static loads applied.

The examples in the above 1 lst marked with an asterisk all have the sane characteristic regions of dynamic instability, and these regions are the ones in Figure (11). The mode shapes for the two lowest modes and information necessary to use the curves shown in Figure (1.) for these examples are given in Table (I). The information necessary for constructing the region of instability corresponding to the fundamental natural frequency of free vibration for the remaining examples with the exceptions of the simply supported plate with $\mathrm{N}_{\mathrm{x}}=0$, $\mathrm{N}_{\mathrm{y}}=0, \mathrm{~N}_{\mathrm{xy}}=\mathrm{N}$ and with $\mathrm{N}_{\mathrm{x}}=.1 \mathrm{~N}_{,} \mathrm{N}_{\mathrm{y}}=.1 \mathrm{~N}, \mathrm{~N}_{\mathrm{xy}}=\mathrm{N}$, is given in Table (II). The first, second, fourth, sixth, and eighth sets of results shown in Table (II) also give the characteristic regions like those in Figure (11) except for very slight variations. However, regions corresponding to higher frequencies tended to differ from those in Figure (11) considerably. The reason for these variations is given below. The results for higher frequencies for the examples in Table (II) are not 
TABLE I

MODE SHAPES, NATURAL FREQUENCIES, AND BUCKLING LOADS FOR SEVERAL PLATES

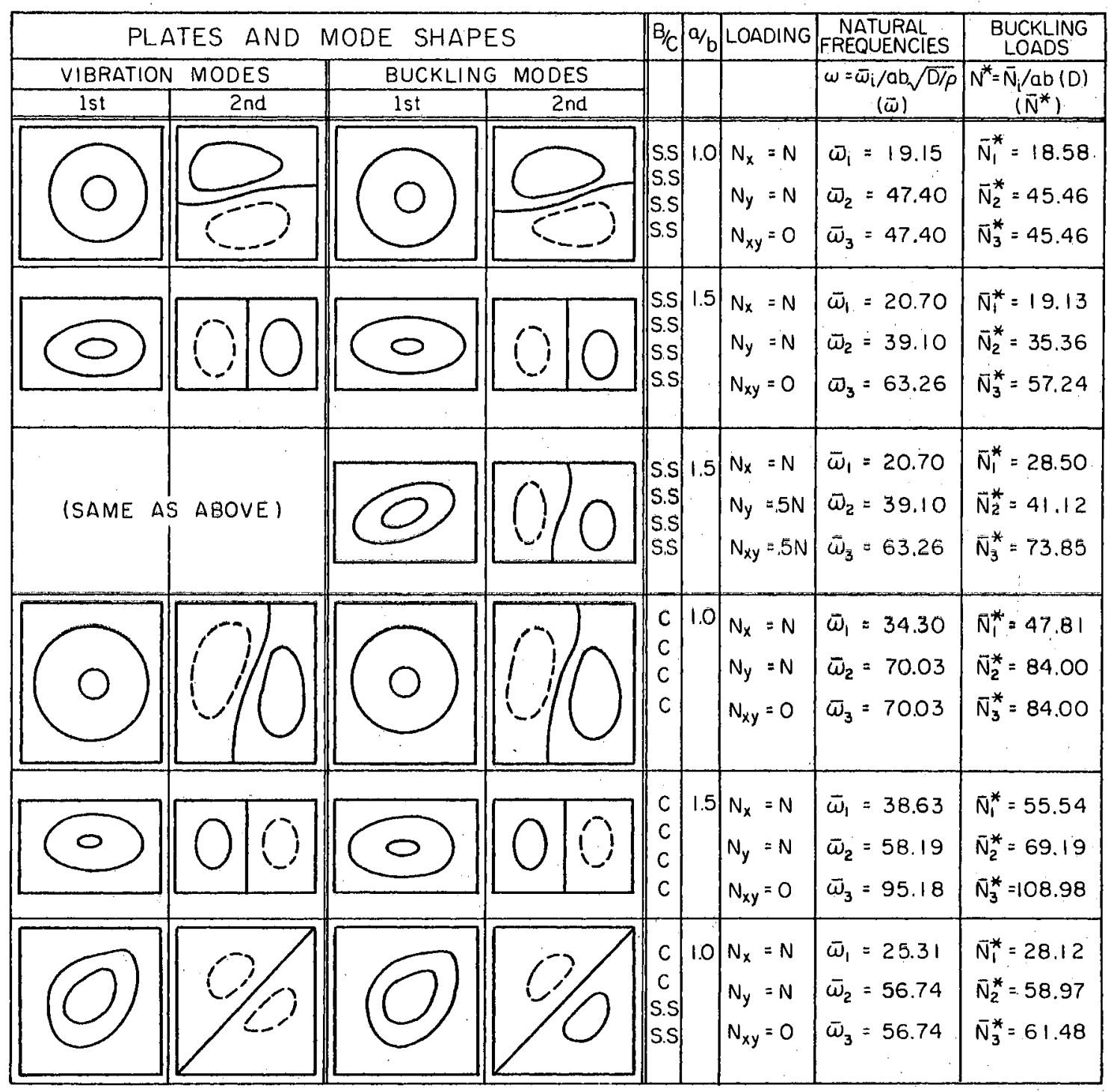


TABLE II

INFORMATION FOR OBTAINING FUNDAMENTAL REGION OF INSTABILITY FOR SEVERAL PLATES

\begin{tabular}{|c|c|c|c|c|c|c|c|c|c|c|}
\hline \multirow{3}{*}{$\begin{array}{l}\frac{B}{C} \\
\text { S.S } \\
\text { S.S } \\
\text { S.S } \\
\text { S.S }\end{array}$} & \multirow{3}{*}{$\frac{\frac{a}{b}}{1.0}$} & \multirow{3}{*}{\multicolumn{2}{|c|}{$\begin{array}{l}\text { Loading } \\
\begin{array}{l}\mathrm{N}_{\mathrm{x}}=\mathrm{N} \\
\mathrm{N}_{\mathrm{y}}=.5 \mathrm{~N} \\
\mathrm{~N}_{\mathrm{xy}}=.5 \mathrm{~N}\end{array}\end{array}$}} & \multicolumn{5}{|c|}{ Regions } & \multirow{2}{*}{$\bar{w}_{1}$} & \multirow{3}{*}{$\overline{\mathrm{N}}_{1} *$} \\
\hline & & & & \multirow{2}{*}{$\begin{array}{l}2 \\
.2 \\
.4 \\
.6\end{array}$} & \multicolumn{2}{|c|}{$a=0$} & \multicolumn{2}{|c|}{$\alpha=0.6$} & & \\
\hline & & & & & $\begin{array}{l}2.18 \\
2.36 \\
2.51\end{array}$ & $\begin{array}{l}1.79 \\
1.56 \\
1.27\end{array}$ & $\begin{array}{l}1.39 \\
1.50 \\
1.60\end{array}$ & $\begin{array}{r}1.14 \\
.99 \\
.81\end{array}$ & 19.15 & \\
\hline $\begin{array}{l}\text { S.S } \\
\text { S.S } \\
\text { S.S } \\
\text { S.S }\end{array}$ & 1.0 & $\begin{array}{l}\mathbb{N}_{X y}^{x} \\
\mathbb{N}_{y}^{*} \\
\mathbb{N}_{x y}\end{array}$ & $\begin{array}{l}=\mathrm{N} \\
=0 \\
=.5 \mathrm{~N}\end{array}$ & $\begin{array}{l}.2 \\
.4 \\
.6\end{array}$ & $\begin{array}{l}2.18 \\
2.35 \\
2.50\end{array}$ & $\begin{array}{l}1.80 \\
1.56 \\
1.28\end{array}$ & $\begin{array}{l}1.40 \\
1.51 \\
1.61\end{array}$ & $\begin{array}{r}1.15 \\
1.00 \\
.82\end{array}$ & 19.15 & 34.07 \\
\hline $\begin{array}{l}\text { S.S } \\
\text { S.S } \\
\text { S.S } \\
\text { S.S } \\
\end{array}$ & 1.5 & $\begin{array}{l}N_{x} \\
N_{y y}\end{array}$ & $\begin{array}{l}=\mathrm{N} \\
=0 \\
=.5 \mathrm{~N}\end{array}$ & $\begin{array}{r}.2 \\
.4 \\
.6\end{array}$ & $\begin{array}{l}2.15 \\
2.30 \\
2.44\end{array}$ & $\begin{array}{l}1.82 \\
1.61 \\
1.35\end{array}$ & & & 20.23 & 52.10 \\
\hline $\begin{array}{l}\mathrm{C} \\
\mathrm{C} \\
\mathrm{C} \\
\mathrm{C} \\
\end{array}$ & 1.0 & $\begin{array}{l}\mathbb{N}_{x x} \\
\mathbb{N}_{y} \\
\mathbb{N}_{x y}\end{array}$ & $\begin{array}{l}=N \\
=.5 \mathrm{~N} \\
=.5 \mathrm{~N}\end{array}$ & $\begin{array}{l}.2 \\
.4 \\
.6\end{array}$ & $\begin{array}{l}2.17 \\
2.32 \\
2.47\end{array}$ & $\begin{array}{l}1.80 \\
1.59 \\
1.31\end{array}$ & $\begin{array}{l}1.43 \\
1.53 \\
1.63\end{array}$ & $\begin{array}{r}1.18 \\
1.03 \\
.85\end{array}$ & 34.30 & 58.89 \\
\hline $\begin{array}{l}c \\
\mathrm{C} \\
\mathrm{C} \\
\mathrm{C}\end{array}$ & 1.0 & $\begin{array}{l}N_{x w} \\
N_{y} \\
N_{x y}\end{array}$ & $\begin{array}{l}=\mathbb{N} \\
=0 \\
=.5 N\end{array}$ & $\begin{array}{l}.2 \\
.4 \\
.6\end{array}$ & $\begin{array}{l}2.15 \\
2.29 \\
2.42\end{array}$ & $\begin{array}{l}1.82 \\
1.61 \\
1.36\end{array}$ & $\begin{array}{l}1.47 \\
1.57 \\
1.66\end{array}$ & $\begin{array}{r}1.23 \\
1.08 \\
.98\end{array}$ & 34.30 & 79.86 \\
\hline $\begin{array}{l}\mathrm{C} \\
\mathrm{C} \\
\mathrm{C} \\
\mathrm{C} \\
\end{array}$ & 1.5 & $\begin{array}{l}\mathrm{N}_{\mathrm{xx}} \\
\mathrm{N}_{\mathrm{y}} \\
\mathrm{N}_{\mathrm{x} x \mathrm{y}}\end{array}$ & $\begin{array}{l}=\mathrm{N} \\
=.5 \mathrm{~N} \\
=.5 \mathrm{~N}\end{array}$ & $\begin{array}{l}.2 \\
.4 \\
.6\end{array}$ & $\begin{array}{l}2.16 \\
2.30 \\
2.45\end{array}$ & $\begin{array}{l}1.81 \\
1.61 \\
1.35\end{array}$ & $\begin{array}{l}1.45 \\
1.56 \\
1.65\end{array}$ & $\begin{array}{r}1.22 \\
1.07 \\
.97\end{array}$ & 38.63 & 74.61 \\
\hline $\begin{array}{l}\mathrm{C} \\
\mathrm{C} \\
\mathrm{C} \\
\mathrm{C} \\
\end{array}$ & 1.5 & $\begin{array}{l}\mathrm{N}_{\mathrm{x}} \\
\mathrm{N}_{\mathrm{y}} \\
\mathrm{N}_{\mathrm{xy}}\end{array}$ & $\begin{array}{l}=\mathbb{N} \\
=0 \\
=.5 \mathrm{~N}\end{array}$ & $\begin{array}{l}.2 \\
.4 \\
.6\end{array}$ & $\begin{array}{l}2.09 \\
2.18 \\
2.26\end{array}$ & $\begin{array}{l}1.59 \\
1.76 \\
1.66\end{array}$ & $\begin{array}{l}1.67 \\
1.73 \\
1.79\end{array}$ & $\begin{array}{l}1.52 \\
1.42 \\
1.28\end{array}$ & 38.63 & 95.42 \\
\hline $\begin{array}{l}\text { C } \\
\text { C } \\
\text { S.S } \\
\text { S.S } \\
\end{array}$ & 1.0 & $\begin{array}{l}N_{x} \\
N_{y} \\
N_{x y}\end{array}$ & $\begin{array}{l}=\mathrm{N} \\
=.5 \mathrm{~N} \\
=.5 \mathrm{~N}\end{array}$ & $\begin{array}{l}.2 \\
.4 \\
.6\end{array}$ & $\begin{array}{l}2.17 \\
2.34 \\
2.49\end{array}$ & $\begin{array}{l}1.30 \\
1.57 \\
1.29\end{array}$ & $\begin{array}{l}1.41 \\
1.51 \\
1.62\end{array}$ & $\begin{array}{r}1.16 \\
1.01 \\
.83\end{array}$ & 25.31 & 36.30 \\
\hline & 2 & $-\pi$ & & & & $\frac{\bar{w}}{2} 7$ & & & $N *=\frac{\bar{N} *}{a b}$ & (D) \\
\hline
\end{tabular}


reported in this thesis.

In a study petformed by this writer on the dynamic instability of beams, it was found that for all common boundary conditions the beams exhibited the same characteristic regions of dynamic instability as those shown in Figure (11). Brown (18) in his study of the dynamic stability of beams on elastic foundations obtained the same regions for certain cases. An analytical explanation as to why certain of these problems give the same characteristic regions of dynamic instability is presented below.

First consider the governing differential equation for the dynamic stability of a plate.

$$
\nabla^{4} w=\frac{1}{D}\left(N_{x x} \frac{\partial^{2} w}{\partial x^{2}}+2 N \frac{\partial^{2} w}{\partial x \partial y}+N_{y} \frac{\partial^{2} w}{\partial y^{2}}-\rho \frac{\partial^{2} w}{\partial t^{2}}\right)
$$

Assuming a solution of the form

$$
w(x, y, t)=f(t) g(x, y)
$$

and substituting into EQ. (76), the following differential equation is obrained;

$$
f^{\prime \prime}+f\left[\frac{\nabla^{4} g}{\rho g}-\frac{1}{D \rho g}\left(N_{x} \frac{\partial^{2} g}{\partial x^{2}}+2 N_{x y} \frac{\partial^{2} g}{\partial x \partial y}+N_{y} \frac{\partial^{2} g}{\partial y^{2}}\right)\right]=0 .
$$

Next consider the governing differential equation for free vibration of the plate

$$
\nabla^{4} w_{1}=-\frac{\rho}{D} \frac{\partial^{2} w_{1}}{\partial t^{2}}
$$

Making the substitution

$$
w_{1}=f_{1}(t) g_{1}(x, y)
$$


into Eq. (78) leads to

$$
\frac{\nabla^{4} \varepsilon_{1}}{g_{1}}=-\rho \frac{f_{1}^{\prime \prime}}{f_{1}}=h^{2}
$$

The natural frequencies for the plate are

$$
w=\sqrt{\frac{h^{2}}{\rho}} .
$$

Finally, from the governing differential equation for static buckling

$$
\nabla^{4} w=\frac{1}{D}\left(N_{x} \frac{\partial^{2} w}{\partial x^{2}}+2 N_{x y} \frac{\partial^{2} w}{\partial x \partial y}+N_{y} \frac{\partial^{2} w}{\partial y^{2}}\right)
$$

the following expression is obtained when the substitution $w_{2}=g_{2}$ is made;

$$
\frac{\nabla^{4} g_{2}}{g_{2}}=\frac{1}{D g_{2}}\left(N_{x} \frac{\partial^{2} g_{2}}{\partial x^{2}}+2 N_{x y} \frac{\partial^{2} g_{2}}{\partial x \partial y}+N_{y} \frac{\partial^{2} g_{2}}{\partial y^{2}}\right)
$$

Now if the assumptions that the mode shape functions

$$
g=g_{1}=g_{2}
$$

and

$$
N_{x}=a N_{t} \cos \theta t, \quad N_{y}=b N_{t} \cos \theta t, \quad N_{x y}=d N_{t} \cos \theta t
$$

where $a, b$, and $d$ are constants, axe made, and Eqs. (79) and (82) are substituted into Eq. (77) the following equation is obtained;

$$
f^{\prime \prime}+w_{i}^{2}\left(1-\frac{N_{t} \cos \theta t}{N_{i}^{*}}\right) f=0
$$

where $\mathbb{N}_{i}^{*}$ is the static buckling load calculated using a loading

$$
\mathrm{N}_{\mathrm{x}}=a \mathrm{~N}_{\mathrm{s}}, \quad \mathrm{N}_{\mathrm{y}}=\mathrm{bN}_{\mathrm{s}}, \quad \mathrm{N}_{\mathrm{xy}}=\mathrm{dN}_{\mathrm{s}} \text {. }
$$


Eq. (83) is of the same form as Eq. (75) which gives the regions of instability that are equivalent to those in Figure (11). It follows, therefore, that if the mode shapes for free vibration and static buckling are the same, the regions of dynamic instability will be those characteristic regions shown for $\alpha=0$ in Figure (11). It can be shown in a similar manner that when a static component of the load is present, the same conclusion can be drawn if the free vibration is taken to be the free vibration of the plate under the action of the static loads. In this case the regions will be the same as the ones shown for $\alpha=0$ with the exception that the horizontal axis should be normalized with respect to the natural frequency for the plate with the loads applied. In all cases where the $i^{\text {th }}$ mode shape for vibration was very similar to the $i^{\text {th }}$ mode shape of static buckling the characteristic regions were obtained. In cases where the mode shapes for vibration and static buckling were very dissimilar, as for example the simply supported plate subjected to the loadings $\mathrm{N}_{x}=0, N_{y}=0$, and $N_{x y}=N$, and $\mathrm{N}_{\mathrm{x}}=.1 \mathrm{~N}_{3} \mathrm{~N}_{\mathrm{y}}=.1 \mathrm{~N}$, and $\mathrm{N}_{\mathrm{xy}}=\mathrm{N}$, the regions of instability differed greatly from those in Figure (11). The results for these two examples are shown in Figures (13) through (16).

In the above mentioned examples, the comparison of mode shapes for vibration and buckling has been done only for modes which were ranked numerically the same. It is not necessary, however, that the modes be of the same numexical rank in order to obtain the characteristic regions. In making the assumption that the shape functions for vibration and buckling be the same in the development of $\mathrm{Eq}$. (83) no mention was made as to whether or not the functions resulted from the same numerically ranked modes. The examples of the cantilevered and fixed 


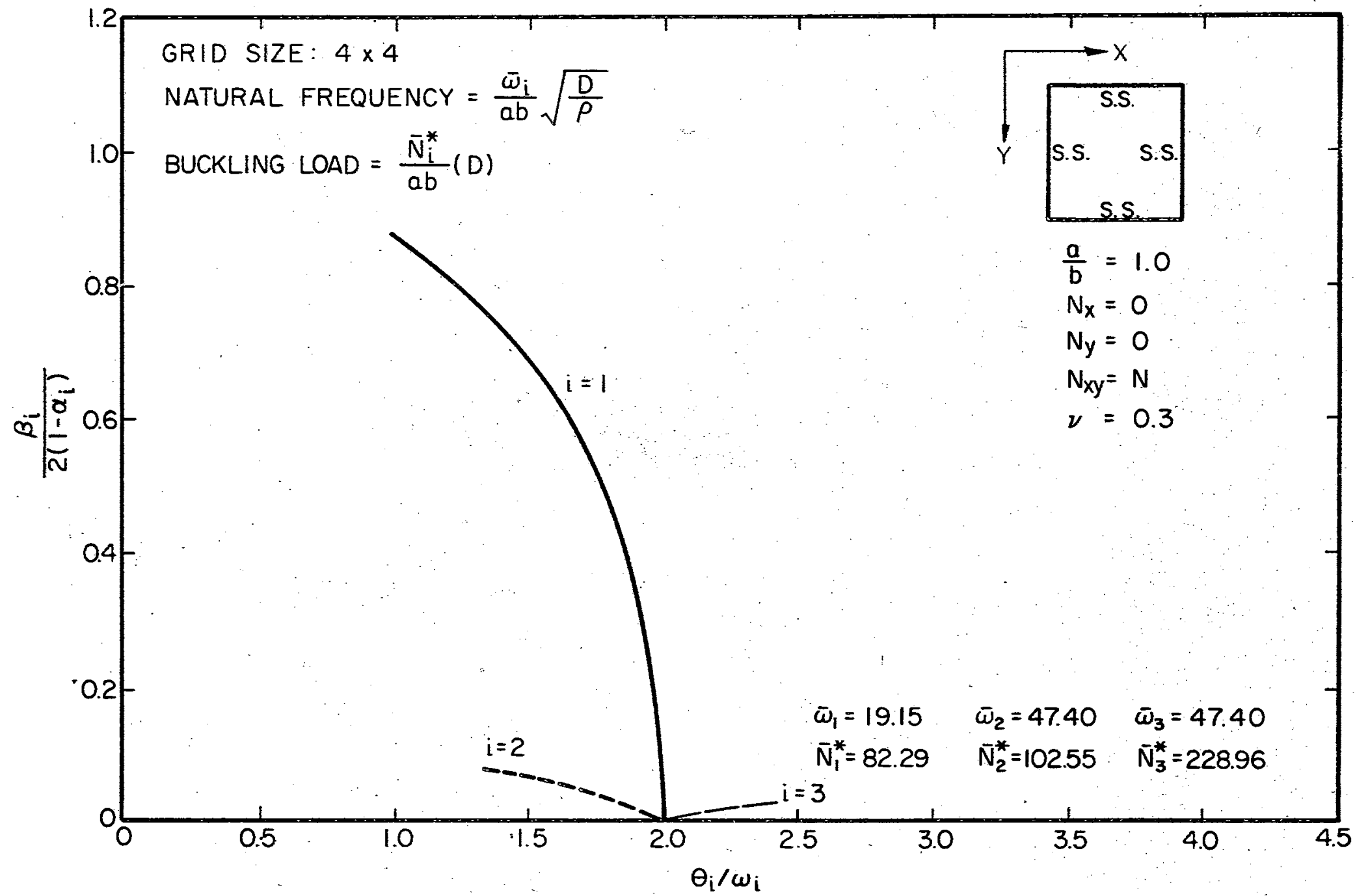

Figure 13. Regions of Dynamic Instability for a Simply Supported Plate $\left(N_{x y}=N_{s} N_{x}=0, N_{y}=0\right)$ 

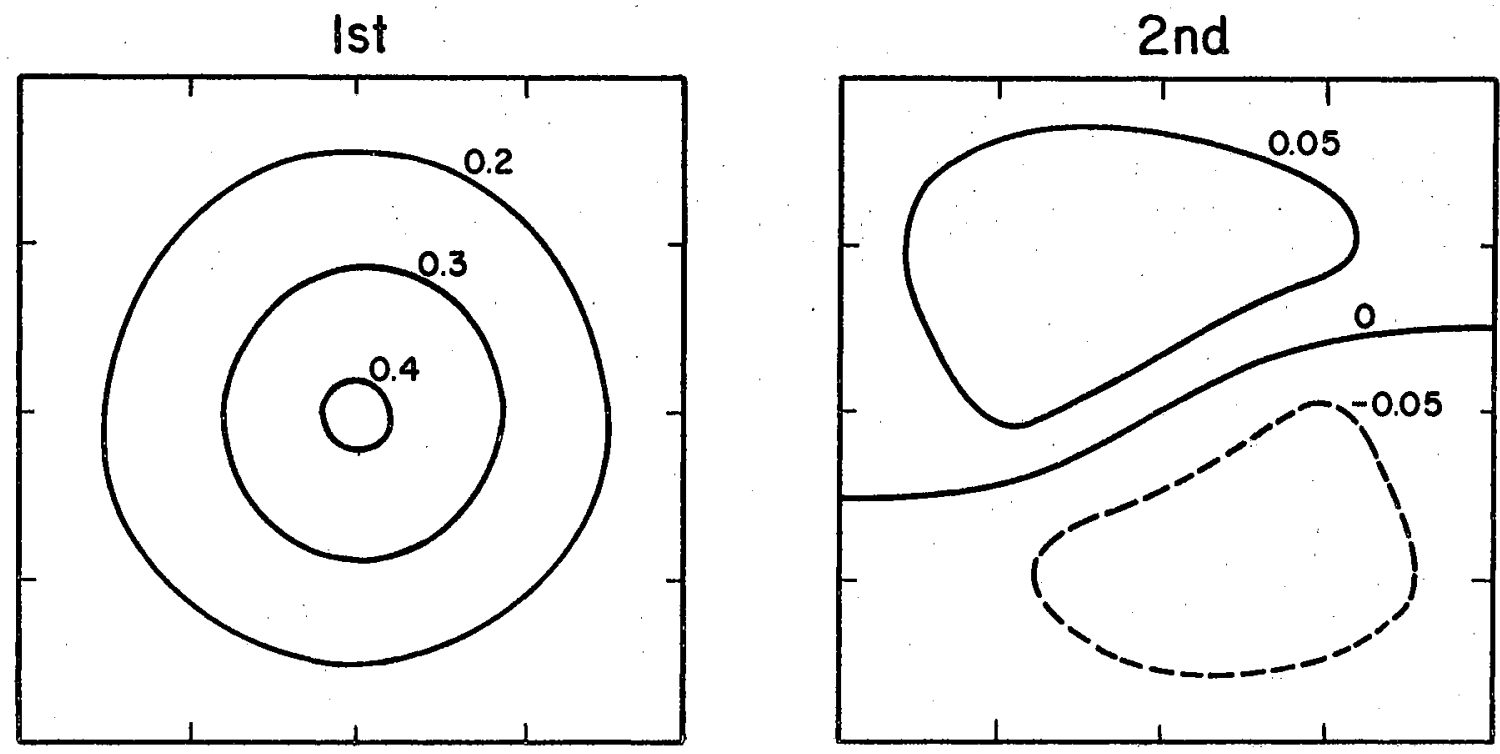

VIBRATION MODES - SIMPLY SUPPORTED PLATE
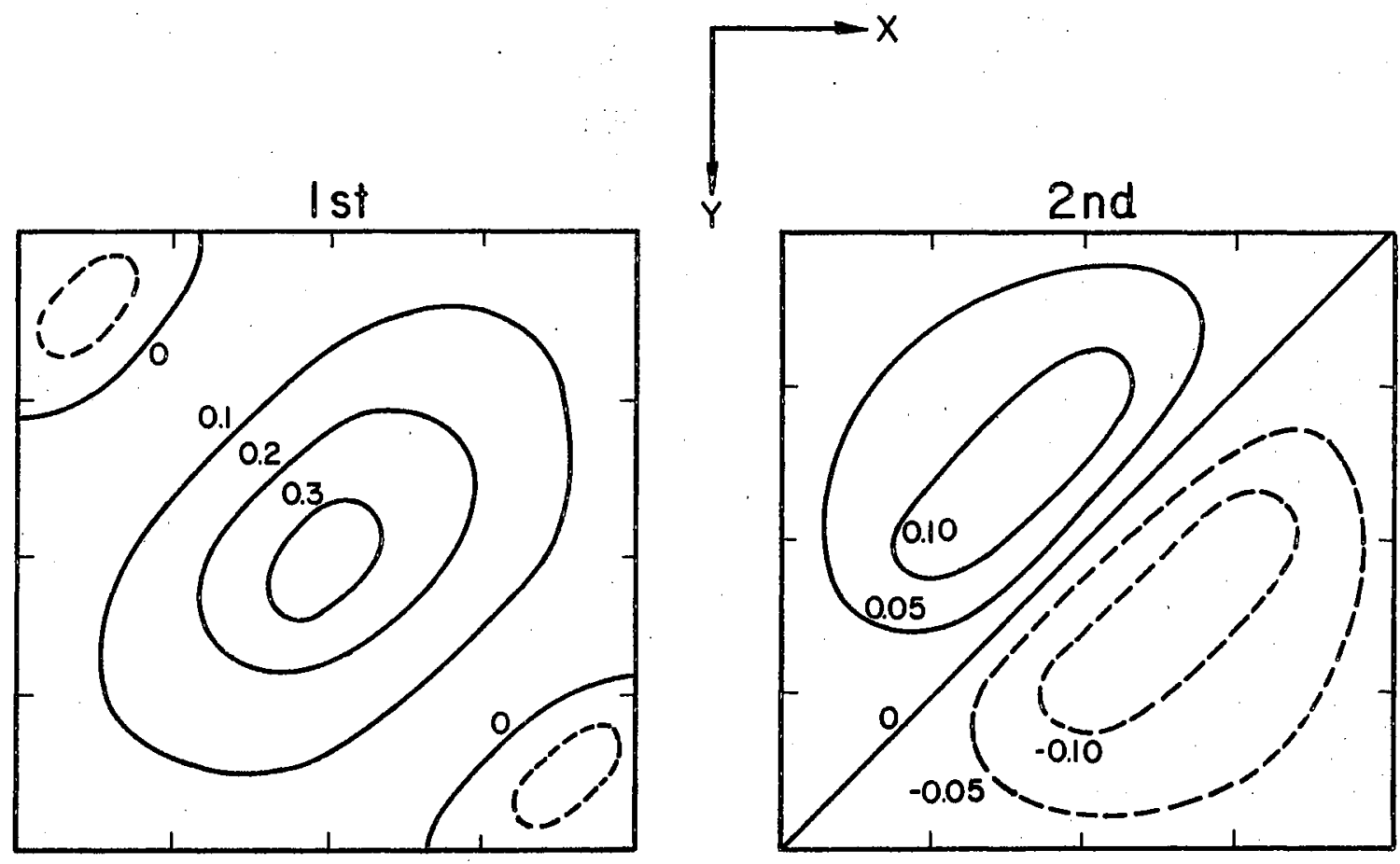

BUCKLING MODES - SIMPLY SUPPORTED PLATE

Figure 14. Mode Shapes for a Simply Supported Plate $\left(N_{x y}=N\right)$ 


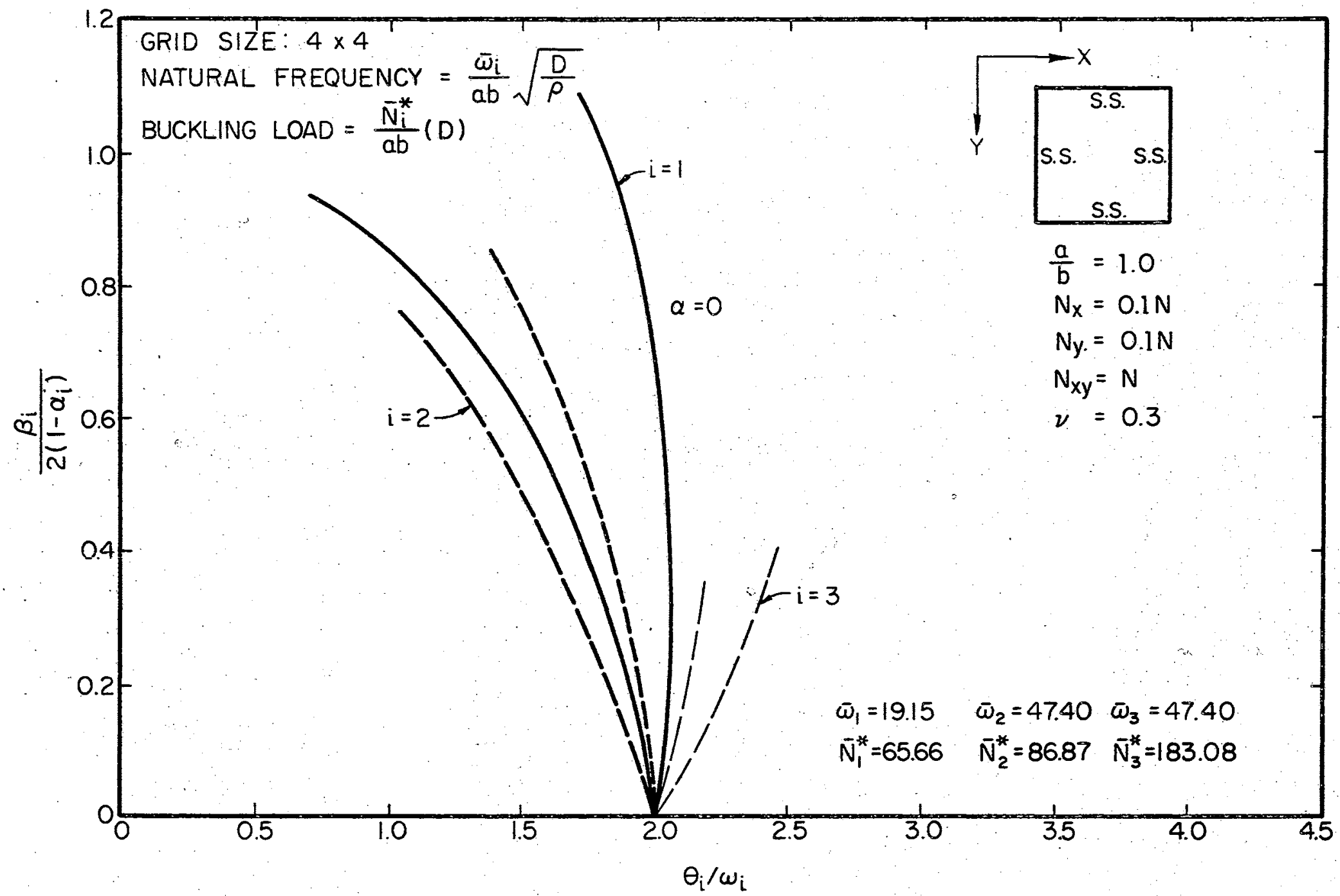

Figure 15. Regions of Dynamic Instability for a Simply Supported Plate $\left(N_{x}=.1 N_{s} N_{y}=.1 N, N_{x y}=0\right)$ 

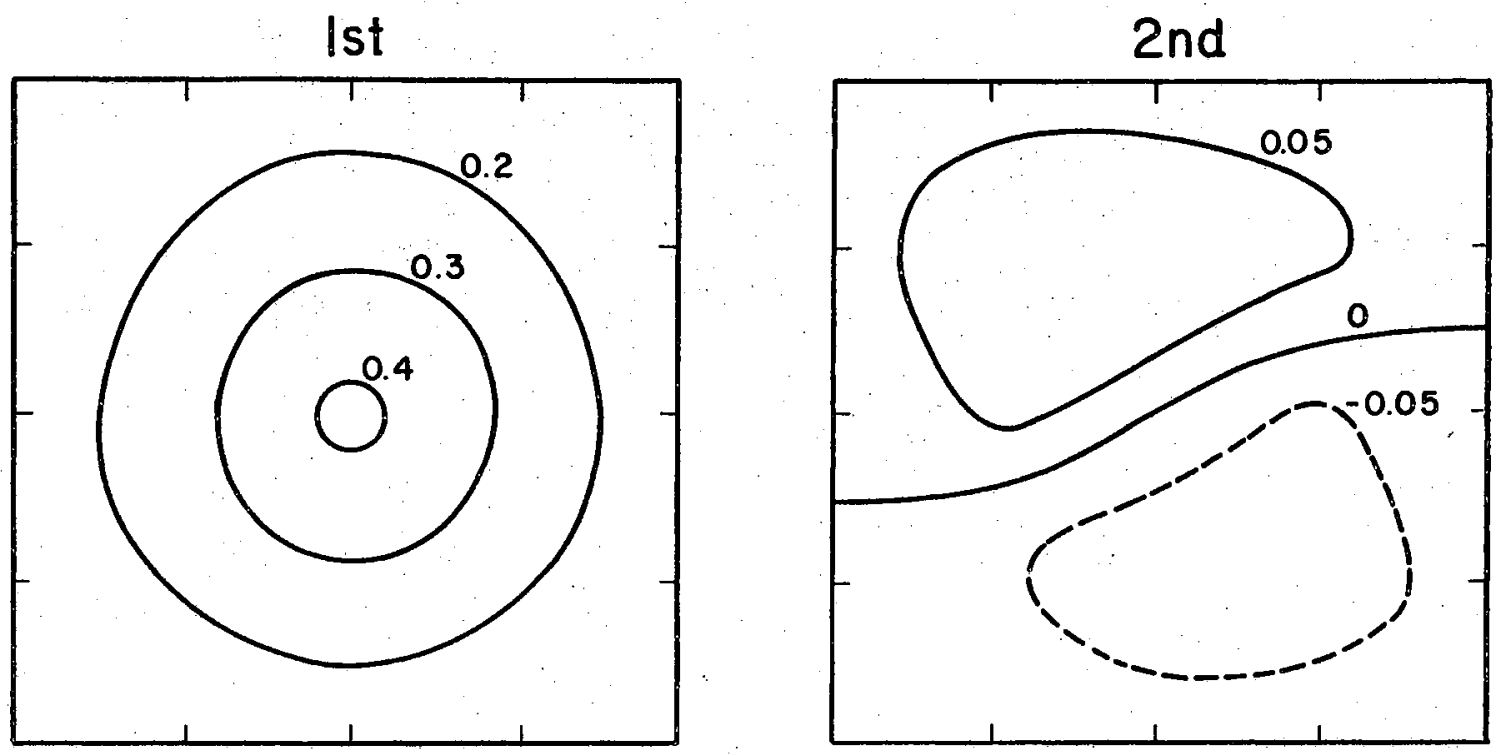

VIBRATION MODES - SIMPLY SUPPORTED PLATE
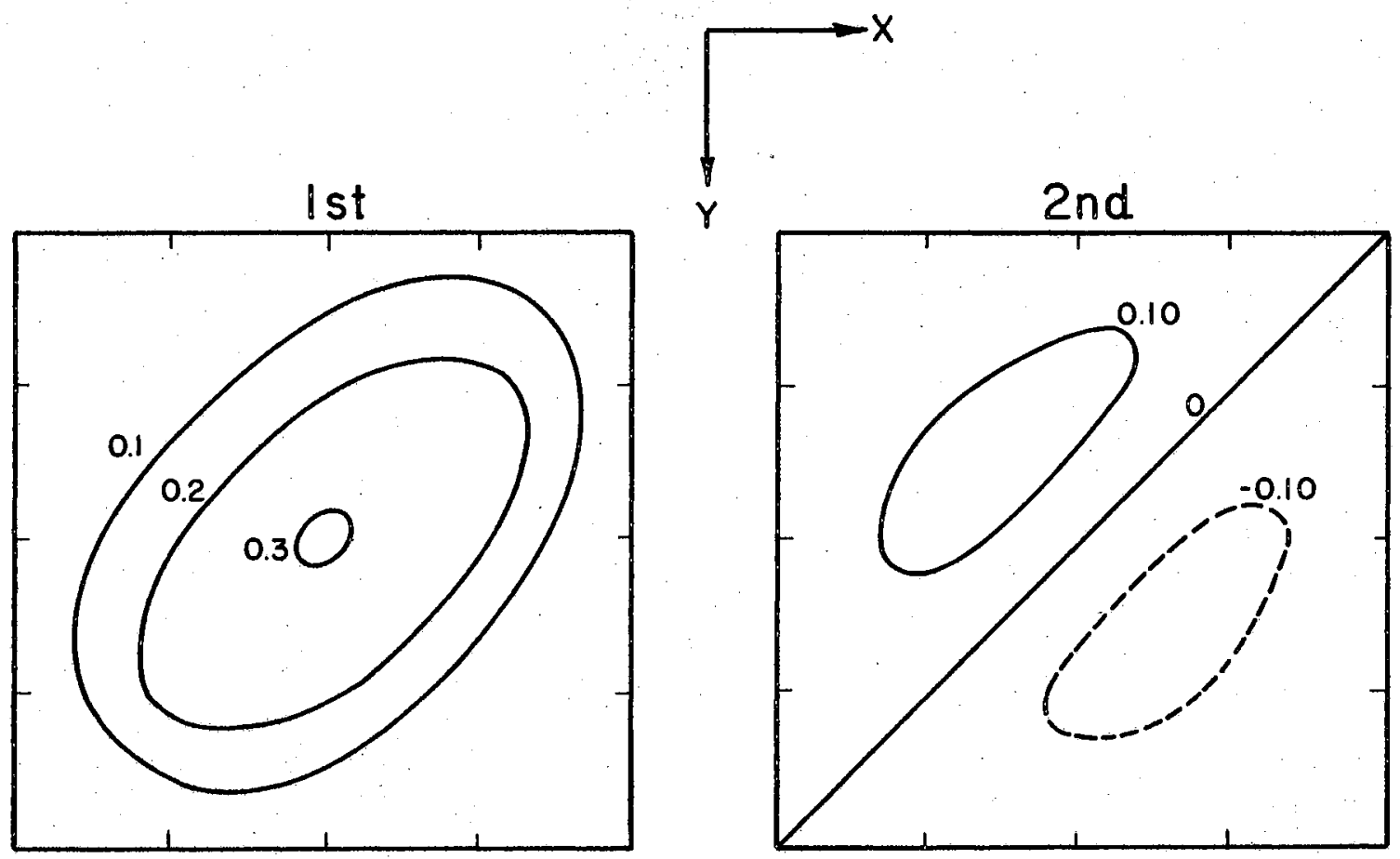

BUCKLING MODES - SIMPLY SUPPORTED PLATE

Figuxe 16. Mode Shapes for a Simply Supported Plate

$$
\left(\mathrm{N}_{\mathrm{x}}=.1 \mathrm{~N}_{2} \mathrm{~N}_{\mathrm{y}}=.1 \mathrm{~N}, \mathrm{~N}_{\mathrm{xy}}=\mathrm{N}\right)
$$


ended plates shown in Figures (17) through (20) illustrate this point. The axes on Figures (17) and (19) are normalized in numerical order as has been done on previous figures of this type. Notice, however, that in both of these examples the second vibration mode is the same as the first buckling mode, and that the curves denoted by $i=2$ become the characteristic curves, denoted here as Bolotin curve, if the vertical axis, load axis, is normalized with respect to the first buckling load and the horizontal axis, frequency axis, is normalized with respect to the second natural frequency.

It is important to recognize that if there exist a buckling mode shape, for instance the $j^{\text {th }}$ mode shape, that is the same as a given vibration mode, as for example the $i^{\text {th }}$ mode, then there exist a region of dynamic instability corresponding to the $i^{\text {th }}$ natural frequency that has the characteristic shape shown in Figure (11) if the load axis is normalized with respect to the $j^{\text {th }}$ buckling load and the frequency axis is normalized with respect to the $i^{\text {th }}$ natural frequency. 


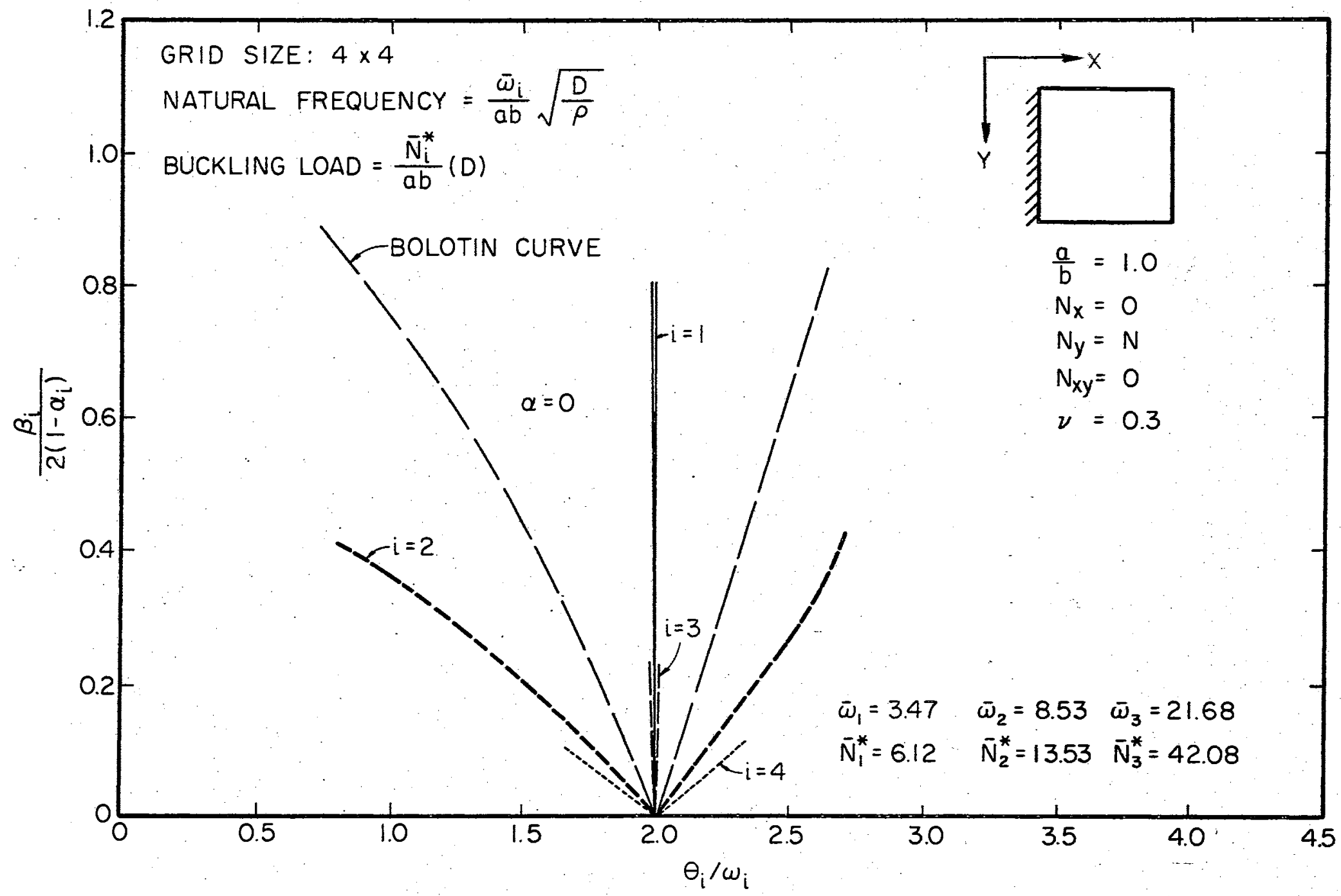

Figure 17. Regions of Dynamic Instability for a Cantilevered Plate $\left(N_{y}=N\right)$ 

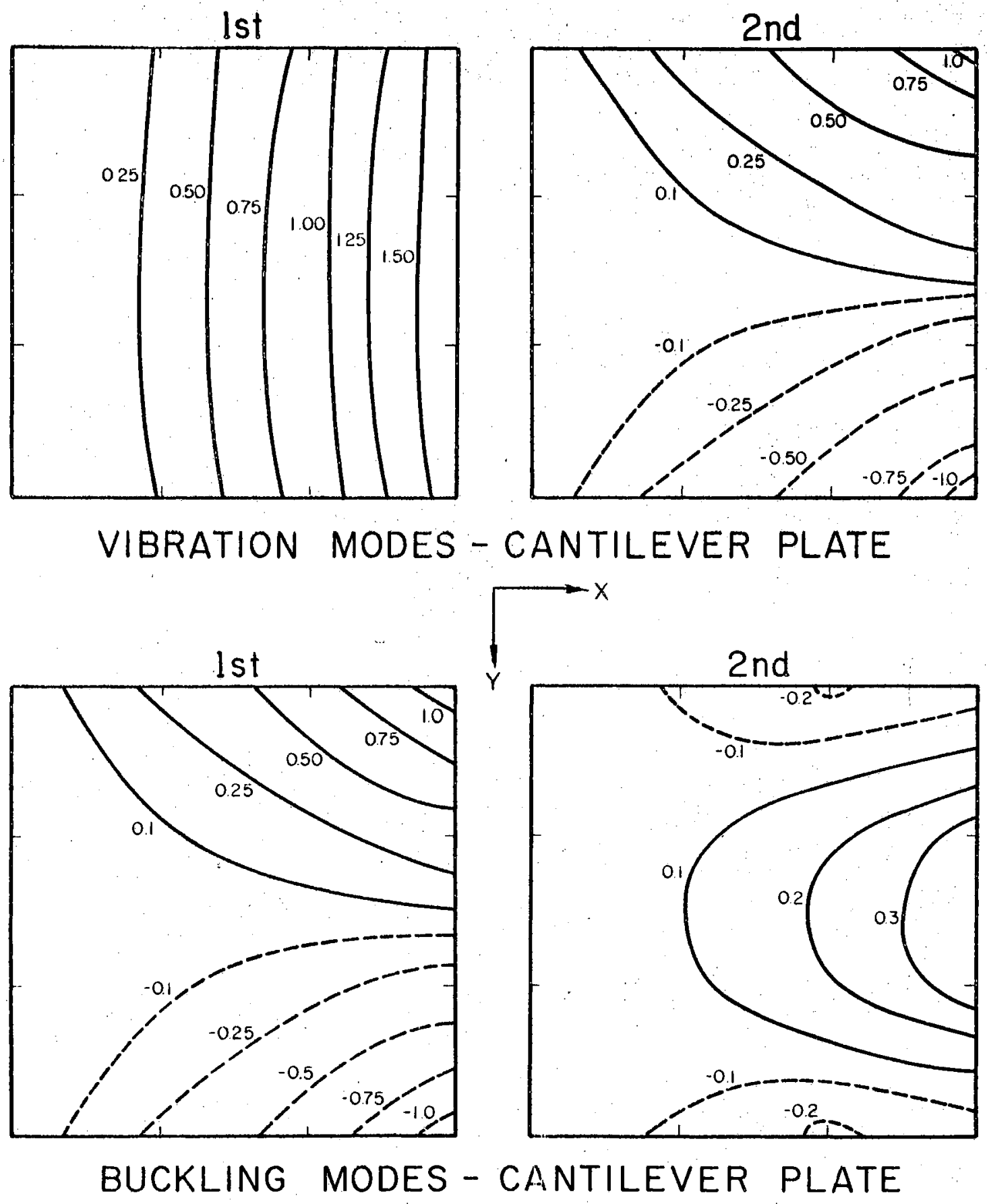

Figure 18. Mode Shapes for a Cantilevered Plate $\left(N_{y}=N\right)$ 


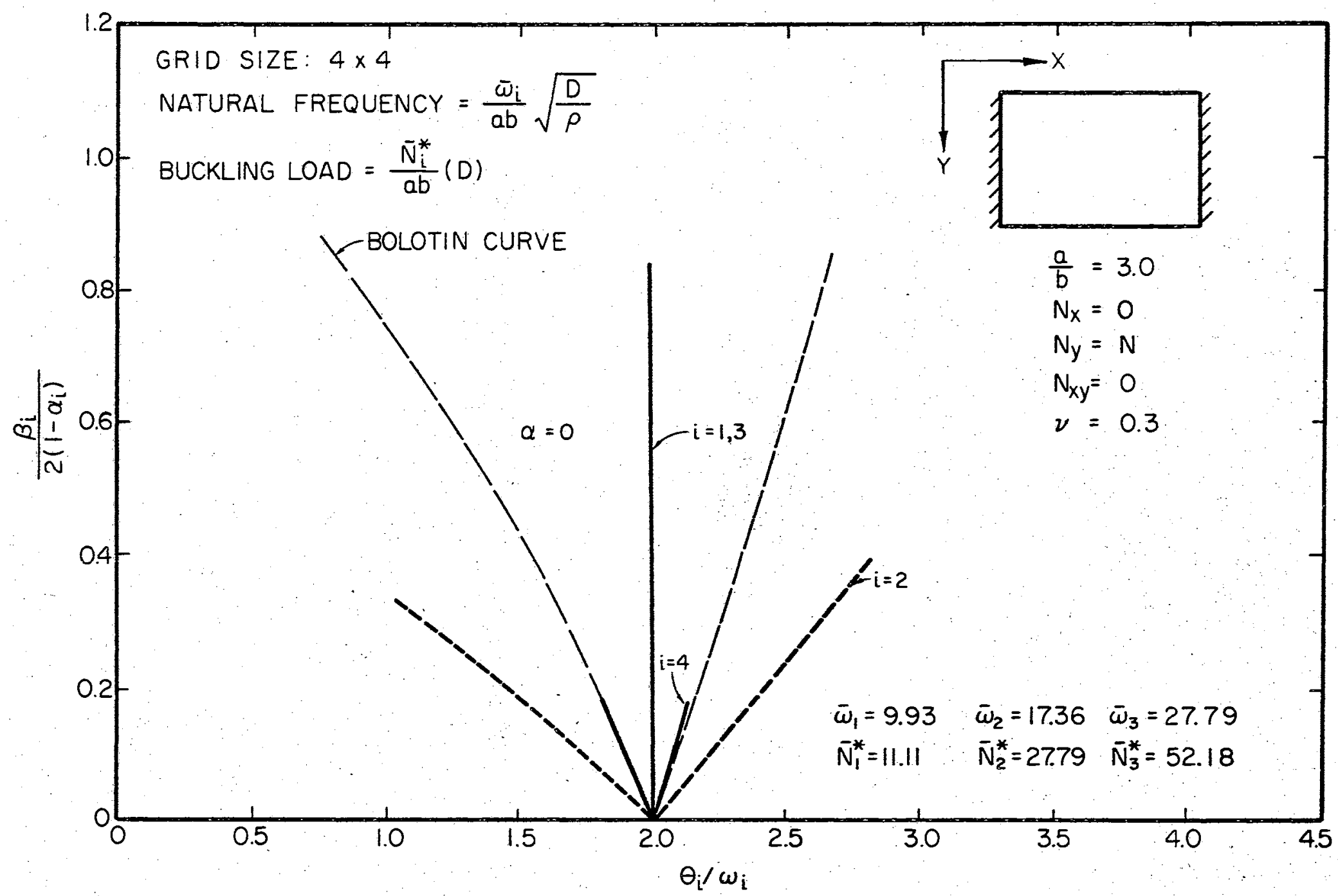

Figure 19. Regions of Dynamic Instability for a Fixed Ended Plate $\left(N_{y}=N\right)$ 

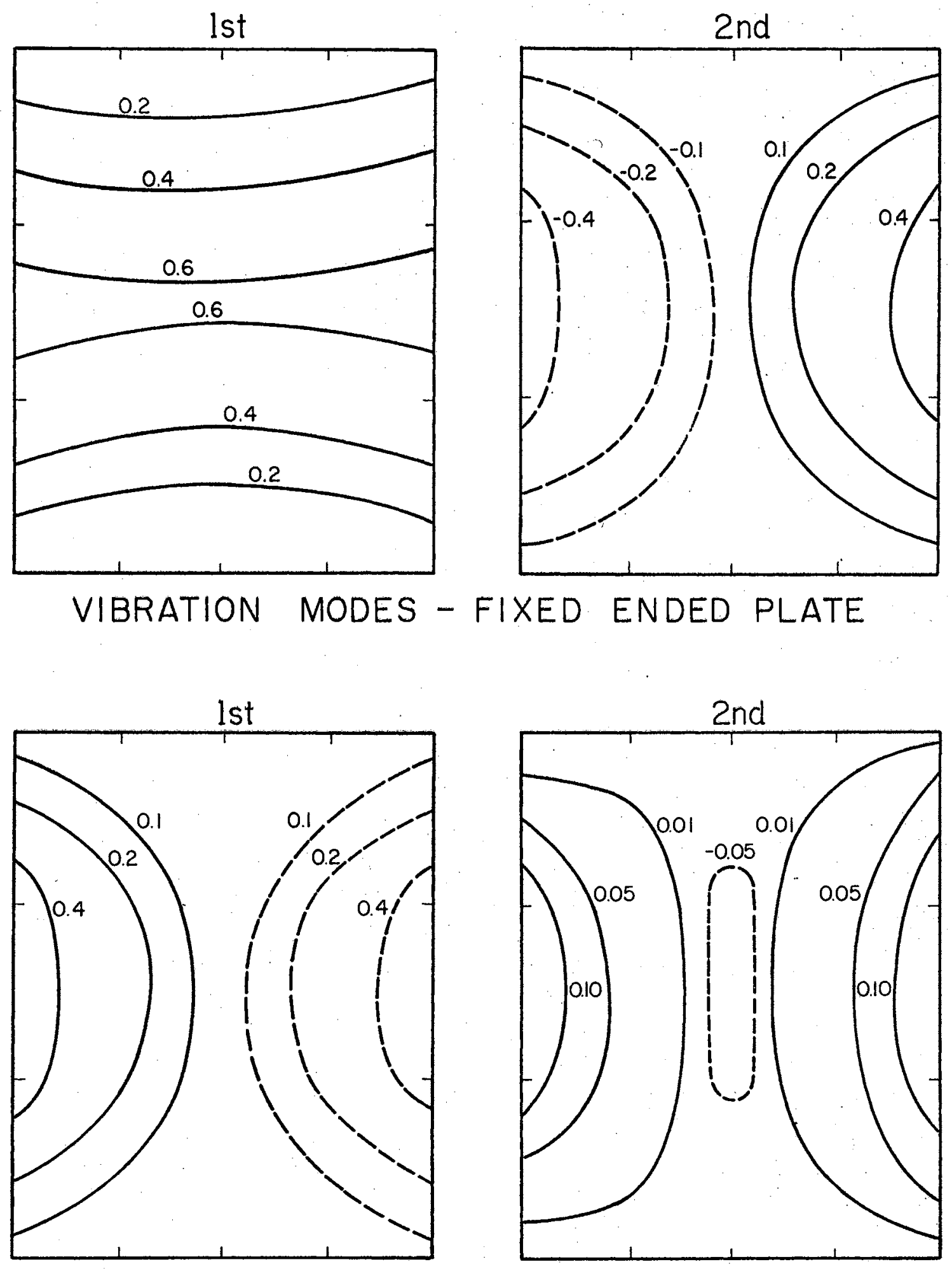

BUCKLING MODES - FIXED ENDED PLATE

Figure 20. Mcde Shapes for a Fixed Ended Plate $\left(N_{y}=N\right)$ 


\subsection{Plates on Elastic Foundations}

The results for a simply supported plate and a clamped plate each loaded with $N_{x}=N_{\theta} N_{y}=N_{s} N_{x y}=0$ and each solved with two different foundation moduli are illustrated in Figures (21) through (30). Here the natural frequencies $(\omega)$ are for free vibration of the plates resting upon the foundations. Notice that for these examples, as was the case with the examples discussed in the previous section, when the mode shapes for vibration and static buckling become similar, the regions of dynamic instability approach the characteristic curves. For these particular examples it is seen that when the foundation modulus is increased the region of instability corresponding to the lowest natural frequency naxrows somewhat, whereas the regions corresponding to higher frequencies appear to be affected to a lesser degree. 


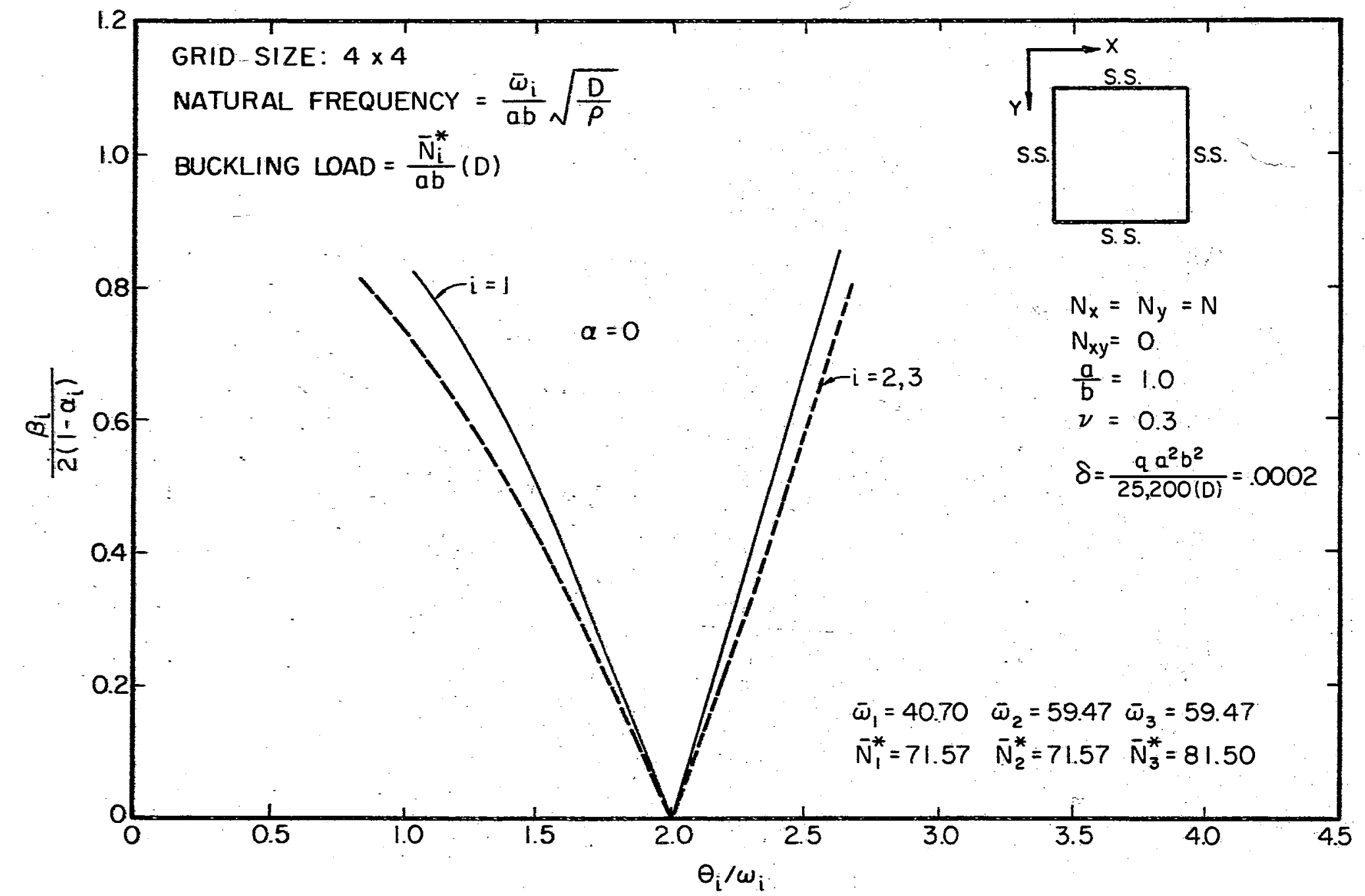

Figure 21. Regions of Dynamic Instability for a Simply Supported Plate on an Elastic Foundafion $(\delta=.0002, \alpha=0)$ 


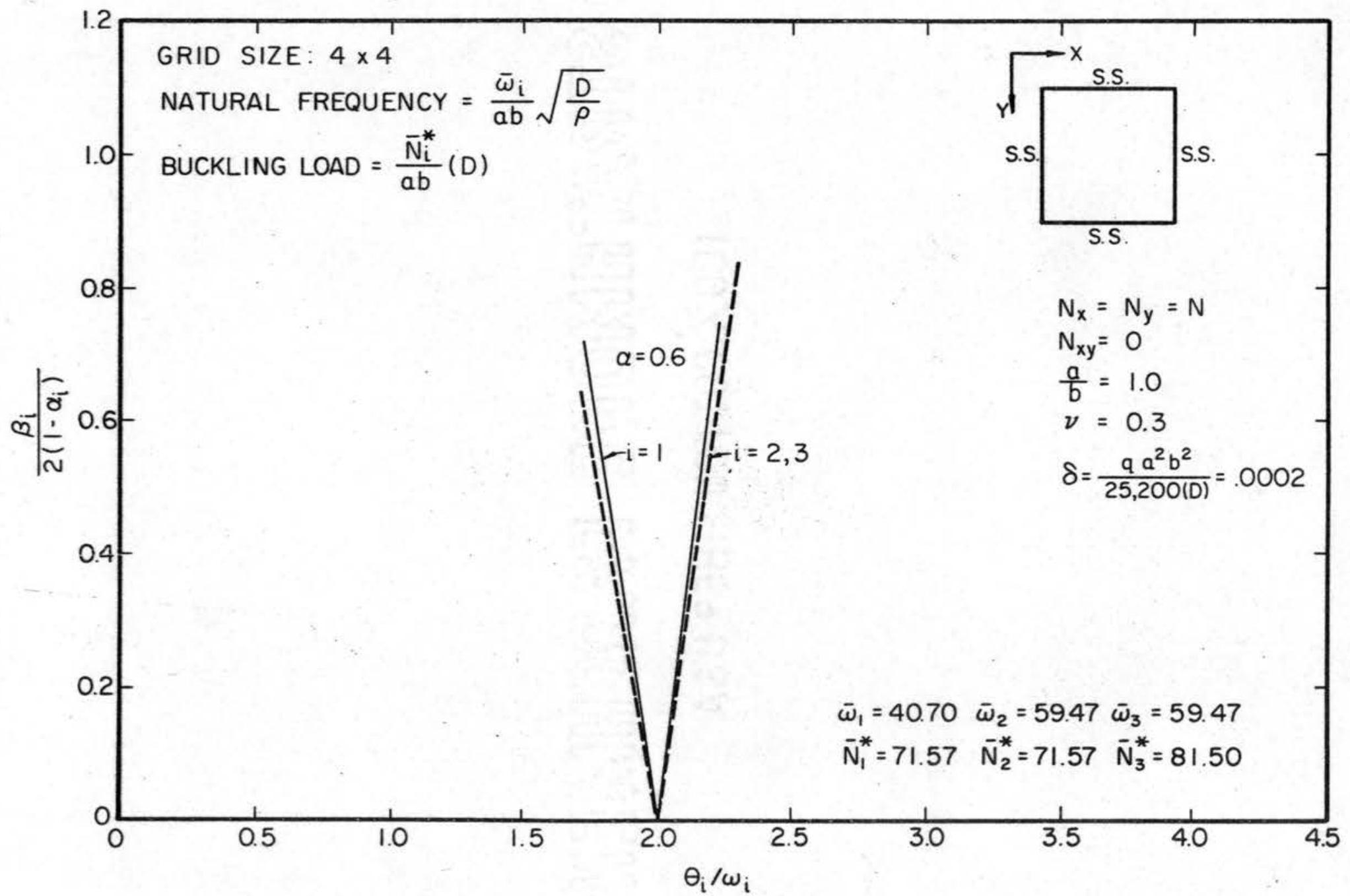

Figure 22. Regions of Dynamic Instability for a Simply Supported Plate on an Elastic Foundation $(\delta=.0002, \alpha=0.6)$ 

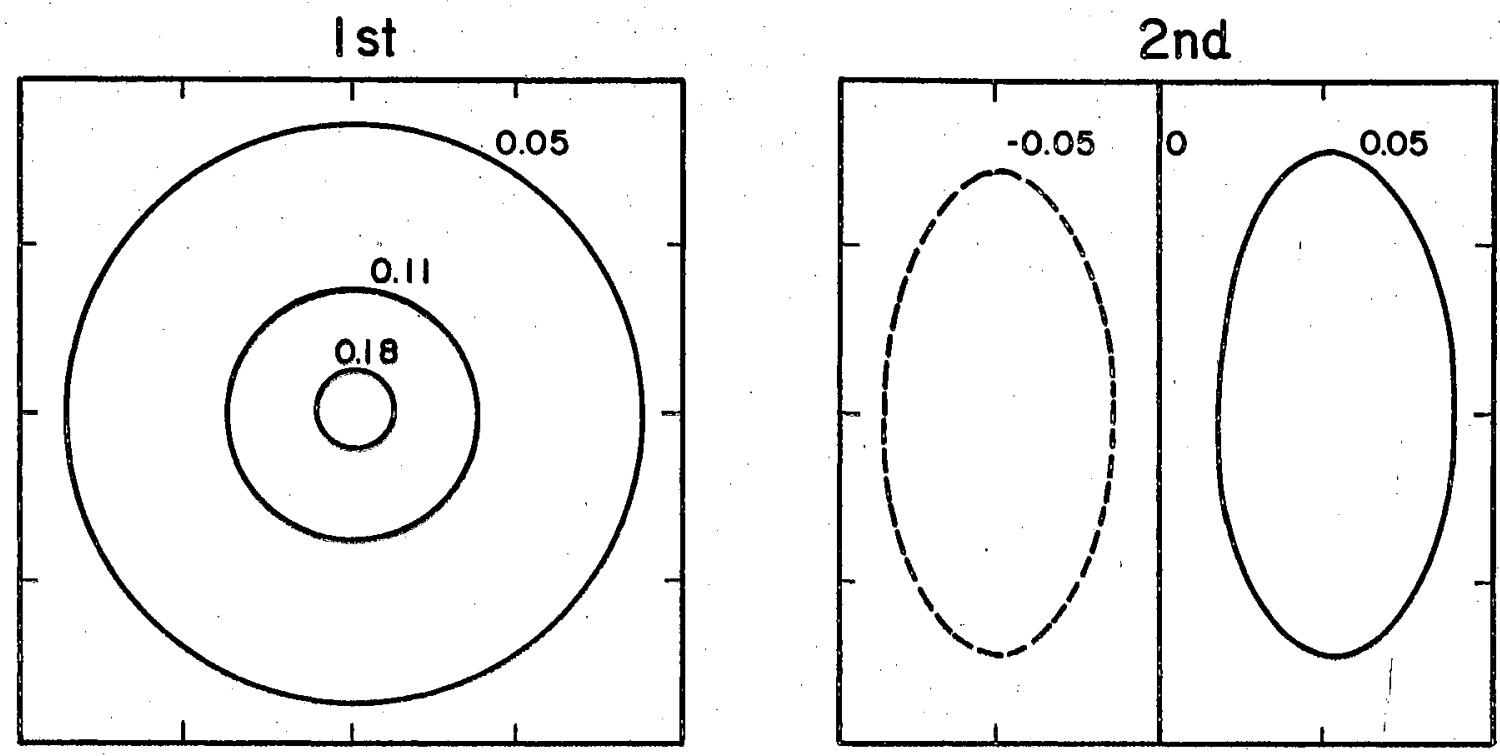

VIBRATION MODES - SIMPLY SUPPORTED PLATE
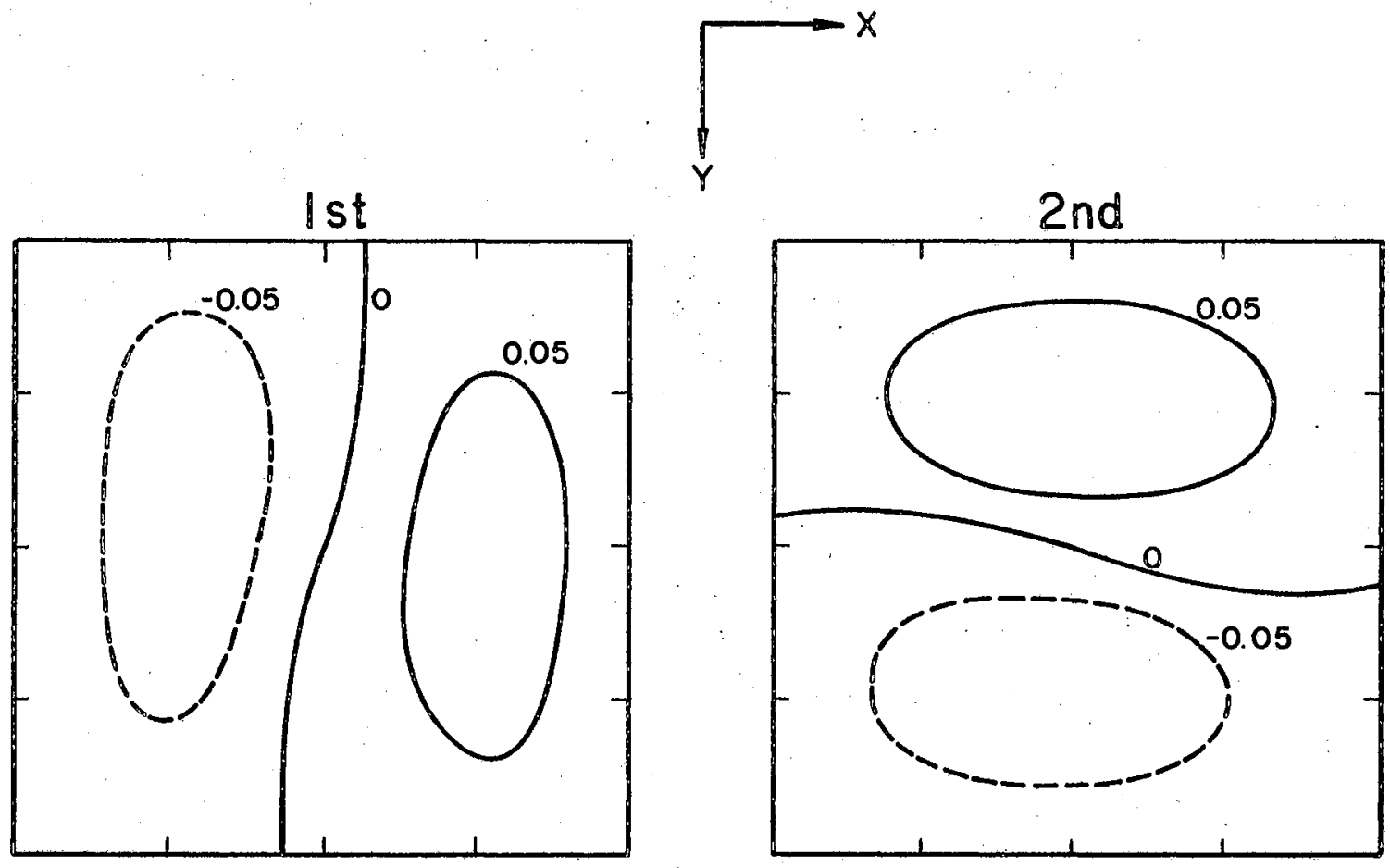

BUCKLING MODES - SIMPLY SUPPORTED PLATE

Figure 23. Mode Sbaper for a Simply Sipported Plate on an Elastic Foundation $\left(\delta=.0002, \mathrm{~N}_{\mathrm{x}}=\mathrm{N}_{\mathrm{y}}=\mathrm{N}\right)$ 


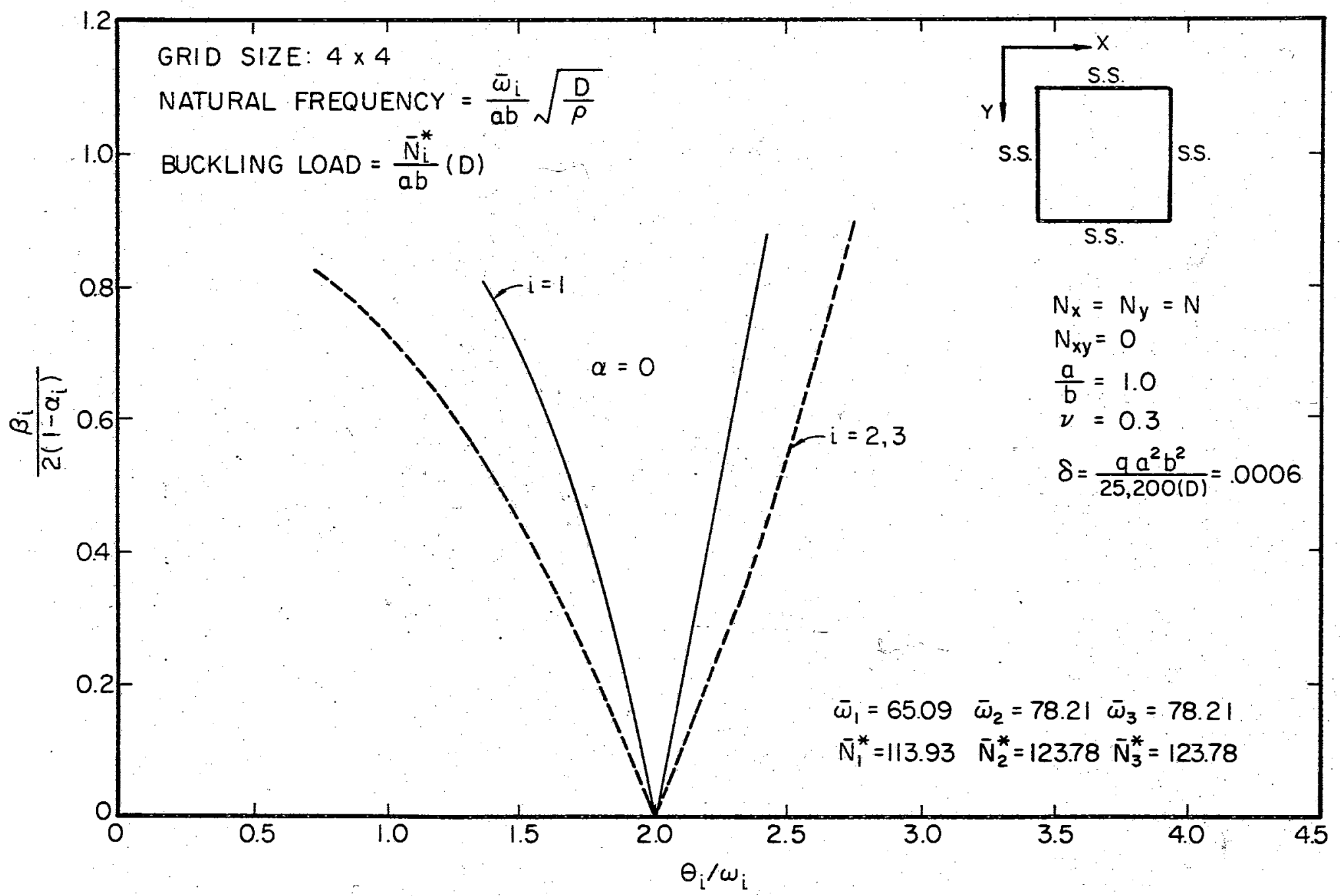

Figure 24. Regicns of Dynamic Instability for a Simply Supported Plate on an Elastic Foundao tion $(\delta=.0006, \alpha=0)$ 


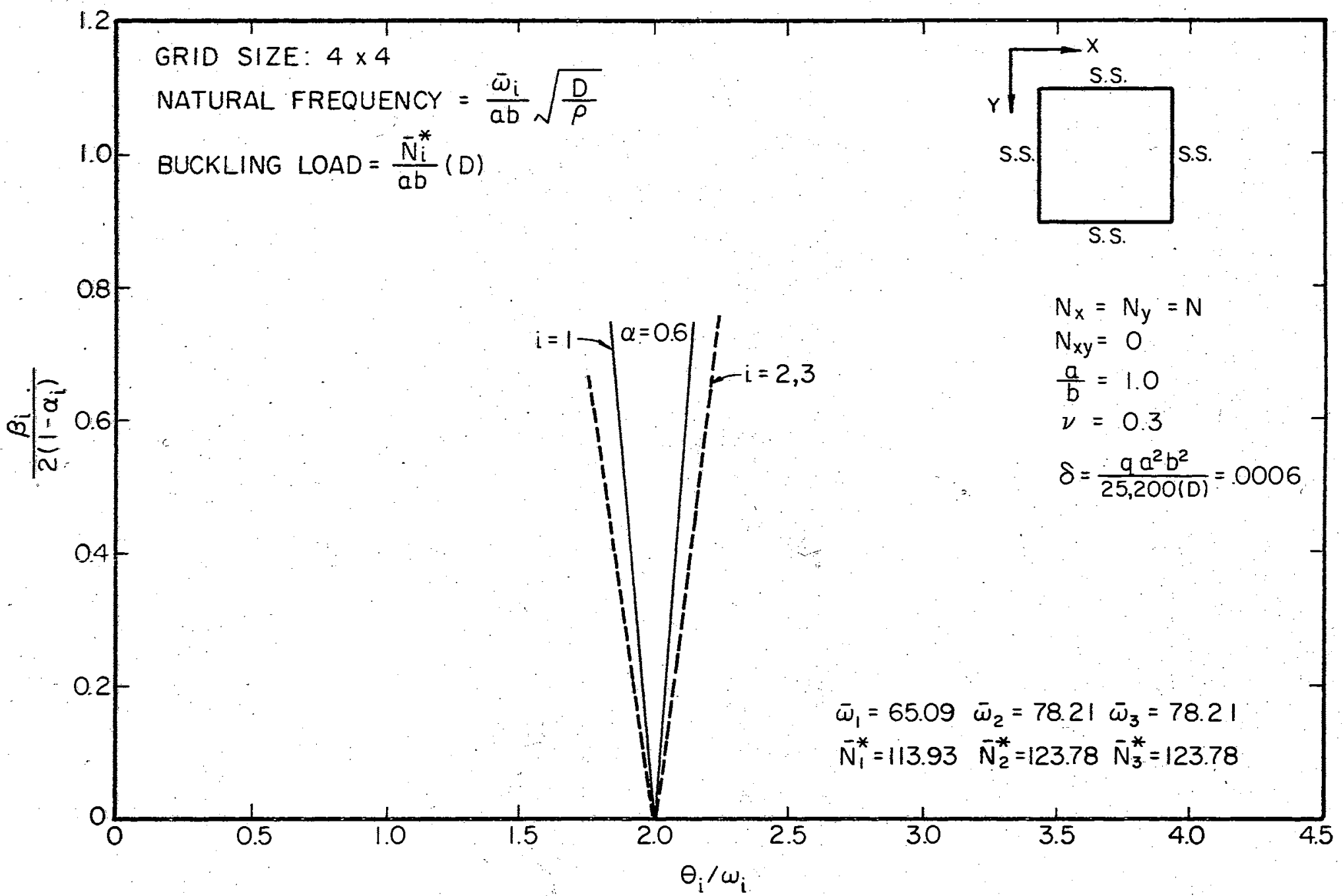

Figure 25. Regions of Dynamic Instability far a Simply Supported Plate on an Elastic Founda tion $(\delta=.0006, \alpha=0.6)$ 

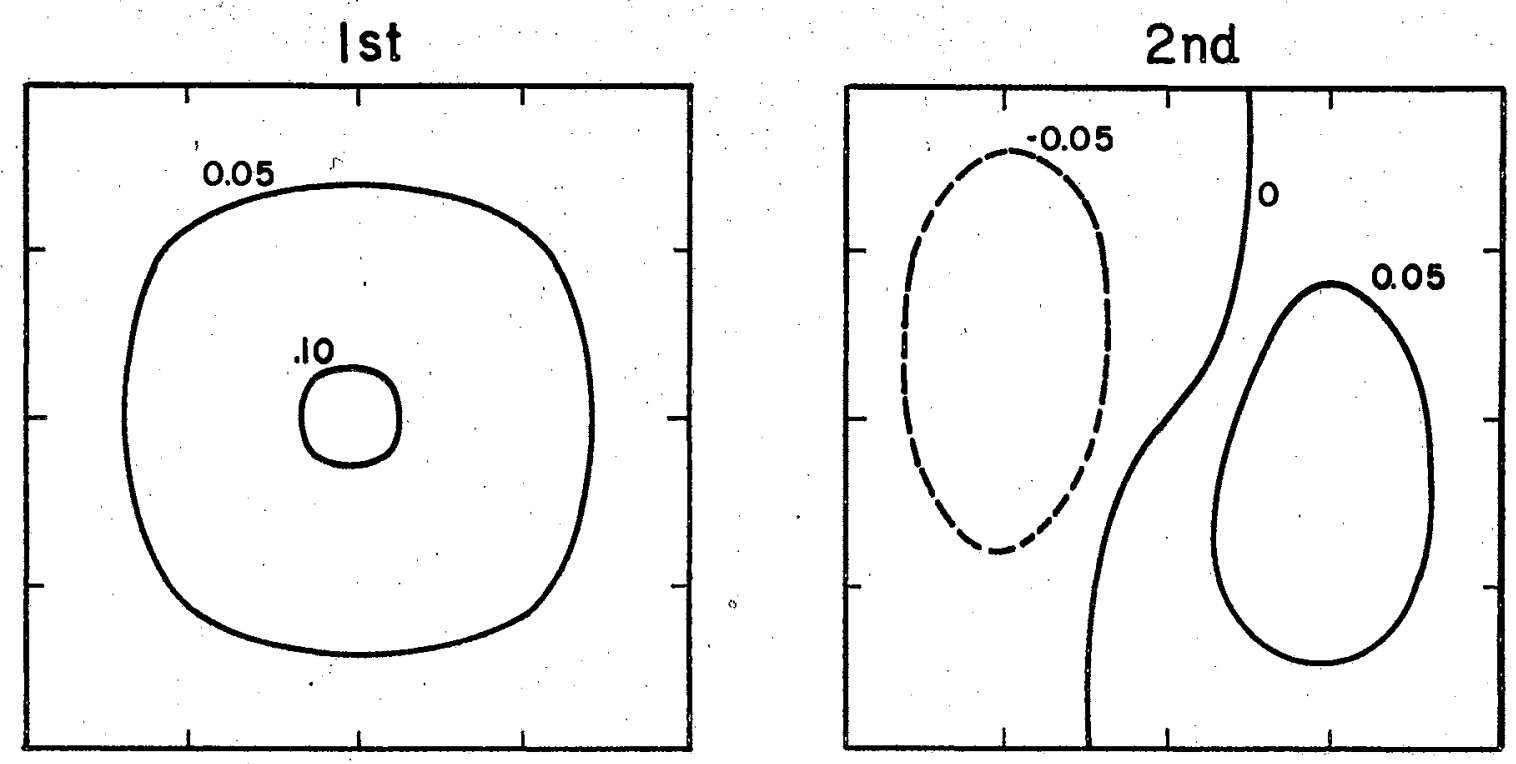

\section{VIBRATION MODES - SIMPLY SUPPORTED PLATE}
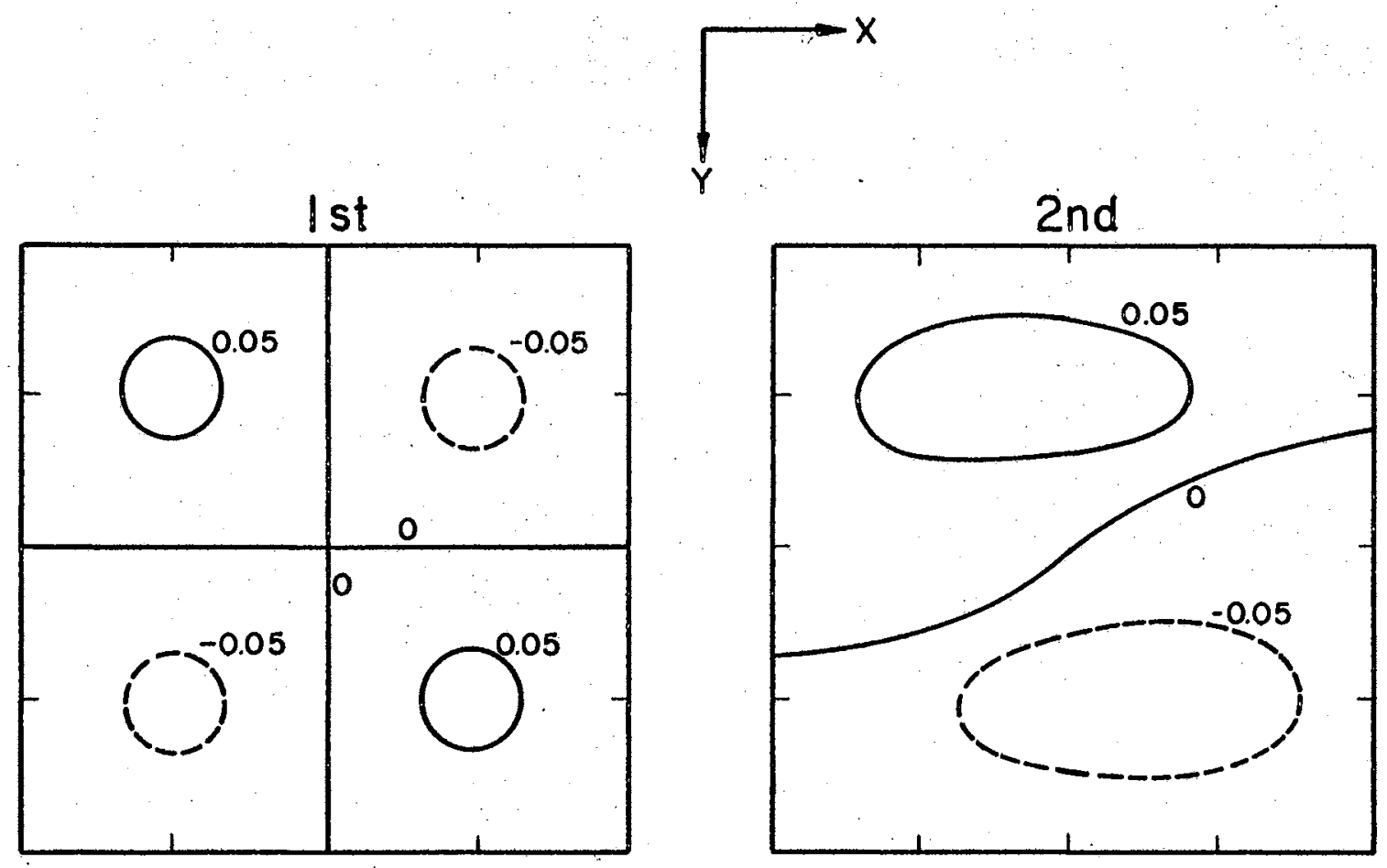

\section{BUCKLING MODES - SIMPLY SUPPORTED PLATE}

Figure 26. Mode Sbapes for a Simply Supported Plate on an Elastic Foundation $\left(\delta=.0006, N_{x}=N_{y}=N\right)$ 


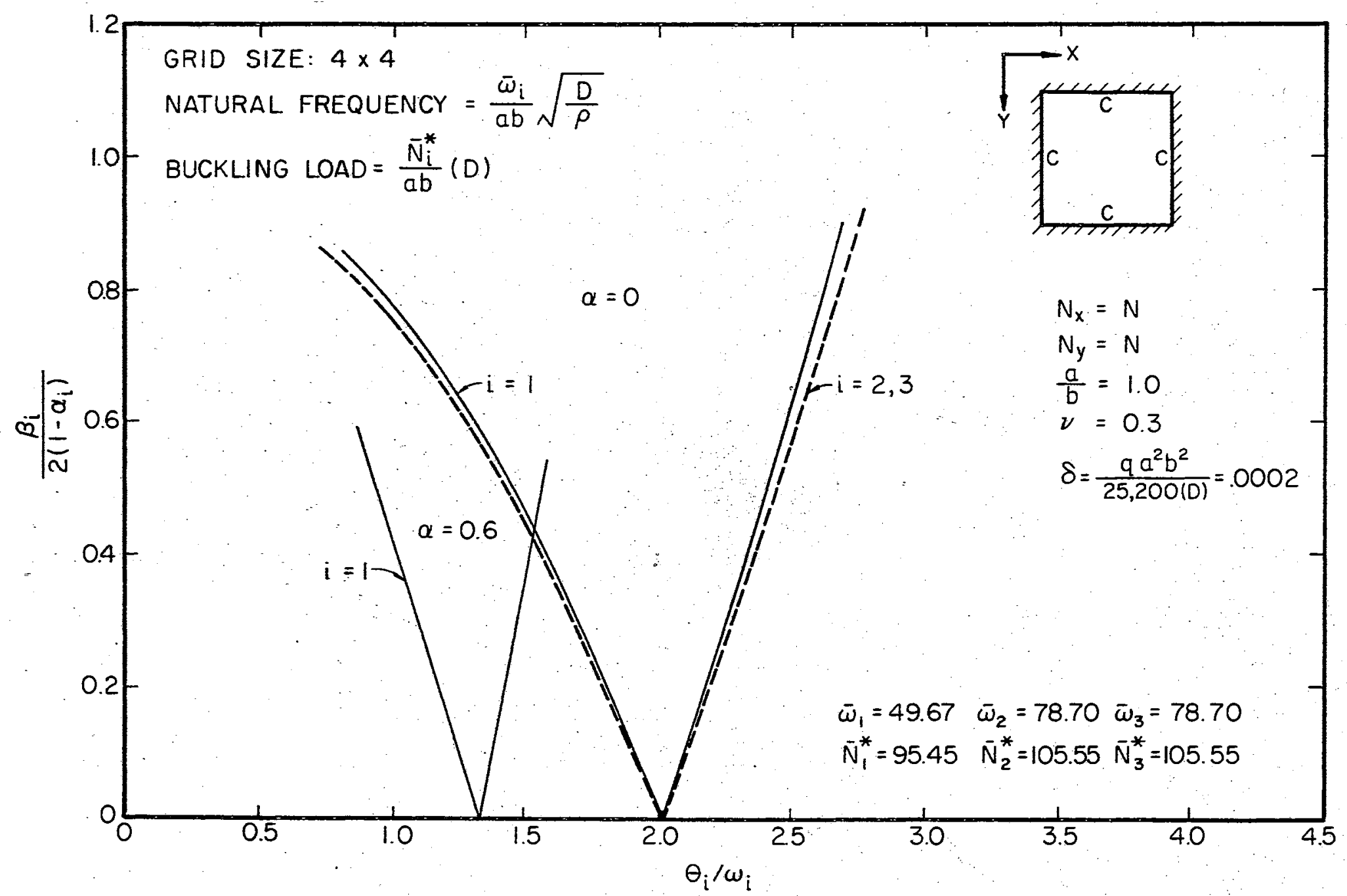

Figure 27. Regions of Dymamid Instability for a Clamped Place on an Elastic Foundation $(\delta=.0002)$ 

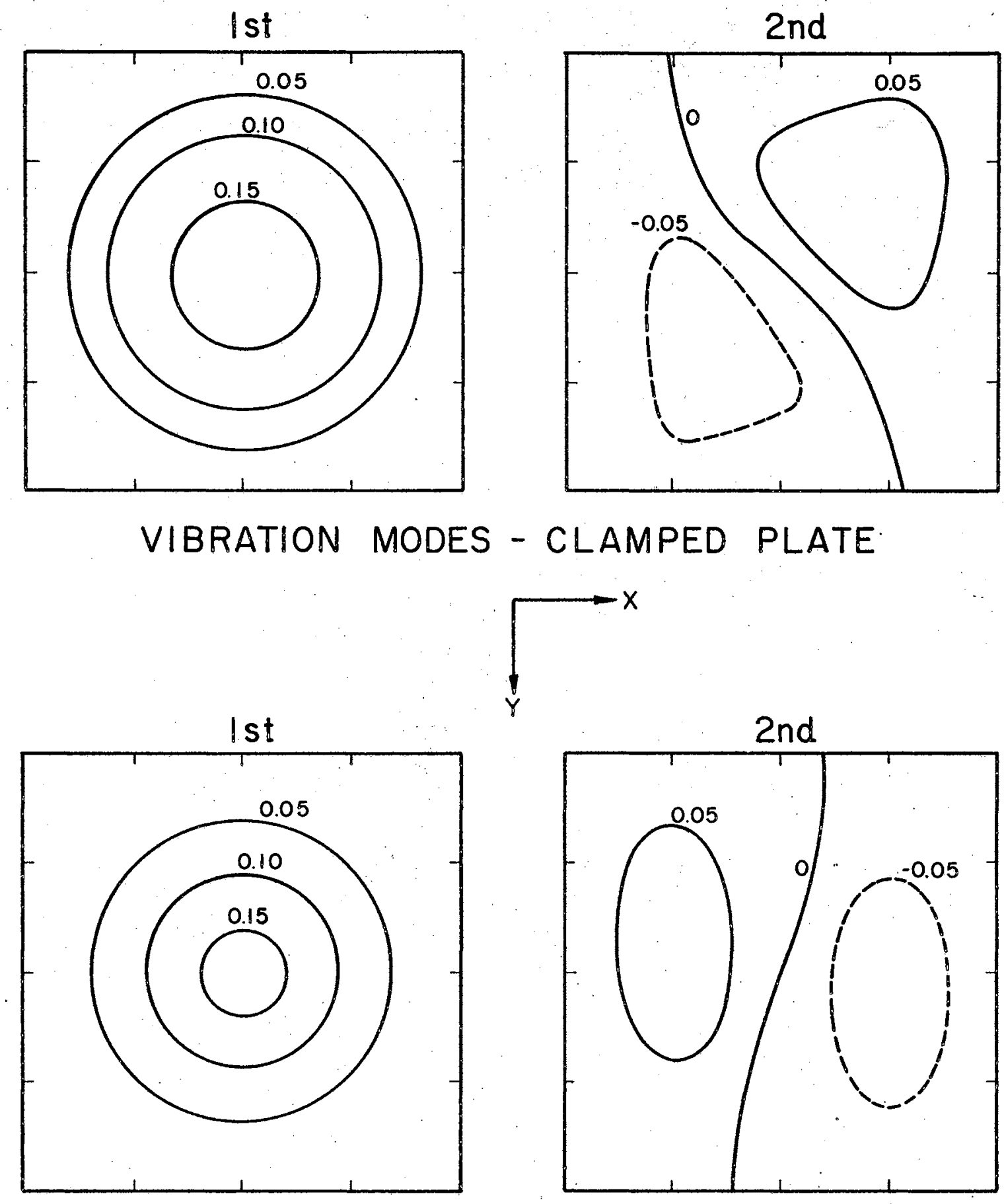

\section{BUCKLING MODES - CLAMPED PLATE}

Figure 28. Mode Shapes for a Clamped Plate an Elastic Foundation $\left(\delta=.0002, N_{x}=N_{y}=N\right)$ 


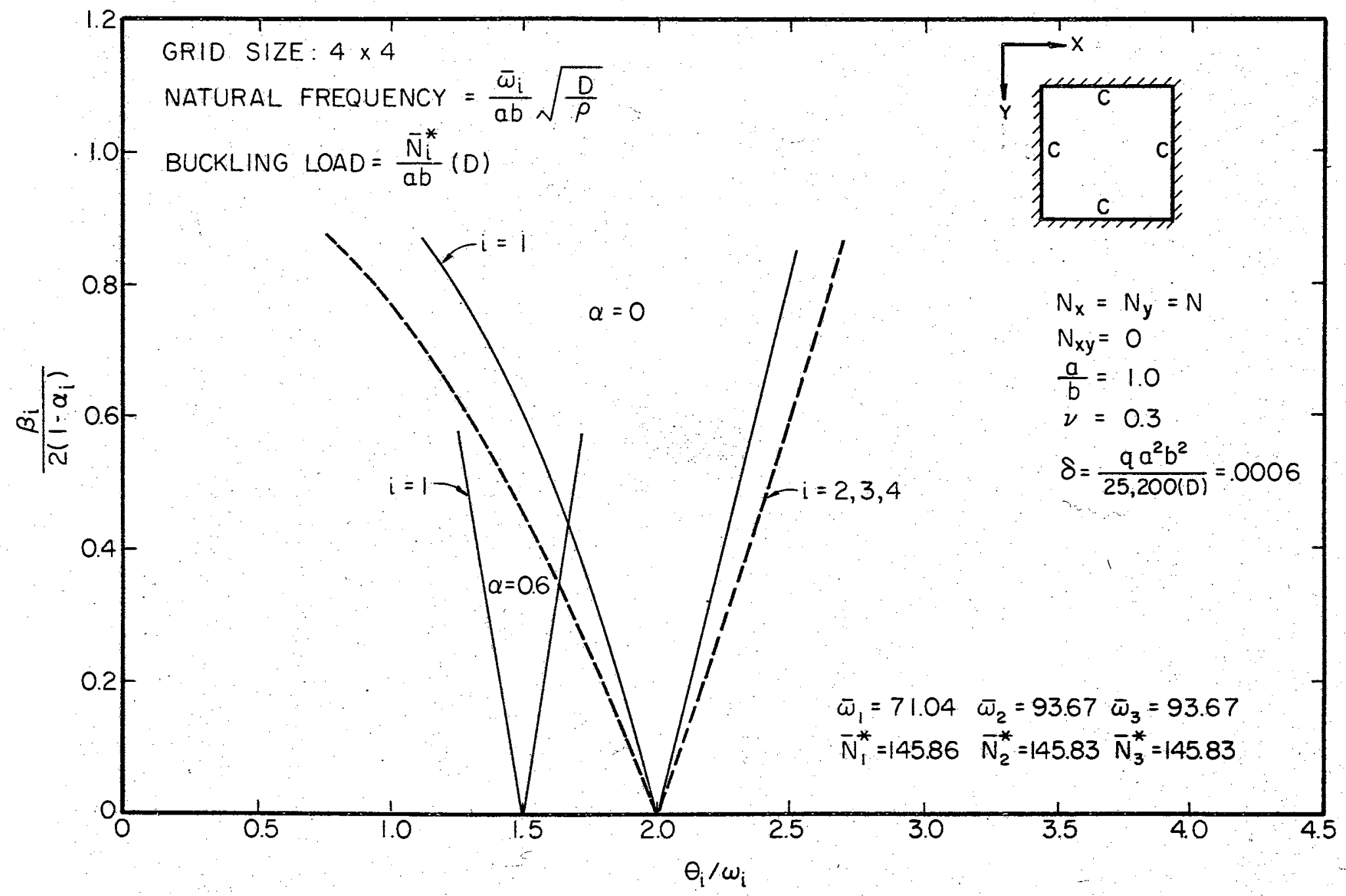

Figure 29. Regions of Dynamic Instability for a Clamped Plate on an Elastic Foundation $(\delta=.0006)$ 

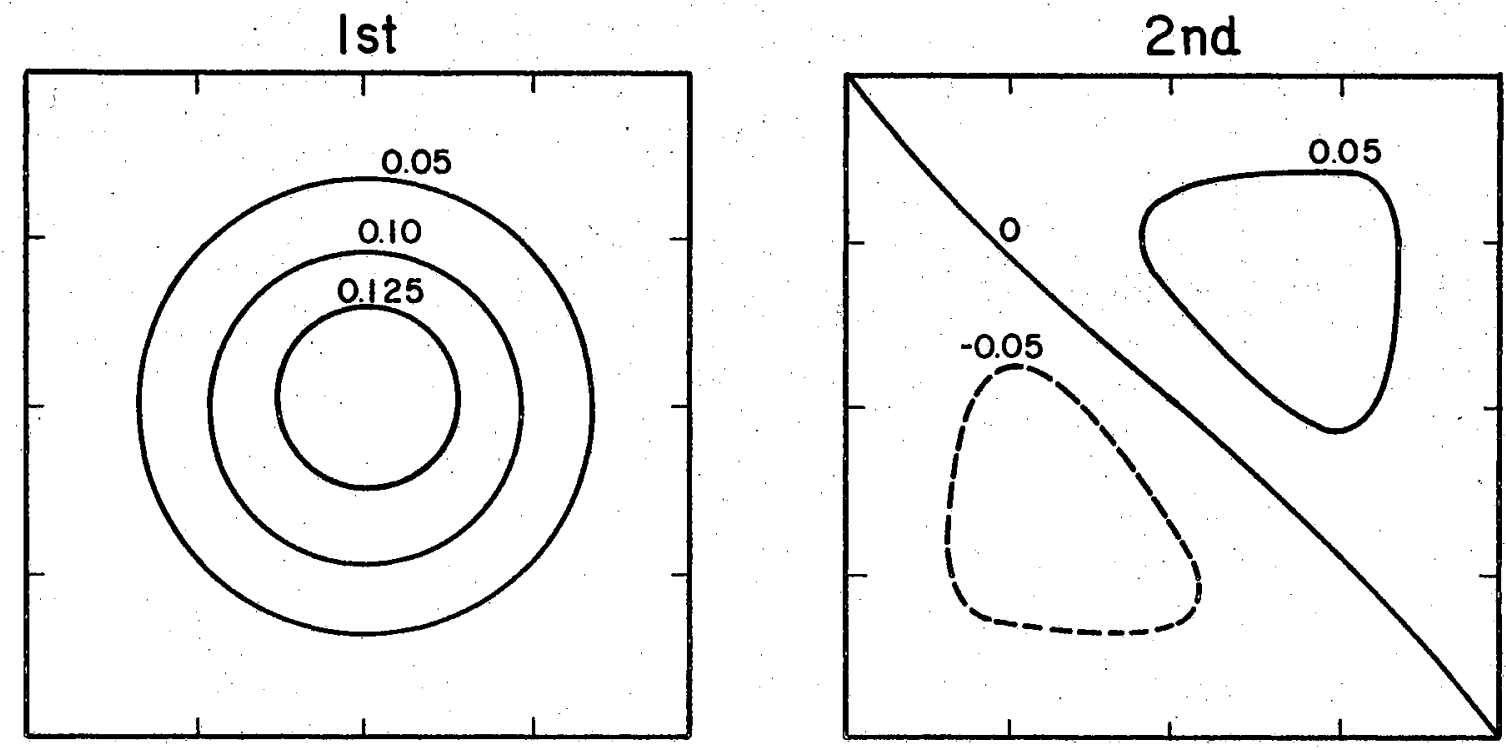

\section{VIBRATION MODES - CLAMPED PLATE}
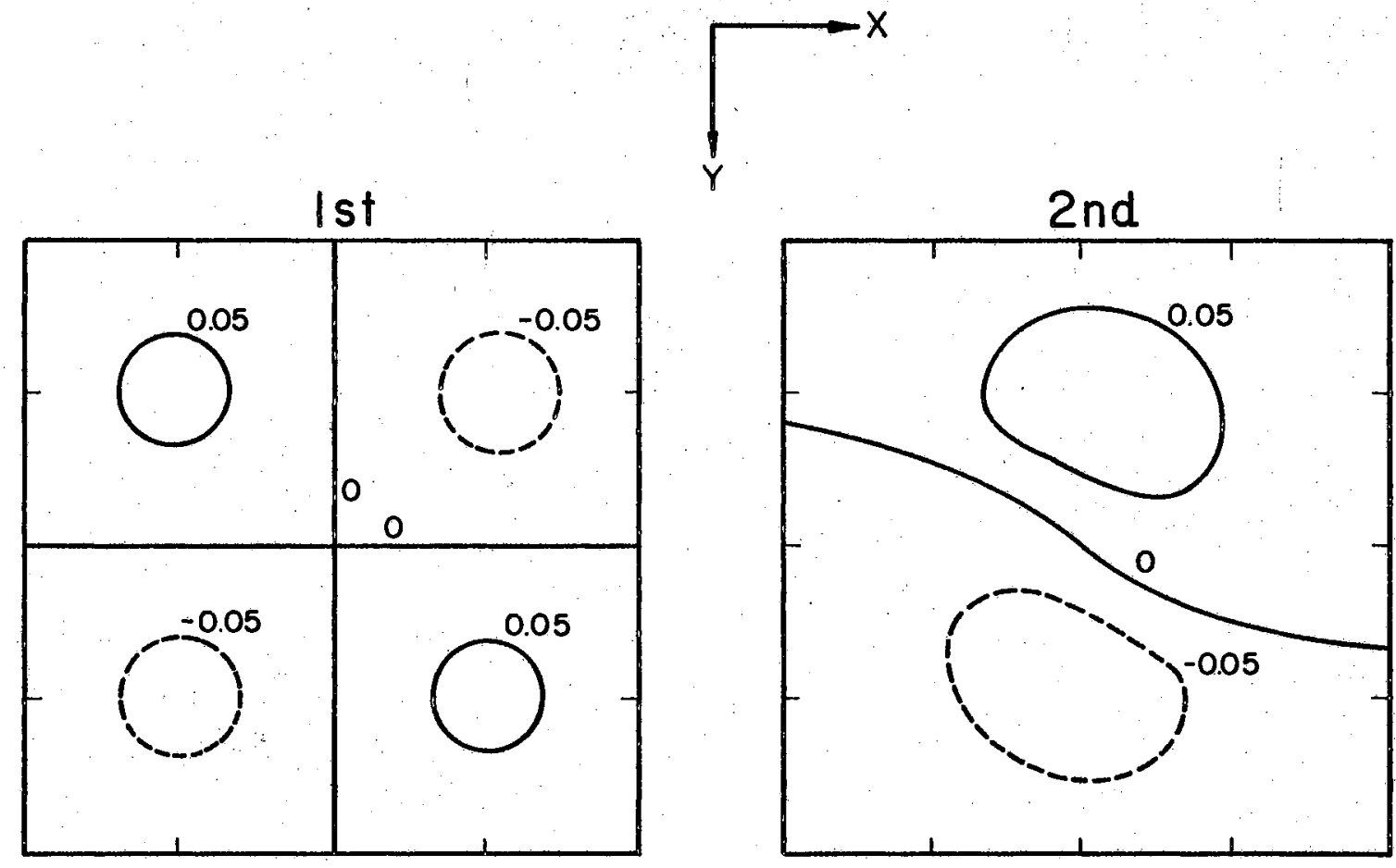

BUCKLING MODES - CLAMPED PLATE

Figure 30. Mode Shapes for a Clamped Plate on an Elastic Foundation $\left(\delta=.000 \sigma_{0} N_{x}=N_{y}=N\right)$ 


\subsection{Plates With Viscous Damping}

Regions of dynamic instability corresponding to the fundamental vibration frequency are found for a simply supported plate and a clamped plate, each subjected to a leading $N_{x}=N_{y}=N$, and $N_{x y}=0$, and viscous damping. These results are illustrated in Figures (31) and (32). The damping coefficients are expressed as a percentage of critical damping. For relatively small damping coefficients, the effect of damping is that the amplitude of the pulsating load must have a finite value before the plates will become dynamically unstable. For example, for the problem illustrated in Figure (31) when $\eta=0.05$ the amplitude of the pulsating load must reach 0.1 times the static buckling load before any instability will occur. As the damping coefficient is increased the load required to produce any instability becomes very large.

\subsection{Plate on Elastic Foundation With Viscous Damping}

Figure (33) shows the region of dynamic instability for a simply supported plate on an elastic foundation subjected to the effect of

viscous damping and a loading of $N_{x}=N_{y}=N$ and $N_{x y}=0$. The purpose of this example is to illustrate the simplieity in handling this class of relatively complex problems by the method developed in this thesis. 


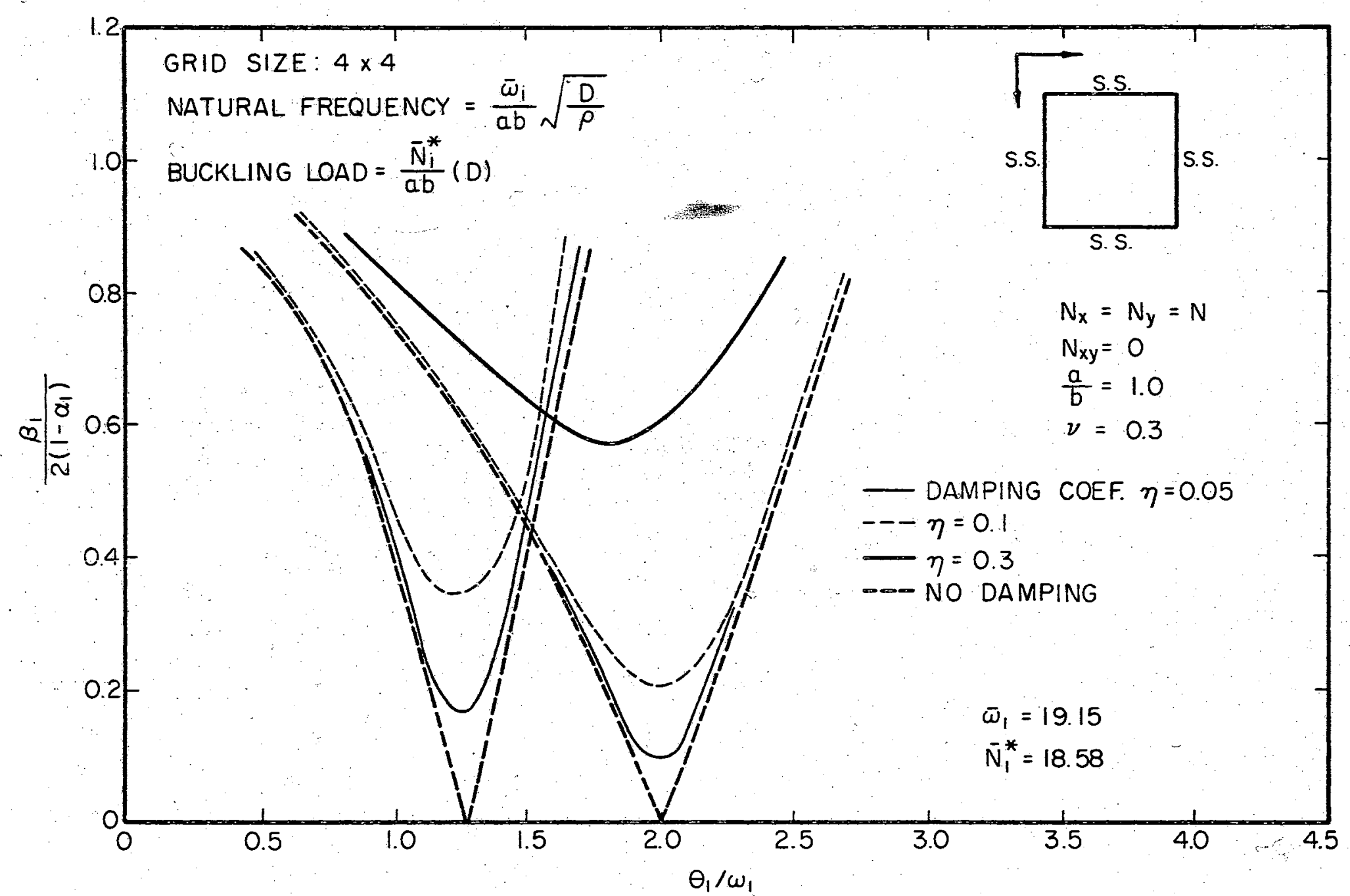

Figure 31. Regjons of Dynamic Instability for a Simply Supported Plate With Viscous Damping 


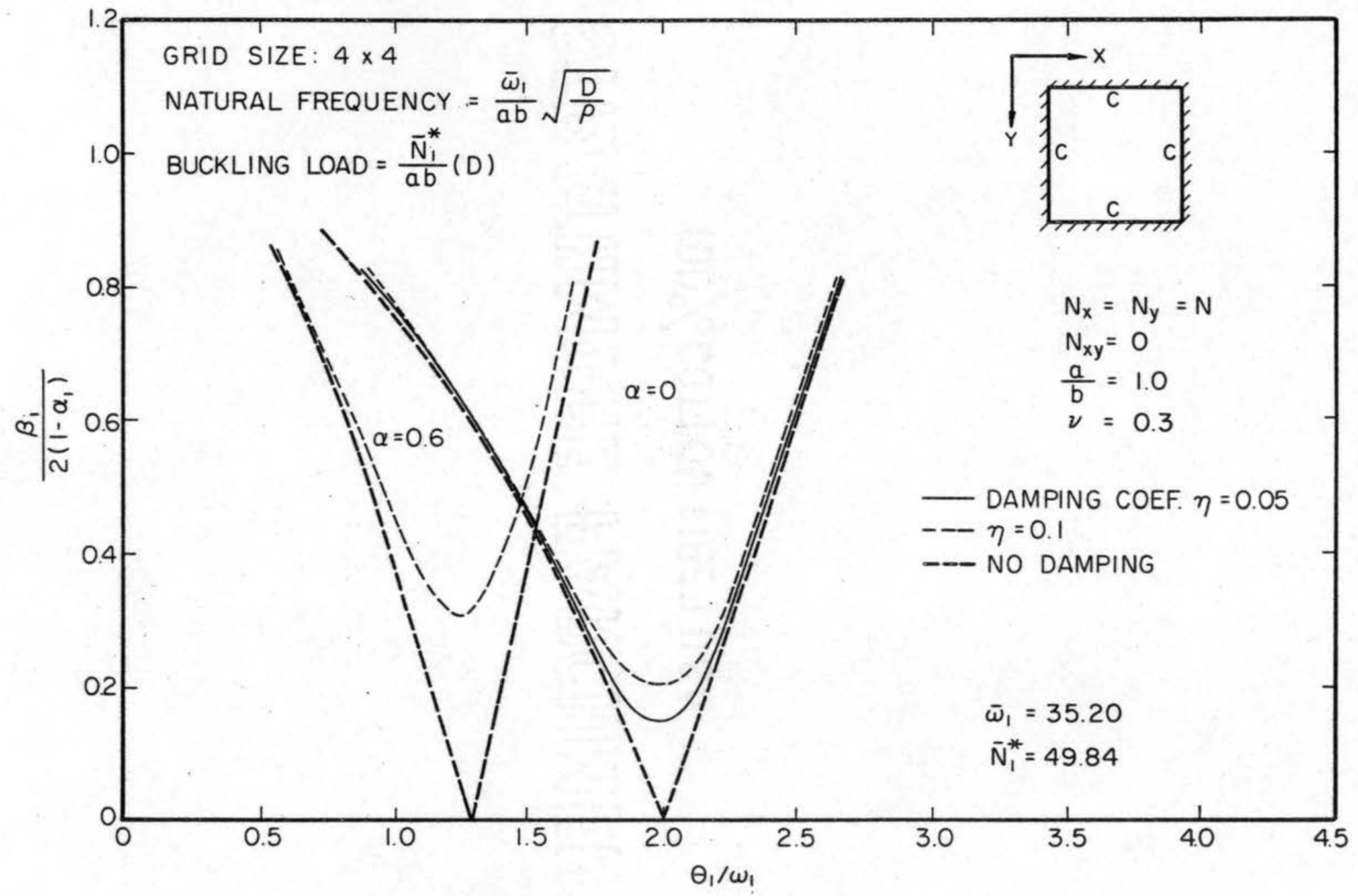

Figure 32. Regions of Dynamic Instabilisy for a Clamped Plate With Viscous Damping 


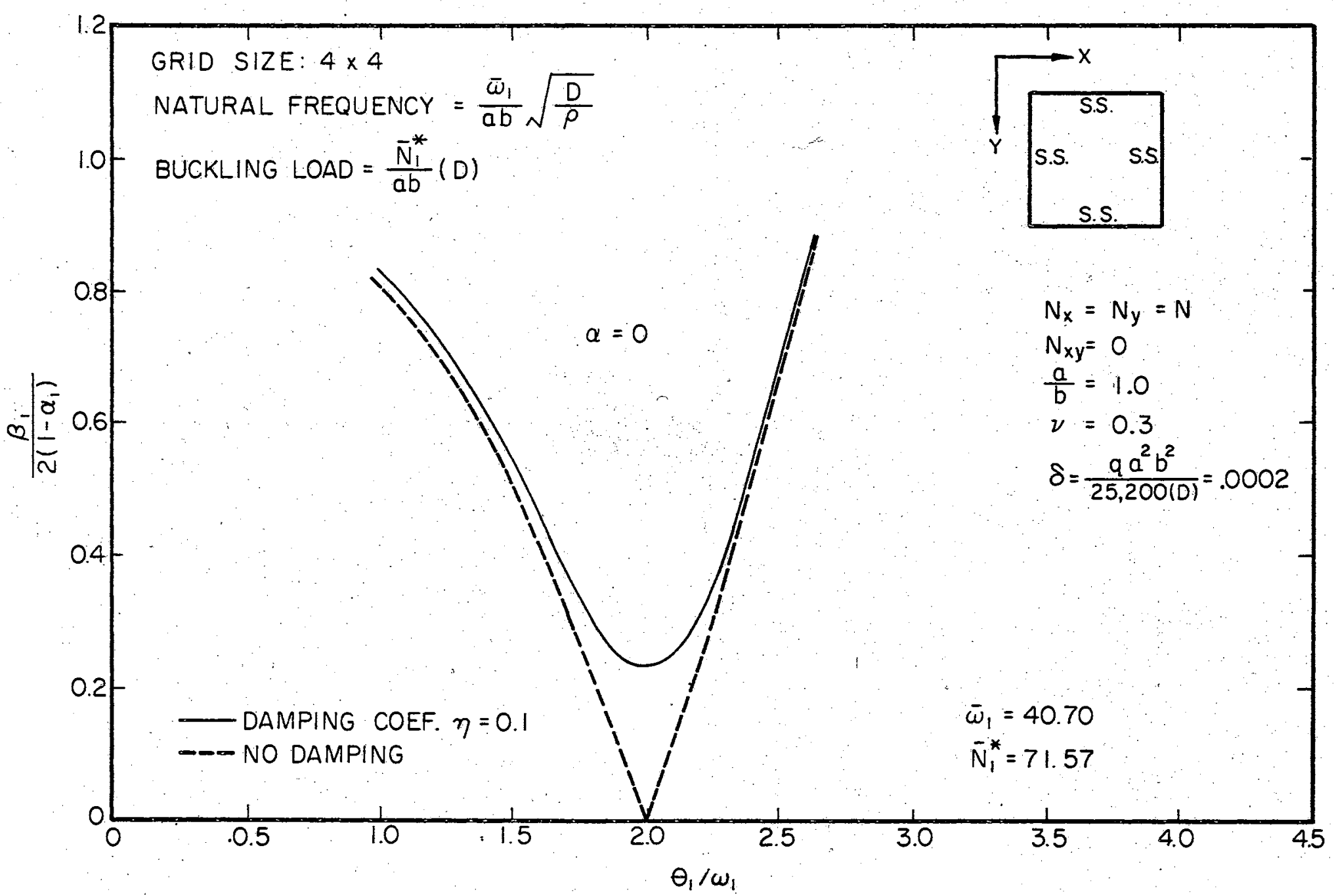

Figure 33. Region of Dynamic Instability for a Simply Supported Plate on an Elastic Foundation With Viscous Damping 


\section{CHAPTER VI}

\section{SUMMARY AND CONCLUSIONS}

\subsection{Sumary and Conclusions}

A method has been developed in this thesis, using finite element stiffness analysis, to determine the principal regions of dynamic instabilicy of rectangular, hømogeneous plates. The procedure employed in the development consists of the derivation of the governing set of ordinary differential equations by applying the Lagrangian equation to the individual finite plate elements, and of the solution of these equations for regions of instability using the methods from the theory of linear differential equations with periodic coefficients. The development of a finite element solution for structural problems using the Lagrangian equation has not, to this writer's knowledge, appeared heretofore in the literature. Although the approach taken by others for the solution of various problems using the finite element method is very similar mechanically to the Lagrangian approach, the Lagrangian method offers a unified approach which is more adaptable for extensions of the finite element procedure. A series of examples which includes plates subjected to several loading and boundary conditions, and plates with and without the effects of viscous damping and an elastic foundation were solved. A limited parametric investigation was made upon these examples.

The method is capable of handing a wide range of complex problems 
with regard to boundary conditions and loading. The method makes no presuppositions with regard to the eigenfunctions for free vibration and static buckling as is the case with most existing analytical solutions. It has been shown that the size of the regions of dynamic Instability depend upon the similarity of the mode shapes of free vibration and static buckling. For the special cases when the mode shapes for vibration and static buckling are the same the regions of instability are the characteristic curves shown in Figure (11). In these cases the governing differential equation can be reduced to one second ordex Mathieumill equation. Al though no attempt was made to develop a criterion for likeness or similarity of mode shapes, it was observed that when the mode shapes were very similar the instability regions were largest, and when the mode shapes were very dissimilar the instability regions were smallest.

The finite element method for analyzing plates for dynamic stabilitey makes it possible to solve large numbers of complex problems, and to analyze the problems with respect to the various parameters which affect the stability of the plates. This type of analysis with other solution methods at the present is unpractical. The treatment of the various boundary conditions which poses probably the biggest problem to analytical solutions is trivial in a finite element analysis. It is possible that the results of finite element analyses of plates might aid in giving direction to analytical research in this area.

\subsection{Suggestion for Further Research}

The examples that have been solved in this thesis have been limited to rectangular, homogeneous plates loaded with uniformly distributed loads across the edges. The method developed is capable, 
however, of handling a much wider range of problems. Other geometrical shapes can be solved, but it might be necessary to use finite element shapes other than rectangular to accommodate the various shapes. In the literature some of the necessary elemental matrices have been developed for finite elements of other shapes. Plates of variable thickness can be analyzed by using the variable mass and rigidity terms in the integrals used in evaluating the elemental matrices. Other types of loading conditions should be analyzed. The loadings used in this thesis were uniformly distributed across the plate edges and the inplane stress distribution due to these loads was known to be constant throughout the plates. The in plane stress distribution caused from other load configurations could be determined using methods similar to those given in works by Lundgren (19) and Apanian (20). Once the stress distributions are known the elemental stability matrices could be evaluated for these conditions and the regions of dynamic stability determined. A dynanic stability analysis of multilayered sandwich plates can be performed using the methods of this thesis and those presented by Lundgren (19).

Other basic factors which should be investigated in relation to the dynamic stability of plates are the effects of in-plane inertia, non-linear damping, and the use of materials which exhibit non-linear or elasto-plastic stress-strain distributions. 


\section{A SELECTED BIBLIOGRAPHY}

(1) Bolotin, V. Vo, Dynamic Stability of Elastic Systems. Holden-Day, Inc., San Franciseo, 1964.

(2) Rayleigh, John William Strutt (Lord), "On the Maintenance of Vibrations by Forces of Double Frequency and on the Propagation of Waves Through a Medium Endowed With a Periodical

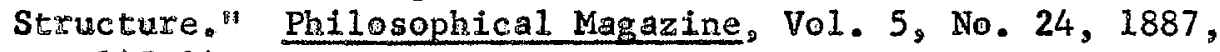
pp. $145-149$.

(3) Beliaev, N. M., "Stability of Prismatic Rods Subjected to Variable Longltudinal Forces." Collection of Papers: Engineering Construction and Structural Mechanics, Leningrad, 1924.

(4) Beilin, E. A. and G. V. Dzhanelidze, "Survey of the Works on the Dynamic Stability of Elastic Systems." Prikl.. Mat. i Mekhan., Vol。16, No.5, 1952, pp。635 648. (Available in English as ASTIA No. AD -264148.$)$

(5) Bodner, V. A., "The Stability of Plates Subjected to Longitudinal Periodic Forces." Prik1.. Mat. i Mekhan., (N.S.) Vol. 2, 1938, pp. 87-104.

(6) Khalilov, 2. I. "The Dyramic Stability of a Plate Under the Action of Pexjodic Longitudinal Forces." Tr. Azerb. Gos. Univ., Sex. Mar., Vol. 1, 1942, pp. 28-32.

(7) Einaudi, R., "Sulle Configurazioni di Equilibxio Instable di una Piastra Sollecitata da Sformi Tangenziali Pulsanti." Atti. Accad. Gidenia, Vol. 1, Memoria XX, 1935-36, pp. 1-5.

(8) Ambartsumian, S. A. and A. A. Khachatrian, "On the Stability and Vibrations of Anisotropic Plates." Izv. Akad. Nauk, SSSR, otd. Tekhn. Nauk. Mekhan. i Mashinostr., Vol. $I_{s} 1950$, pp. 113-122.

(9) Mettlex, E., "Biegeschwingungen eines Stabes mit kleiner Vorkxumung, exzentrisch angreifender publsierender Axiallast und statischer Querbelastung." Forshungshefte aus d. Geb. d. Stah1baues, Fo1. 4, 1941, pp. 1-23.

(10) Naunov, K. A., "The Stability of Prismatic Rods Allowing for Damping." Tr. Mosk. Inst. Ingh. Transp., Vol. 69, 1946, pp. $132-141$. 
(11) Mettler, E., and F. Weidenhamer, "Der axial Pulsierend belastete Stab mit Endmasse." Z. angew. Mat. Mekhan,, Vol. 36, 1956, pp. $284-287$.

(12) Chelomei, V. N., The Dynamic Stability of Elements of Aircraft Structures. Aeroflot, Moscø, 1939.

(13) Turner, M. J., R.W. Clough, H. C. Martin, and I. J. Topp, "Stiffness and Deflection Amalysis of Complex Structures." Jour. Aero. Sciences, Vol. 23, No. 9, 1956, pp. 805-823.

(14) Flugge, W., ed., Handbook of Engineering Mechanics. McGraw-Hill Book Company, Inc., New York, 1962.

(15) Cesari, Lamberto, Asympototic Behavior and Stability Problems in Ordinary Differential Equations. Springer-Verlag, Berlin. Gottingen. Heidelburg, 1959.

(16) Chetayev, N. G. The Stability of Motion. The Pergamon Press, 1961. (Translated from the Russian.)

(17) MeLacklan, N. W., Theory and Application of Mathieu Functions. Dover Publications, Inc., New York, 1964.

(18) Brown, John E, "Dynamic Stability of Bars by the Finite Element Method." Mastex"s Report, Oklahorna State University, Stillwater, Oklahona, 1968.

(19) Lundgren, Haxry $R_{0}$, "Buckling of Multilayer Plates by Finite Elements. water, Oklahorna, 1967 .

(20) Apanian, Ronald A. "Frame Andysis of Thin Shells." Ph.D. Thesis, OkI hora State University, Stillwater, Oklahoma, 1967. 
VITA

Johnny Mack Hutt

Candidate Eor the Degree of

Decter of Philosophy

\section{Thesis: DYNAMIC STABILITY OF PLATES BY FINITE ELEMENTS}

\section{Major Field: Engineering}

Biographical:

Personal Data: Born at Tuscaloosa, Alabama, September 12, 1940, the son of Joe and Mildred Hutt.

Education: Attended gxade school at Tuscaloosa, Alabama; graduated from Tuscaloosa High School in 1958; received the Bachelor of Science degree from the University of Alabama, at University, Alabama, with a majox in Civil Engineering, in August, 1953; received the Master of Science degree from the Universicy of Alabama, at University, Alabama, with a major in Civil Engineering, in May, 1965; completed the requirements for the Doctor of Philosophy degree in May, 1968.

Professional Experience: Craduate research assistant and parttime instructor in the school of Civil Engineering, University A Alabara, 1964-1965. Graduate teaching assistant and part-time instructor in the school of Civil Engineering, Oklahoma State University, 1965-1967. Associate Member of American Society of Civil Ergineers. 